\title{
Impression management throughout the professional life
}

Citation for published version (APA):

Schmitte, K. (2019). Impression management throughout the professional life: an examination across context and time. [Doctoral Thesis, Maastricht University]. ProefschriftMaken Maastricht. https://doi.org/10.26481/dis.20190612ks

Document status and date:

Published: 01/01/2019

DOI:

10.26481/dis.20190612ks

Document Version:

Publisher's PDF, also known as Version of record

\section{Please check the document version of this publication:}

- A submitted manuscript is the version of the article upon submission and before peer-review. There can be important differences between the submitted version and the official published version of record.

People interested in the research are advised to contact the author for the final version of the publication, or visit the DOI to the publisher's website.

- The final author version and the galley proof are versions of the publication after peer review.

- The final published version features the final layout of the paper including the volume, issue and page numbers.

Link to publication

\footnotetext{
General rights rights.

- You may freely distribute the URL identifying the publication in the public portal. please follow below link for the End User Agreement:

www.umlib.nl/taverne-license

Take down policy

If you believe that this document breaches copyright please contact us at:

repository@maastrichtuniversity.nl

providing details and we will investigate your claim.
}

Copyright and moral rights for the publications made accessible in the public portal are retained by the authors and/or other copyright owners and it is a condition of accessing publications that users recognise and abide by the legal requirements associated with these

- Users may download and print one copy of any publication from the public portal for the purpose of private study or research.

- You may not further distribute the material or use it for any profit-making activity or commercial gain

If the publication is distributed under the terms of Article $25 \mathrm{fa}$ of the Dutch Copyright Act, indicated by the "Taverne" license above, 


\section{Impression Management}

Throughout the Professional Life:

An Examination across Context and Time

\section{Katharina Schmitte}
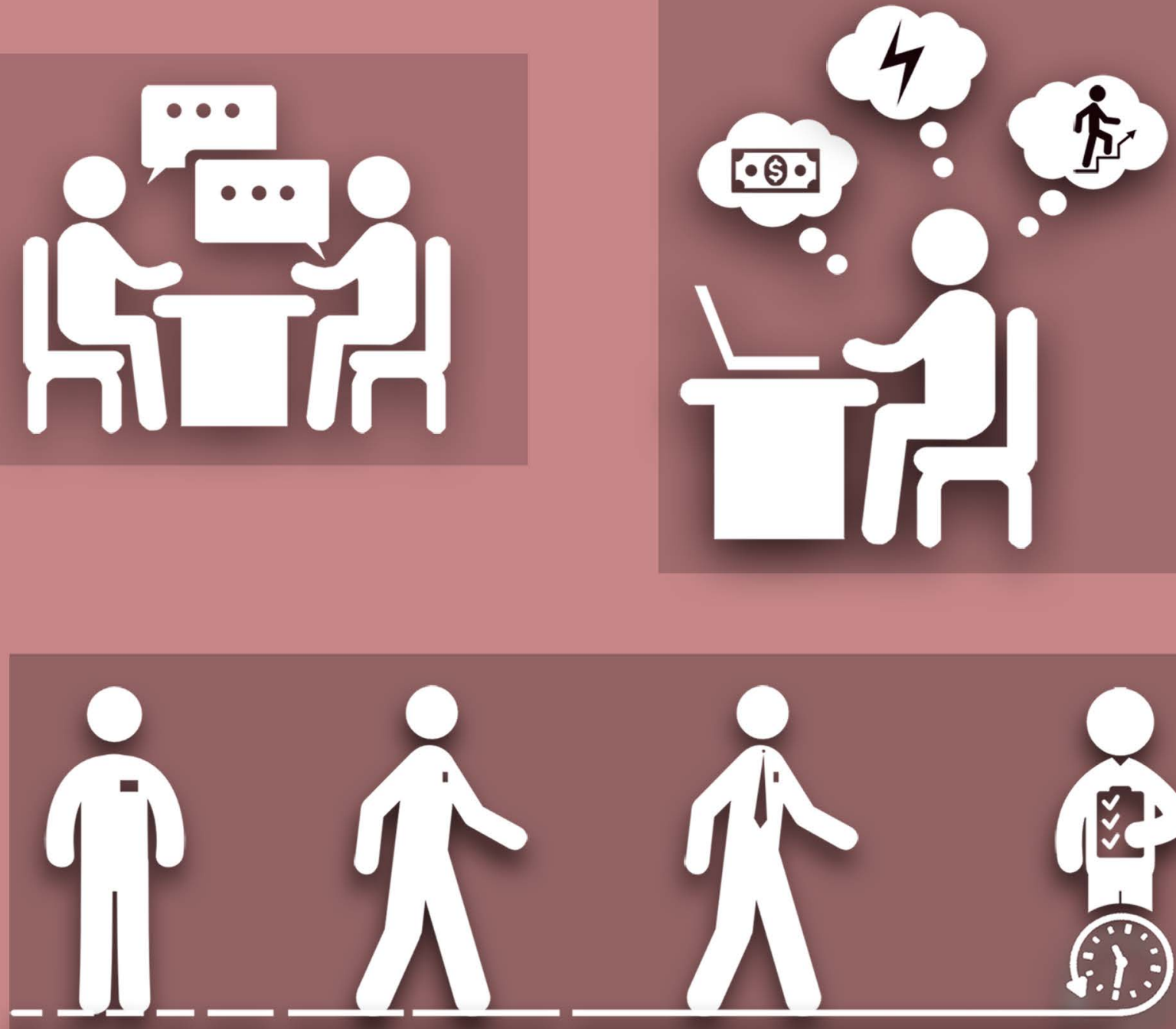



\section{Impression Management throughout the Professional Life:}

An Examination across Context and Time 
The research presented in the dissertation was conducted at the School of Business and Economics (SBE), Department of Organization \& Strategy, Maastricht University.

(C) Katharina Schmitte, Maastricht 2019

All rights reserved. No part of this publication may be reproduced or utilized in any form or by any means, including electronic, mechanical, photocopying, recording or otherwise, without prior permission in writing from the author.

ISBN: 978-94-6380-367-0

Cover Design: Ruzanna Navoyan

Published: ProefschriftMaken || www.proefschriftmaken.nl 


\title{
Impression Management throughout the Professional Life:
}

\section{An Examination across Context and Time}

\author{
DISSERTATION \\ To obtain the degree of Doctor at Maastricht University \\ on the authority of the Rector Magnificus, \\ Prof. Dr. Rianne M. Letschert \\ in accordance with the decision of the Board of Deans, \\ to be defended in public \\ on Wednesday June $12^{\text {th }}, 2019$, at $12: 00$ hours
}

by

Katharina Schmitte 


\section{Supervisors}

Prof. dr. Mien Segers

Prof. dr. Simon B. de Jong

\section{Co-supervisor}

Dr. Bert Schreurs

\section{Assessment Committee}

Prof. dr. Wil Foppen (Chairman)

Dr. Nele de Cuyper (Katholieke Universiteit Leuven, Belgium)

Dr. Hannes Guenter

Prof. dr. Roland Pepermans (Vrije Universiteit Brussels, Belgium) 


\section{Acknowledgments}

The PhD has been an intense time. When looking back, I am thankful to what I have learned and to the people I met. At first, I would like to thank my promotor Mien. Thank you for taking over my PhD supervision, for your flexibility, and for always having been there for me. Your way of working with a clear focus on targets and timelines helped me to bring structure back into my PhD. Another big gratitude goes to Bert. Thank you for passing on your passion about research - not only teaching me how to approach academic research but also teaching me how to write concisely. Thank you for sharing (almost) the entire PhD time with me. I also thank Simon who acted as a co-promotor at the end of my journey. Thank you for your willingness to assist in the finalization of my dissertation and the time and energy invested. Above that, I would like to explicitly mention two collaborators on my papers, one of them being a colleague at SBE: Melvyn, thank you for bringing in your expertise on experiments and for making our paper a success. Jim, thanks for joining on another research project and for sharing your scientific knowledge with me. Speaking of great colleagues, Hannes, thank you for your constructive feedback, your time, and help every time I jumped in with a question. Another big thank you goes to Anita and Adela for helping me with administrative issues of any kind. I also greatly thank the Professors of the assessment committee for the time and effort taken to read and evaluate my thesis - thank you to Wil, Roland, Nele, and Hannes. Moreover, time at SBE would not have been the same without my PhD colleagues. First of all, my two paranymphs Anna and Sofya: Anna, my friend in crime, and help in all situations. I am thankful for having shared the office with you. I am convinced that the time we spent with each other has welded us together in a special way. Second of all, I would like to thank Sofya. Thank you for always having been so caring to me, for your positive attitude, and your expertise. Next to being a colleague whom I could always count on, you became a very good friend of mine. I also like to thank Nina, Matthias, Caren, Jasper, Dinah, Kars, Sonja, Ewa, Nardo, and Nazareno, the PhDs of O\&S who joined more recently, and close PhDs of other departments. Thank you for all your support, your conversations about (PhD) life, and all the cozy coffee and lunch breaks we had together. Additionally, I like to mention former PhDs of the O\&S department. Desirée, thank you for your friendship and the first time at SBE, where you helped me to become acquainted with everything new. I would also like to thank Tom, Darja, Roy, and Bart for always having had an open ear and for all your support. A special thank you goes to my husband Jannik for his patience and support and for giving me a place where I belong. I am endlessly happy with our small family. Thank you also to my parents in law for the constant support. Finally, I would like to thank my parents and sisters for the endless support, kind words, and continuous encouragement whilst writing my dissertation, and for making me the person who I am today. 



\section{Contents}

Chapter 1 An Introduction and Literature Review 9

1.1 Introduction to the Dissertation 11

1.2 A Brief Summary of Previous Impression Management Research 12

1.3 Aim of the Dissertation 16

$1.4 \quad$ Literature Review and Evolving Research Gaps 17

1.5 Theoretical Model of the Dissertation 24

1.6 Outline of Empirical Chapters 26

Chapter 2 Self-Promotion during Job Interviews: A Two-Study Test of the Construal Compatibility Effect 29

2.1 Introduction 31

2.2 Theoretical Background and Hypotheses 33

2.3 Experiment $1 \quad 37$

2.4 Method 39

2.5 Results 41

2.6 Experiment 2 44

2.7 Method 45

$\begin{array}{lll}2.8 & \text { Results } & 47\end{array}$

2.9 General Discussion 49

2.10 Conclusion 53

Chapter 3 Impressing to Preserve? The Role of Threat Appraisal, Job Control, and Proactivity on Exemplification $\quad 55$

3.1 Introduction 57

3.2 Theoretical Background and Hypotheses 59

3.3 Method 63

3.4 Convergent and Discriminant Validity 65

$\begin{array}{lll}3.5 & \text { Results } & 67\end{array}$

$\begin{array}{lll}3.6 & \text { Discussion } & 70\end{array}$

$\begin{array}{lll}3.7 & \text { Conclusion } & 74\end{array}$

Chapter 4 Within-Subject Variability in Ingratiation as a Function of Self-Esteem and Time: A Dynamic Perspective $\quad 75$

$\begin{array}{lll}4.1 & \text { Introduction } & 77\end{array}$

4.2 Theoretical Background and Hypotheses 79

4.3 Methods 82 
$\begin{array}{lll}4.4 & \text { Results } & 84\end{array}$

$\begin{array}{lll}4.5 & \text { Discussion } & 87\end{array}$

4.6 Conclusion 90

Chapter 5 General Discussion and Conclusion 91

5.1 Introduction 93

5.2 Summary of Main Findings 94

5.3 Theoretical Implications 95

5.4 Limitations and Directions for Future Research 98

5.5 Practical Implications 99

$\begin{array}{lll}5.6 & \text { Conclusion } & 101\end{array}$

$\begin{array}{ll}\text { Valorization Addendum } & 103\end{array}$

Relevance 105

$\begin{array}{ll}\text { Target Groups } & 106\end{array}$

$\begin{array}{ll}\text { Implications } & 106\end{array}$

$\begin{array}{ll}\text { Innovative Activities } & 107\end{array}$

$\begin{array}{ll}\text { Planning and Realization } & 109\end{array}$

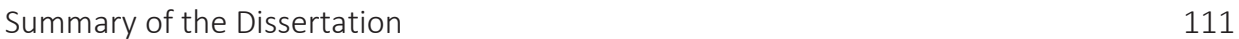

$\begin{array}{ll}\text { Appendices } & 117\end{array}$

$\begin{array}{ll}\text { Appendix A } & 119\end{array}$

$\begin{array}{ll}\text { Appendix B } & 121\end{array}$

$\begin{array}{ll}\text { References } & 123\end{array}$

$\begin{array}{ll}\text { About the author } & 143\end{array}$ 
Chapter

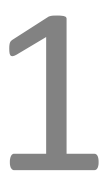

An Introduction and Literature Review 



\subsection{Introduction to the Dissertation}

In real life you don't react to what someone did; you only react to what you think someone did. The gap between action and perception is bridged by the art of impression management

Jonathan Haidt, social psychologist and Professor at Stern School of Business, New York

Every day, people strive to present themselves in a way that is perceived favorably by others. In an attempt to appear favorable, individuals try to manage impressions. Based on how individuals manage their personal impressions, people receiving these impressions (i.e., also referred to as targets) draw conclusions of the respective person, leading either to favorable or unfavorable assessments made. This idea is referred to as impression management (IM), defined as the process whereby individuals seek to influence the image others have of them (Rosenfeld, Giacalone, \& Riordan, 1995).

In our daily lives, it happens frequently that we make evaluations of somebody based on the impressions an individual conveyed (Schlenker, 1980). When looking back at our daily activities over the past two weeks, it becomes apparent that we experienced many instances in which we, as targets of IM, drew evaluations of an individual based on the person's managed impressions. For instance, think of the acquaintance your friend brought along to dinner at the restaurant last week, the cashier who served you at the gas station the other morning or the job candidate who recently applied for the vacant job position in your project team. In the three examples provided above, the drawn evaluations typically range from a pleasant to unpleasant acquaintance, a friendly to unfriendly cashier or a competent to incompetent job candidate.

Whereas for the person evaluating the difference mainly lies in the favorableness of the final assessment made, for the person receiving the evaluation the favorableness of the assessment can have more far-reaching consequences, especially when future outcomes are affected (Schlenker \& Pontari, 2000). Therefore, IM is of foremost importance to our professional lives, given its significant impact on future career outcomes. Every time our performance, and especially our professional performance is evaluated, important future consequences can arise. When applying this idea to the three scenarios provided above (i.e., the acquaintance at the restaurant, the cashier at the gas station or the job candidate at work), it becomes clear that, in particular, the assessment of the job candidate during the job interview is likely to impact future career outcomes. The assessment of the job candidate can thus be characterized as a high-consequence context.

Yet, the appraisal of a job applicant applying for a job is not the only highconsequence context throughout an individual's professional life (Posthuma, Morgeson, \& Campion, 2002). Professional lives incorporate a large variety of high-consequence contexts. Due to this, both the motives as well as the desired outcomes of IM use great- 
Iy depend on the precise context in which IM is used. Individuals therefore constantly try to make good impressions in their professional lives during which they are constantly appraised by others - typically influential others higher up in the hierarchy.

This dissertation studies why individuals engage in IM throughout their professional lives and the effects that IM use can have on different career outcomes. In doing so, the dissertation identifies three high-consequence contexts, in which the use of IM may have important consequences: The first context is a recruitment context, and within this context I examine how applicants' engagement in IM during a job interview affects interviewer evaluations of the respective applicant. The second context is an organizational context, and within this context I examine the effect that threat appraisal at work and perceived by employees has on individual IM use at work. The third context is an educational context, and within this context I examine the extent to which individuals throughout the progression of an academic course at university use increasingly more IM over time as the final performance appraisal event approaches. The first two contexts investigate IM as snap-shots, suggesting that IM is used by an individual only at one particular moment in time which is of high-consequence. The last context investigates individual IM use across a period of time and focuses on the examination of IM used by one and the same person over time, thus suggesting that there are moments in which IM is used more or less.

The dissertation tries to answer the following research question:

Why do individuals engage in IM throughout their professional lives and what are the outcomes of IM use in high-consequence contexts?

In the next part of the introduction, and after a brief summary of previous IM research, the aim of the current dissertation is identified. After that, a more detailed analysis of IM research is provided in the form of a literature review, out of which research gaps forming the basis for the current dissertation are identified. The introductory chapter continues with an overarching theoretical model illustrating the different empirical chapters as well as the relations between those chapters. The chapter ends with an outline of the empirical chapters of the dissertation (Chapters 2, 3, and 4), including a short description of the research models studied and the samples used. Chapter 5 concludes the dissertation by discussing both theoretical and practical implications as well as emerging future research opportunities.

\subsection{A Brief Summary of Previous Impression Management Research}

Previous IM research typically identifies five tactics. The best-known and most frequently-used typology is the one by Jones and Pittman (1982), which distinguishes between self-promotion, ingratiation, exemplification, intimidation, and supplication (see Table 1.1 for more information). The former three can be referred to as more assertive IM 
tactics, and the latter two as more defensive tactics (Turnley \& Bolino, 2001). Assertive tactics are used by individuals to acquire and promote favorable impressions (Tedeschi \& Norman, 1985).

Table 1.1 Overview of Impression Management Tactics

\begin{tabular}{ll}
\hline Name of IM tactic & Description of IM tactic \\
\hline $\begin{array}{l}\text { Self-promotion } \\
\text { Ingratiation }\end{array}$ & Individuals point out their skills, abilities, and accomplishments in order to be seen as competent \\
Exemplification & Individuals go above and beyond the call of duty in order to appear committed and hard-working at work \\
Intimidation & Individuals use power or potential to punish in order to be seen as dangerous \\
Supplication & Individuals point out their weaknesses or shortcomings in order to been seen as needy and to avoid certain job responsibilities \\
\hline
\end{tabular}

Defensive tactics, in contrast, are used by individuals in order to protect or correct one's image (Higgins, Snyder, \& Berglas, 2013). The most commonly used behavioral examples of defensive IM tactics are apologies (i.e., accepting responsibility for a negative event, and promising to perform better in the future), justifications (i.e., acknowledging responsibility for a negative outcome but not accounting for the negative implications associated), and excuses (i.e., shifting responsibility from a personal to an external cause) (Tsai, Huang, Wu, \& Lo, 2010). Whereas assertive tactics are used to create a positive image in someone, defensive tactics are used to repair for a target's negative concern about an individual's unfavorable performance. When looking at the concrete context of a job interview, the interviewer may raise a negative concern towards the applicant, based on the applicant's unfavorable performance during a previous job interview task. As a consequence, the concern may arise that the candidate is not skilled enough for the vacant job position. Through this, recruiters evoke in most of the applicants the feeling that the candidate should effectively try to address this concern, hence creating the motivation to engage in defensive IM behaviors.

Beyond creating or correcting for a positive image, individuals may also decide to use IM to intentionally create a negative image. Concrete examples of intentionally used negative IM behaviors range from decreases in overall performance, not working to potential, withdrawal intentions, displaying bad attitudes at work, to broadcasting personal limitations (Becker \& Martin, 1995). Potential reasons for such types of IM behaviors are appearing incompetent in order not to be appointed for a job position or avoiding to take over unpleasant job tasks and responsibilities. Another reason to intentionally look bad at work is the overall aim to reduce stress connected to a heavy workload (Leary \& Miller, 1986).

The dissertation at hand argues that people are motivated to reach out for new and higher goals. In this attempt, individuals try to assertively and positively manage their personal impressions, when the impressions they make on others are relevant to the 
fulfilment of a certain goal (i.e., a social, material or personal goal) (Leary \& Kowalski, 1990). The dissertation investigates this idea in the context of professional life, including individual growth and development, and focuses on an individual's autonomous and self-initiated motivation to create a good impression - that is to make progress in the career. Based on this premise, I do not conceptualize IM as the correction or reparation of a negative image created, nor as an intentionally created negative behavior by individuals. Instead, I conceptualize IM as an active and positive attempt to improve future career outcomes. As a consequence, the current dissertation limits itself to both assertive and intentionally positive IM tactics, namely to self-promotion, ingratiation, and exemplification behaviors.

When looking at the effects of IM in the context of personnel selection, IM use during job interviews has, among others, been associated with increased hiring decisions, starting salaries, perceived qualifications, as well as increased general applicant performance (e.g., Barrick, Shaffer, \& De Grassi, 2009; Ellis et al., 2002; Gilmore \& Ferris, 1989; Proost, Schreurs, De Witte, \& Derous, 2010; Roulin, Bangerter, \& Levashina, 2015). Out of the IM tactics studied, especially self-promotion has been found to increase job interview success (e.g., Stevens \& Kristof, 1995; Swider, Barrick, Harris, \& Stoverink, 2011).

Alongside research in the area of personnel selection, another professional context prone for IM are performance appraisals, most commonly evaluated by the supervisor at work in which IM is used by an employee towards the superior. Research in the work context found that subordinates who engage in IM, and especially ingratiation, receive more favorable performance appraisal ratings, more compliments, recommendations, as well as less criticisms from their supervisor during performance appraisal meetings (e.g., Harris, Kacmar, Zivnuska, \& Shaw, 2007; Higgins, Judge, \& Ferris, 2003; Swencionis \& Fiske, 2016; Wayne \& Kacmar, 1991; Wu, Kwan, Wei, \& Liu, 2013).

Another stream of research studied antecedents of IM and mainly looked at the effect of dispositional and situational variables on individual IM use. Research showed dispositional (i.e., personality) variables such as emotional stability, extraversion, selfmonitoring, agreeableness, and conscientiousness (e.g., Bourdage, Wiltshire, \& Lee, 2015; Higgins \& Judge, 2004; Van Iddekinge, McFarland, \& Raymark, 2007) to positively impact individual IM use. Also situational variables such as the need for power, job involvement, and leader-member exchange have been positively associated with individual IM use (e.g., Kacmar, Carlson, \& Bratton, 2004).

From the different research streams presented above, it becomes apparent that a significant proportion of research studied the effect of individual IM use on performance appraisal outcomes, either during job interviews or at the workplace. Particularly in the context of job interviews, previous IM research also began to study the effect of boundary conditions, affecting when IM used by the applicant is rated more or less favorably; thereby trying to minimize the effect that individual IM use has on hiring chances and on later career outcomes. Previous research, among others, found the 
effect of IM to be reduced when the interview is more structured (Tsai, Chen, \& Chiu, 2005), longer in duration (Peeters \& Lievens, 2006) or when multiple assessors are used (Ellis et al., 2002). Overall, these findings point to the importance of interview trainings, suggesting that a better understanding of the job interview by the interviewer is able to reduce likely selection biases. Although the role of more structural aspects of the interview has been addressed by previous research, there is a lack of literature on the effect that seemingly more trivial and subconscious aspects of the job interview can have on applicant evaluations.

One main assumption of earlier research in both the job interview and work context is that individuals typically engage in IM to boost performance evaluations received. At the same time, whilst this might be true for job interviews, in which applicants usually engage in IM to increase the likelihood of being hired, employees at work may also use IM for other reasons; for example, to retain current job features in the near future (Fugate, Prussia, \& Kinicki, 2012). One concrete situation in which an individual perceives current job features to be at risk are changes in work processes, practices, and routines. Although there are reasons to assume that IM may also be used for other purposes at the workplace rather than to boost job evaluations received, previous research has largely ignored this possibility by mostly considering the current job as a given in the near future. Yet, individuals may also use IM in an attempt to retain the job as it presently is, including current job features at risk. This motivation is also referred to as job preservation motivation (Shoss, 2017).

Moreover, all of the above mentioned studies presumed that individuals only use IM at one moment in time, and therefore looked at IM from a cross-sectional perspective. Only a very small fraction of research examined the effect that individual IM use has over time, i.e. from a longitudinal perspective. For instance, Wayne and Liden (1995) examined the effect that an individual's one-time use of IM has on supervisor ratings of the subordinate six months later. They found that IM use positively affected delayed supervisor ratings and found supervisor perceptions of similarity between the subordinate and the supervisor to cause this effect, acting as a mediator in the IM - performance evaluation relationship.

In contrast to Wayne and Liden (1995), Bolino, Klotz, and Daniels (2014) looked at repeated IM use over a period of time. However, the focus still lay on the consequences (i.e., supervisor ratings) of individual IM use over time. The authors found that subordinates' repeated use of IM reduced the positive effect on supervisor evaluations, such that supervisors evaluated subordinates gradually less positively over time. Although both papers looked at IM from a longitudinal perspective, the authors neglected to acknowledge the idea that individual IM use might also vary over time, such that there are moments in which IM is used more or less. Despite the few longitudinal studies conducted, earlier research solely focused on the consequences (i.e., changes in supervisor evaluations) caused by an individual's repeated IM use and thereby examined IM as a construct that varies only between and not within individuals (over time). 
After the brief summary of former IM research, pointing to IM's main research streams and findings and already referring in short to evolving research gaps, in the next paragraph leading questions building the basis for the current dissertation are developed. Hereafter, a more extensive literature review of previous IM research is provided. On that basis, a short outline is presented on how each of the empirical chapters attempts to answer the respective leading questions.

\subsection{Aim of the Dissertation}

This dissertation contributes to IM research in three empirical chapters, whereby each of the empirical chapters takes a different focus attempting to answer one of the following leading questions:

1) When does individual IM use during the job interview lead to more or less favorable interviewer evaluations?

2) Why do individuals use IM in the context of threat appraisal at work?

3) What is the role of time for individual IM use - to what extent does individual IM use vary within (and not only between) persons over time?

The first empirical chapter (Chapter 2) looks at IM in the currently most researched context, namely job interviews, and tries to further our knowledge on how seemingly more trivial aspects of the job interview lead to more or less favorable interviewer evaluations of the applicant. More specifically, the chapter investigates the interactive effect of different types of self-promotion used (i.e., low versus high abstractness of language used) with a seemingly trivial aspect, namely the spatial distance between the applicant and interviewer (i.e., both across the globe in form of a virtual versus face-toface interview and distance in seats in the interview room), on interviewer evaluations (i.e., the likelihood of being hired).

The second empirical chapter (Chapter 3) studies IM in an organizational setting, and, more precisely, in the context of threat appraisal triggered by changes in work processes, practices, and routines. The chapter introduces IM as a form of job preservation behavior - the motivation to retain current job features at stake (Shoss, 2017). In doing so, two forms of control, namely job control (i.e., a form of control bestowed by the organization) and proactivity (i.e., a personal form of control) are investigated as contingency factors, thus hypothesizing a three-way interaction effect.

The third and last empirical chapter (Chapter 4) studies IM in a university context throughout the progression of an academic course at university and introduces IM as a construct that changes within individuals over time as a function of increases in salience to achieve good evaluations. This chapter examines individual IM use in an environment 
characterized by approaching performance appraisal events, and examines for whom, i.e. individuals low versus high in self-esteem, IM use increases more steeply over time.

Each of the empirical chapters looks at one specific assertive IM tactic in isolation which is of superior relevance to the concrete context studied, instead of looking at IM holistically: Self-promotion (e.g., pointing out one's own skills and abilities) is typically used in order to be seen as competent (Bolino \& Turnley, 1999) and is thus deemed especially useful in job interviews (i.e., Chapter 2); exemplification (e.g., going above the call of duty) is typically used in order to be seen as dedicated and hard-working at work (Bolino \& Turnley, 1999) and is deemed especially useful to secure one's job, including current job features at work, when confronted with threat appraisal at work (i.e., Chapter 3); and ingratiation (e.g., engaging in flattering behaviors) is typically used in order to be seen as likeable (Bolino \& Turnley, 1999) and is therefore deemed especially useful in an attempt to retain or upgrade relationships with authority figures (i.e., persons responsible for academic course grades; Chapter 4). This focus on only one IM tactic at a time allows to examine the distinctive feature of each tactic in the respective context studied.

\subsection{Literature Review and Evolving Research Gaps}

\subsubsection{Origins of Impression Management and Where Research All Began}

IM belongs to the broader classification of influence tactics; yet some scholars use both terms interchangeably (e.g., Higgins \& Judge 2004; Judge \& Bretz, 1994; Wayne \& Ferris, 1990). Influence tactics, in contrast to IM, refer to a larger set of behaviors and do not only include ingratiation (i.e., a specific type of IM) but also behaviors such as consultation, rational persuasion, inspirational appeals, coalitions, sanctions, as well as upward appeals (Bolino \& Turnley, 2003; Kipnis, Schmidt, \& Wilkinson, 1997; Yukl \& Falbe, 1990).

The concept of IM first came into existence with the dramaturgical perspective of social interaction by Goffman (1959), in which individuals are seen as actors on a theatrical stage. The concept was later applied to organizations (Gardner \& Martinko, 1988), where employees and job applicants are, to some extent, considered to be actors on an organizational stage. Consequently, researchers began to focus on the topic of IM in an organizational setting from the 1980s onwards.

\subsubsection{Impression Management Research in the Context of Job Interviews}

A significant amount of IM research investigated the effectiveness of IM tactics in the context of personnel selection (i.e., job interviews). The use of IM tactics during job interviews has been positively associated with increased hiring intentions, higher perceived qualifications, higher interviewer assessments of person-job fit, and higher start- 
ing salaries (Gilmore \& Ferris, 1989; Kacmar, Delery, \& Ferris, 1992; Stevens \& Kristof, 1995; Peeters \& Lievens, 2006; Roulin et al., 2015). Out of the three IM tactics described earlier (i.e., ingratiation, self-promotion, and exemplification), especially selfpromotion, with the intention to boost the assessment of competence (Jones \& Pittman, 1982; Rudman, 1998), appeared to be superior in having an impact on job interview evaluations (Higgins et al., 2003; Stevens \& Kristof, 1995; Swider et al., 2011).

Alongside research examining the effect of individual IM use on job interview outcomes, another, less dominant stream of research studied different personality traits as antecedents of IM tactics used during job interviews. Results demonstrated that emotional stability and self-monitoring relate positively to both ingratiation and selfpromotion use (Bourdage et al., 2015; Van Iddekinge et al., 2007). Extraversion relates positively to self-promotion use (Higgins \& Judge, 2004), agreeableness relates positively to non-verbal IM tactics such as a smiling and the maintenance of eye contact (Higgins \& Judge, 2004), and conscientiousness relates positively to exemplification use (Bourdage et al., 2015).

A third stream of research looked at the potential ways in which the effect of selfpromotion during job interviews can be attenuated. Howard and Ferris (1996) were among the first to examine the moderating effect of interviewer training on the effectiveness of applicant IM use. They found that IM tactics, and especially the use of selfpromotion by the applicant was less effective for interviewers who had received interview training beforehand, compared to interviewers who had not. As a continuation of this research stream, other scholars looked at the contingency effect of structural formats of the job interview and their potential to reduce interviewer overrating of the applicant as a result of IM use. For instance, Tsai et al. (2005) and Peeters and Lievens (2006) showed that more structured and longer interviews reduce the effect that IM has on subsequent job interview evaluations and Ellis et al. (2002) demonstrated the presence of multiple assessors during the job interview to have a similar effect.

Although self-promotion use has been typically associated with a boost in overall job interview ratings, a few scholars noted that the effectiveness of self-promotion is not always that clear and predictable (Berman et al., 2015). While other scholars concluded that self-promotion increases overall hiring decisions and recruiters' perceptions of person-job fit (Kristof-Brown et al., 2002), more recently it has been found that the use of self-promotion is unrelated or even negatively related to recruiters' overall fit perceptions and hiring recommendations (Higgins \& Judge, 2004; Berman et al., 2015). Referring to the latter line of thought, Berman et al. (2015) highlighted the idea that self-promotion use can also backfire, such that, as a result of using too much selfpromotion, applicants may also appear as arrogant and less competent. This idea is referred to as the self-promotor's paradox, presuming that the use of self-promotion during the job interview may either increase or decrease subsequent job interview ratings (Berman et al., 2015). As a way to offset this paradox, scholars argued for the possibility to engage in more abstract and indirect forms of self-promotion (Douglas \& 
Sutton, 2010), by also referring to connections that a person has to other people, institutions or successful others in general.

Whereas the effect of more structural contingencies of the job interview has been investigated (Bolino, Long, \& Turnley, 2016), still less is known about more subconscious and seemingly trivial contingencies of the interview determining whether selfpromotion attempts as rated by the interviewer succeed or fail. In the current dissertation, I look at one more subconscious boundary condition of the job interview: The spatial distance between the applicant and interviewer during the job interview. Furthermore, I argue that it is neither the spatial distance between the applicant and interviewer (i.e., close or far spatial distance) nor the type of self-promotion used alone (i.e., direct/concrete or indirect/abstract self-promotion), leading to more or less favorable job interview evaluations. More particularly, it is assumed that differences in interviewer evaluations are also likely to arise from the interaction between the type of selfpromotion used and the spatial distance between the applicant and interviewer - an idea supported by construal level theory (CLT). CLT investigates how spatial distance to objects or events affects the level of abstractness when thinking about an object or event (Fujita, Henderson, Eng, Trope \& Liberman, 2006; Fujita, Eyal, Chaiken, Trope, \& Liberman, 2008).

In Chapter 2, I apply this idea to the area of personnel selection, by proposing that the spatial distance between the interviewer and applicant during the job interview is likely to impact subsequent interviewer evaluations. More specifically, close (as opposed to far) spatial distance between the interviewer and applicant during the job interview in interaction with low (as opposed to high) abstraction of self-promotion used is anticipated to lead to more favorable interviewer evaluations of the applicant (i.e., the likelihood of being hired). By applying CLT to job interviews, Chapter 2 aims to provide new insights into a seemingly trivial contingency factor impacting the effectiveness of individual IM use during job interviews.

\subsubsection{Impression Management Research in the Context of Work and Career Outcomes}

The effectiveness of IM has also been studied in the context of general performance appraisals at work, whereby IM is typically used by an employee during performance appraisal meetings (e.g., Wayne \& Liden, 1995; Wu et al., 2013) or other supervisorsubordinate interactions (e.g., Foulk \& Long, 2016; Swencionis \& Fiske, 2016; Wayne \& Ferris, 1990). Previous research demonstrated that subordinates who engage in IM tactics receive overall more favorable performance ratings (Harris et al., 2007; Higgins et al., 2003; Wayne \& Kacmar, 1991). The use of IM during performance appraisal meetings has also been linked to concepts such as supervisor liking and perceived similarity, acting as mediators in the IM - performance appraisal relationship (Wayne \& Ferris, 1990; Wayne \& Liden, 1995; Weng \& Chang, 2015). These studies highlighted the par- 
ticular effectiveness of supervisor-focused IM tactics, i.e. ingratiation, influencing supervisors' liking for subordinates, and, in turn performance outcomes.

All of the aforementioned studies, and the majority of previous IM research, investigated the effect of IM on performance evaluations at work by typically taking the actual job, including current job features, as a given (i.e., an exception is the research stream investigating IM in the context of uncertainty, e.g. Huang, Zhao, Niu, Ashford, \& Lee, 2013; Kang, Gold, \& Kim, 2012). The majority of previous IM studies thereby presumed retention of the current job in the near future and did not take into consideration potential changes in terms of job features. In this vein, employees were typically assumed to engage in $\mathrm{IM}$ to boost performance evaluations received and to reach higher career outcomes. At the same time, there are reasons to suggest that employees at the workplace are not only occupied with attempting to increase the performance appraisals they receive from others but the reasons to engage in IM might, in reality, be more diverse. This line of thought suggests that another shortcoming of previous IM research pertains to the lack of attention to other objectives of IM use. One context of relevance are organizations characterized by changes in work processes, practices, and routines, thereby not guaranteeing a retention of current job features in the near future.

New work routines, processes, and practices can lead to employees' perceptions of job threat due to their unforeseen effects on a variety of job features. Threat appraisal refers to an individual's subjective perception of job features at stake (Fugate et al., 2012). Such unforeseen effects on job features often necessitate employees to use different competencies in their jobs compared to those needed before the change initiative, implying some degree of competency obsolescence. As a result, employees tend to feel concerned about potential job feature loss in the near future. This can take many facets and forms (i.e., relationships to co-workers and supervisors, general working conditions, job opportunities at the current employer, pay and benefits, as well as job stability itself; Fugate et al., 2012). As a result of changes in work processes, practices, and routines, employees may decide to engage in behaviors attempting to preserve current job features in the near future. One concrete behavior is IM, i.e. by making a good impression on the supervisor (Shoss, 2017).

Shoss (2017) suggested that, as a result of qualitative job insecurity - a construct similar to threat appraisal - individuals might engage in behaviors with the motivation to retain current job features. This idea is also referred to as job preservation motivation (Shoss, 2017). Out of the different IM tactics, especially exemplification, the attempt to go beyond the call of duty by appearing hard-working and committed at work (i.e., a type of job-focused IM; Tedeschi \& Melburg, 1984), is relevant for job preservation. Among others, De Cuyper, Schreurs, Van der Elst, Baillien, and De Witte (2014) studied the effect of exemplification on employees' self-ratings of performance and emotional exhaustion, moderated by job insecurity. The authors found exemplification use, especially for high levels of job insecurity, to positively affect self-rated performance. At the same time, engaging in exemplification during times of job insecurity 
seems to be effortful, as exemplification use also related positively to emotional exhaustion. This finding is somewhat in line with previous research demonstrating that job insecurity, an environmental trigger that is typically associated with reduced well-being and performance-related outcomes (Gilboa, Shirom, Fried, \& Cooper, 2008) might also steer individuals to work harder (Staufenbiel \& König, 2010).

A further stream of research investigated threat appraisal as an antecedent of individual IM use. By connecting threat appraisal at work to the concept of IM, this stream of research presumed that the experience of job threat can lead to individual increases in the motivation to work harder, i.e. through the engagement in exemplification behaviors. Whereas Huang et al. (2013) observed a positive relationship between employee perceptions of job threat and exemplification, Kang et al. (2012) found a negative relationship between these variables. Both papers departed from proactivity theory, hypothesizing that, as a result of threat appraisal, individuals initiate some form of proactive coping.

The proactivity rationale suggests that individuals experiencing job threat decide to go the extra mile primarily out of self-initiated action, hence engaging in behaviors such as increases in productivity (Probst, Stewart, Gruys, \& Tierney, 2007), working more hours (De Cuyper, Bernhard-Oettel, Berntson, De Witte, \& Alarco, 2008) or voice (Sverke \& Hellgren, 2001). At the same time, it is surprising that, when experiencing an environmental trigger such as threat appraisal at work, employees engage in such types of behaviors out of proactivity alone. This is also what Kang et al. (2012) argued, thereby trying to explain their unexpected negative relationship found. The authors argued that, when experiencing job threat - a type of workplace stressor - it is doubtful whether individuals are ultimately driven by proactive behaviors.

Based on the authors' reasoning, in Chapter 3, the second empirical chapter of the dissertation, I introduce exemplification (i.e., going above the call of duty) as a form of job-preservation behavior. This idea is based on premises of conservation of resources (CoR) theory, stating that individuals strive to protect themselves from potential, future resource loss. Attempting to protect potential, future resource loss, individuals strive to mobilize additional resources. Resources are perceived to be threatened once invested resources do not lead to anticipated returns (Hobfoll, 1989, 2001). To this end, the appraisal of threat at work constitutes one such violation against anticipated returns, i.e. the idea that hard work does not result in a stable and predictable work situation in the near future. Based on this line of thought, in Chapter 3, an alternative theoretical rationale is offered as to why individuals, as a result of experiencing job threat, engage in exemplification. Referring back to the above-mentioned drivers of exemplification, I suspect another reason for individuals to engage in exemplification is out of job preservation motivation (Shoss, 2017), and not out of proactivity alone, as previous research suggested. Moreover, individuals who feel in control of work processes and possibilities to counteract potential job feature threat (i.e., are high in job control) and who use self- 
initiated behavior to influence related outcomes (i.e., are high in proactivity) are expected to engage most in exemplification, hypothesizing a three-way interaction effect.

To study the above-described research model, CoR theory is used and is favored over other theories, like e.g. appraisal theory of stress. According to appraisal theory, when experiencing job threat, a person's evaluation of the environment (i.e., referred to as primary appraisal), plays a critical role for subsequent individual behavior (Webster, Beehrs, \& Love, 2011). Essentially, based on appraisal theory, an individual's emotional appraisal of a situation (e.g., whether a threat is perceived more as a challenge or a hindrance stressor) causes behavioral responses of a person to counteract the threat. Opposed to that, and based on CoR theory, when experiencing job threat, individual motivation drives the need to obtain, maintain, and protect valuable resources (Westman, Hobfoll, Chen, Davidson, \& Laski, 2004) attempting to counteract the threat. CoR theory further postulates that, once invested resources do not lead to anticipated returns (Hobfoll, 1989, 2001), individuals are motivated to protect themselves from resource loss by engaging in behaviors to mobilize additional resources. When bringing the main assumptions of both theories to a more general level, it becomes apparent that appraisal theory assumes that peoples' emotions are obtained from evaluations (e.g., the appraisal of events), resulting in specific behavioral reactions as a result. In contrast, CoR theory assumes that peoples' motivations drive reactions and hence behavior.

Similar as to CoR theory, also IM theory (Goffman, 1959) argues that IM behaviors are driven by an individual's goal-directed motivation to influence others' perceptions of oneself. IM theory therefore assumes that IM results out of an individual's attempt to achieve certain goals (i.e., personal, social or material goals) (Leary \& Kowalski, 1990), instead of focusing on which kind of emotion translates into subsequent behavior. For this reason, CoR theory is used as a basis to predict individual motivations for IM (i.e., exemplification) behaviors at work.

\subsubsection{Impression Management Research and the Role of Time}

All of the above-described studies on IM are based on the premise that individuals engage in IM tactics once at a time. Only a vanishingly small amount of research investigated IM over time (e.g., Cooper, 2005; Wayne \& Liden, 1995), and if so, typically from an outcome-driven perspective by looking at the outcomes of IM over time. Also Bolino et al. (2014) studied how performance appraisals rated through the supervisor change over time based on the repeated use of IM by an employee. The authors supposed that, next to using ingratiation once at a time, it can also be used over an extended period of time. Yet, they focused on changes in perceived effectiveness (i.e., how performance appraisals of the supervisor changed over time) based on the employee's continuous IM use. Findings showed that re-using IM over a longer time reduces the effect that IM has on subsequent performance evaluations. 
Although a handful of previous studies looked at IM longitudinally, none of previous $\mathrm{IM}$ research raised the idea that IM tactics used by one and the same individual might vary over time, such that there are moments when it is used more or less. This lack of research is surprising, since already Leary and Kowalski (1990) argued that the motivation to manage impressions is not stable but is a factor that varies over time. Leary and Kowalski (1990) argued that the motivation to manage impressions is driven by individual goals (i.e., the desirability to achieve a certain outcome) and values (i.e., the importance to achieve a certain outcome). More particularly, the authors assumed that the extent to which individuals make use of IM is affected by the goal relevance of impressions (e.g., the extent to which behavior is public, the extent to which an individual is dependent on the target), and the value of desired goals (e.g., a highly desirable job, a target who is of high status or power). The authors suggest that, as one of the components changes, individual IM use also changes. As such, as an individual's desirability to achieve a positive performance appraisal increases, individual IM use increases in order to attempt to accomplish this goal.

Despite Leary and Kowalski's (1990) influential paper, one major assumption of previous IM research until now was that IM differs between but not within individuals. Previous scholars thereby neglected the idea that IM tactics may also be used by one and the same individual over a longer period of time (Bolino, Kacmar, Turnley, \& Gilstrap, 2008). As demonstrated above, there are strong reasons to assume that IM itself varies (i.e., is used more or less) by one individual over time. This would suggest that, next to between-person variability, IM also shows significant within-person variability.

Previous empirical evidence already demonstrated that ingratiation follows as a function of performance-related behaviors which are conceptually dynamic in nature, e.g. leader-member-exchange, and role ambiguity, acting as typical antecedents of IM tactics (Kacmar, Carlson, \& Bratton, 2004). Above that, one unique characteristic of all behaviors in general is that they are discrete and episodic, and hence likely to be temporally dynamic (Beal, Weiss, Barros, \& MacDermid, 2005). Since IM is an active behavior people engage in, it is reasonable to assume that also IM happens in a discrete and episodic way. However, previous research treated IM as behavior that solely varies between, and not within, individuals. Therefore, a third shortcoming of IM research is a consequence of no research to date investigating the idea that individual IM use varies over time. Prior research has assumed that there are moments in which a person is motivated more or less to engage in IM - yet irrespective of time. Knowledge as to whether an individual engages in IM to different extents over time would provide new theoretical insights into the dynamics of individual IM use.

In an attempt to overcome this shortcoming, hypothesizing that individual IM use is also likely to change over time, in the last empirical Chapter 4, I study ingratiation (i.e., engaging in flattering behaviors) in a context characterized by approaching performance appraisal events. Approaching performance appraisal events lead to increases in both perceived goals and values (i.e., the desirability and importance to perform well), and 
have an impact on the salience of achieving good evaluations; thereby eliciting ingratiation. Moreover, and based on basic assumptions of behavioral plasticity theory (BPT) (Brockner, 1988) individuals with low, in comparison to high, self-esteem are anticipated to be more susceptible to environmental events (Pierce, Gardner, Dunham, \& Cummings, 1993), translating into steeper increases in ingratiatory behaviors over time.

\subsection{Theoretical Model of the Dissertation}

Figure 1.1 illustrates the overall theoretical model of this dissertation, including the three empirical chapters (Chapters 2, 3, and 4). Whilst IM acts as an independent variable in Chapter 2, it serves as an outcome variable in Chapters 3 and 4 . The focus of Chapter 2 is on both the individual and organizational level by studying the effect of self-promotion, i.e. an individual factor, and spatial distance between the applicant and interviewer during the job interview, i.e. an organizational factor. Chapter 3 builds the bridge between the organizational and individual level by investigating employees' perceptions of threat appraisal contingent on two forms of control, i.e. job control referring to a form of control bestowed by the organization, and proactivity - referring to a personal form of control. Finally, Chapter 4 looks at IM clearly from the individual level, through its focus on within-person variability over time and contingent on individual levels of self-esteem. Finally, please note that all empirical chapters have been written as separate manuscripts and may thus also be read independently of each other. 
An Introduction and Literature Review

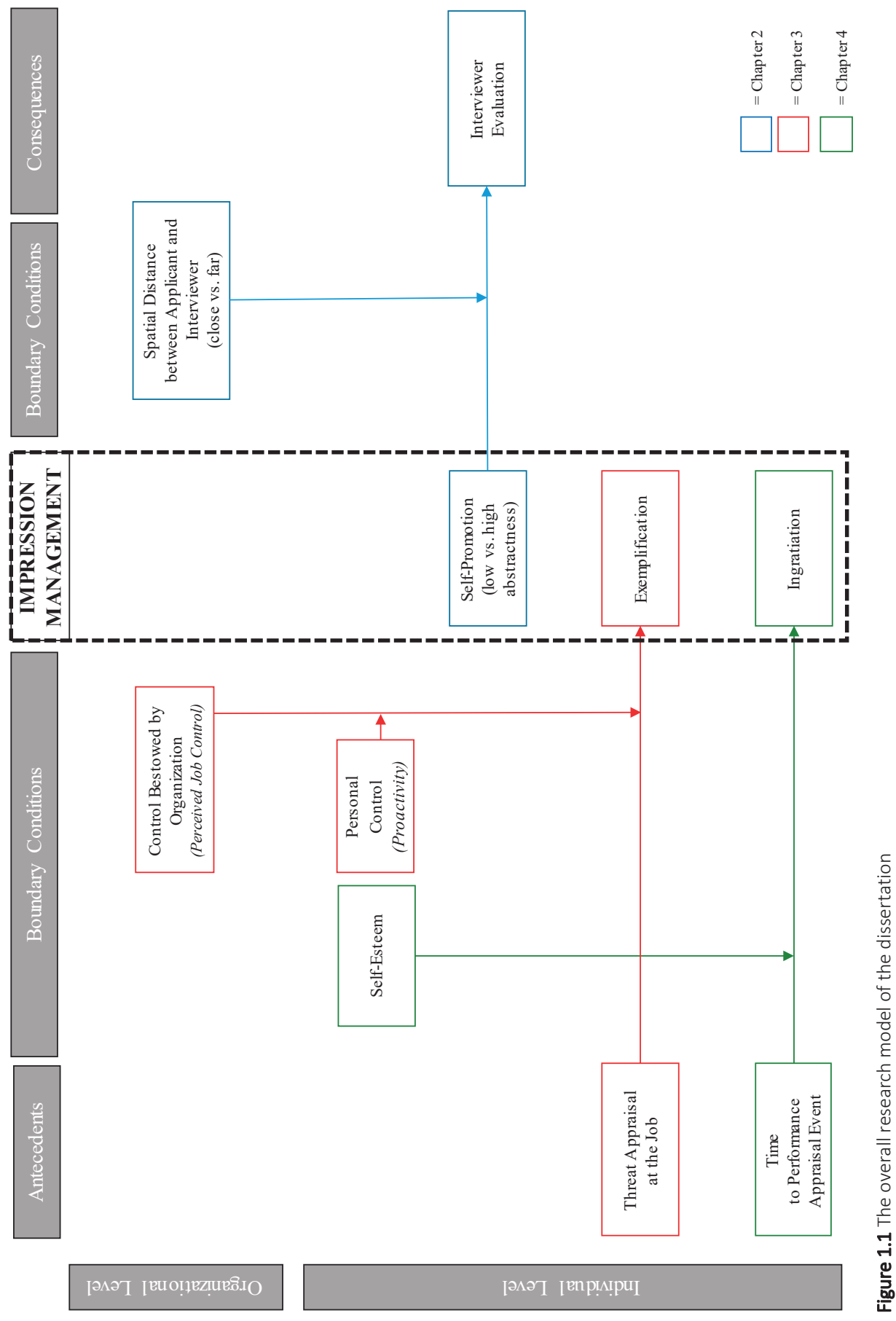




\subsection{Outline of Empirical Chapters}

The research to date lays the foundations for understanding the effect of IM on performance appraisals used during job interviews and at work. Whilst there are abundant studies on the contingency effect of structural aspects of the job interview, the effect of seemingly more trivial and subconscious aspects determining whether recruiters react more or less favorably to individual IM use is lacking (Bolino et al., 2016). Furthermore, former IM research on employees at the workplace mainly focused on the effect that individual IM use has on subsequent performance appraisals, by taking current job features as a given in the near future. However, alongside attempting to boost performance appraisals, IM may also be used for other reasons. In the particular context of changes in work processes, practices, and routines, individuals might also engage in IM in an attempt to retain current job features at stake. Thirdly, scholars observed that IM has solely been investigated from a cross-sectional perspective (Bolino et al., 2008). At the same time, the idea has already been developed that the extent to which an individual engages in IM changes as a function of changes in individual goals and values, i.e. the desirability and importance of achieving an outcome (Leary \& Kowalski, 1990); yet support hereof is missing. As distance to the performance appraisal event is decreasing, individual IM use is likely to increase over time, as a function of increases in salience to achieve good evaluations.

This dissertation adds to the above-mentioned shortcomings in the following ways: First, the dissertation attempts to provide new insights into a seemingly trivial contingency impacting performance evaluations during job interviews, by studying the spatial distance between the interviewer and applicant. Second, the dissertation investigates $\mathrm{IM}$ in an under-researched work context relevant to IM use, i.e. job features perceived to be at risk as triggered by changes in work processes, practices, and routines. Third, the dissertation looks at individual IM use over time by examining IM in a university context throughout the progression of an academic course with an approaching performance appraisal event.

To allow for a more extensive investigation of $\mathrm{IM}$, a variety of research methods is applied. In Chapter 2, two experimental studies were conducted, investigating the combined effect of different types of self-promotion used and different degrees of spatial distance. Chapter 3 is in the form of a field study and investigates IM in the context of changing work routines, processes, and practices. More specifically, an employee's perception of job threat is studied as an antecedent of IM contingent on a "dual" view of control, i.e. job control (a form of control bestowed by the organization) and proactivity (a personal form of control), thus hypothesizing a three-way interaction effect. Chapter 4 uses a growth model analysis and studies the effect of time on IM use as a function of an approaching performance appraisal event, contingent on individual levels of self-esteem. 


\subsubsection{Chapter 2. Self-promotion during Job Interviews: A Two-Study Test of the Construal Compatibility Effect}

In Chapter 2, I study the interactive effect of type of self-promotion used (low versus high abstractness of language used) and spatial distance (close versus far) between the applicant and interviewer on interviewer evaluations of the applicant (i.e., the likelihood of being hired). Based on predictions of construal level theory (CLT) (Trope \& Liberman, 2010), low abstractness of language used (direct/concrete self-promotion) was anticipated to be evaluated more favorably with a close spatial distance and high abstractness of language used (indirect/abstract self-promotion) with a far spatial distance (i.e., also referred to as the construal compatibility effect hypothesis). Two experimental studies were conducted in which spatial distance was manipulated in different ways. In experiment 1 , spatial distance was manipulated as the degree of home place detachment (i.e., a face-to-face interview versus a virtual interview via Skype). In experiment 2, spatial distance was manipulated as the degree of separation between the applicant and interviewer in the interview room (i.e., distance in centimeters across the table). Participants of the first experiment were 76 employees working in different organizations around Amsterdam, with the majority of participants holding some degree of previous experience in recruiting. Participants of the second experiment were $100 \mathrm{em}$ ployees of an international hotel chain. Similar to experiment 1 , the majority of participants held previous experience in recruiting. Results of both experiments were predominantly in line with the construal compatibility effect hypothesis, such that low abstraction of self-promotion used was evaluated more favorably with a close spatial distance. High abstraction of self-promotion used was evaluated more favorably with a far spatial distance.

\subsubsection{Chapter 3. Impressing to Preserve? The Role of Threat Appraisal, Job Control, and Proactivity on Exemplification}

In Chapter 3, I examine employees' perceptions of job threat triggered by changes in work routines, processes, and practices as an antecedent of IM, and more specifically exemplification, use. Previous research suggested that, as a consequence of experiencing threat appraisal at work, employees engage in proactive behaviors, e.g. increases in productivity, working more hours or voice. I presume that employees experiencing job threat do not engage in those behaviors out of proactivity alone but more out of the motivation to preserve current job features (i.e., including relationships to co-workers and supervisors, general working conditions, and job stability related aspects) - a motivation referred to as job preservation (Shoss, 2017). Based on this idea, exemplification (i.e., going above the call of duty) is used as one concrete IM behavior attempting to preserve job features at stake as a result of workplace threat appraisal. Originated on conservation of resources theory (CoR; Hobfoll, 1989, 2001), it is therefore argued that, 
as employees strive to protect themselves from future resource loss, they start to engage in exemplification. In order to understand individual differences in the use of exemplification, a "dual" view of control is examined: Job control (i.e., a form of control bestowed by the organization) and proactivity (i.e., a personal form of control), anticipating a three-way interaction effect. Employees holding high levels of both job control and proactivity are expected to engage most in exemplification in response to perceived workplace threat. Data have been collected from 356 employees working in different sectors in the US. The regression and simple slope analyses support the hypothesized three-way interaction, suggesting that high levels of job control and proactivity together have a positive and reinforcing effect on the threat appraisal - exemplification relationship.

\subsubsection{Chapter 4. Within-Subject Variability in Ingratiation as a Function of Self- Esteem and Time: A Dynamic Perspective}

Previous research studied IM predominantly from a between-person perspective. This observation is surprising, given that Leary and Kowalski (1990) already stated that the extent to which individuals engage in IM is likely to vary as a function of changes in individual motivation, i.e. their goals (the desirability of achieving an outcome) and values (the importance of achieving an outcome). Based on their core assumptions, in Chapter 4, I take a within-person perspective to theorize why the use of IM increases and for whom. I posit that as the appraisal event draws closer, the salience of achieving good evaluations increases, leading to an increasing use of ingratiation (i.e., the engagement in flattery behaviors) over time. Drawing on behavioral plasticity theory (BPT) (Brockner, 1988), self-esteem is introduced to explain inter-individual differences in intra-individual changes in the use of ingratiation. Data were collected in three biweekly waves throughout the progression of an academic course across a time span of six weeks from 349 university students. Participants were students enrolled in an academic course at a Dutch university and these students were evaluated by tutors who assigned course grades. A total of 898 data points was collected for all three consecutive measurement moments. The results were analyzed using random coefficient modeling. The analysis of the hierarchical growth model indicates that the use of ingratiation increased as time to the appraisal event decreased, and that low (relative to high) selfesteem individuals ingratiated more as time progressed. 


\section{Chapter}

\section{Self-Promotion during Job Interviews: A Two-Study Test of the Construal Compatibility Effect}

Another, shorter version of the chapter (i.e., including one of the two experiments) exists as the following manuscript:

Schreurs, B., Hamstra, M. R. W., Segers, M., \& Schmitte, K. (2018). Where to seat the applicant? How spatial distance influences the effect of self-promotion on interviewer evaluations. Journal of Applied Social Psychology, 48(8), 448-456.

The research idea originated from the first author. The manuscript has mainly been written by the first authors for publication to the journal. The PhD candidate has collected a second experiment and has written a separate, two-experimental version of the manuscript as part of her thesis.

An earlier version of the manuscript was also presented as:

Schmitz, K., Schreurs, B., Proost, K., Germeys, F., \& Van den Broeck, A. The influence of self-promotion and spatial distance on interview outcomes. Proceedings of the 2014 Conference of the Academy of Management, Philadelphia, PA, August, 2014. 



\subsection{Introduction}

Job interviews hold opportunities and risks for both the applicant and the interviewer. For the applicant, a favorable job interview can be associated with increased stability, security, and a regular income (Barrick, Shaffer, \& DeGrassi, 2009). For the interviewer, an effective hiring decision can be related to increases in shared revenue, as well as a productive work climate (Weiss \& Feldman, 2006). At the same time, job interviews can also be associated with risks. For the applicant, the risk might be not getting hired for the job because another candidate is favored for the job vacancy. For the interviewer, one potential risk is to hire a candidate, who eventually might turn out to be unqualified for the job. Given that the interview performance is one of the most weighted factors during hiring decisions, it is not surprising that applicants engage in diverse strategies in order to influence interviewers' decisions in their favor during job interviews (Higgins \& Judge, 2004; Higgins, Judge, \& Ferris, 2003), and to reduce the risks connected to not obtaining the job.

One strategy applicants often make use of during job interviews is impression management (IM), defined as the process through which individuals aim to influence the image others have of them (Rosenfeld, Giacalone, \& Riordan, 1995). In this way, individuals aim to boost the chances of appearing competent and fit for the job, and, in turn, achieve the main objective of the job interview; i.e. to get hired for a particular vacancy (Leary \& Kowalski, 1990). Earlier IM research has typically distinguished between five main tactics, namely self-promotion, ingratiation, exemplification, intimidation, and supplication (Turnley \& Bolino, 2001), of which self-promotion, in particular, has been found to be effective during job interviews (Stevens \& Kristof, 1995; Swider, Barrick, Harris, \& Stoverink, 2011). Self-promotion encompasses behaviors, which are intended to draw attention to one's positive qualities, future plans, or past accomplishments (Stevens \& Kristof, 1995). To the extent that these qualities are irrelevant for the job or are over-rated by the interviewer, self-promotion may bias interviewer judgments and thus result in suboptimal hiring decisions (Giacalone \& Rosenfeld, 1986; Higgins et al., 2003; Roulin, Bangerter, \& Levashina, 2015). Accordingly, selection scholars have invested much effort in identifying ways to attenuate the effect of selfpromotion. For example, it is suggested that the effect of self-promotion is nullified when structured and longer interviews are used or when multiple assessors are involved (Ellis, West, Ryan, \& DeShon, 2002; Peeters \& Lievens, 2006; Tsai, Chen, \& Chiu, 2005; Van Iddekinge, McFarland, \& Raymark, 2007). This suggestion stems from the idea that distant decision-making, characterized by more standardized and consistent procedures, is less subjective, and therefore has higher validity by reducing the biasing effect of self-promotion use (Huffcutt \& Arthur, 1994).

Another stream of research found that self-promotion use during job interviews does not always lead to over-ratings by the interviewer, given that, as an overdose of using self-promotion, individuals may also end up looking self-interested and less com- 
petent (Berman, Levine, Barasch, \& Small, 2015; Jones \& Pitman, 1982). This phenomenon is referred to as the self-promotor's paradox. In an attempt to overcome the selfpromotor's paradox, scholars recommend applicants to engage in more abstract and indirect forms of self-promotion (Douglas \& Sutton, 2010).

The present study moves beyond examining the direct effects of IM applicant evaluations by the interviewer to also consider how its effect may change with varying degrees of spatial distance between the applicant and interviewer during the job interview. Based on previous research findings, the authors suggest that differences in job interview outcomes (i.e., the likelihood of being hired) are likely to depend on both the way IM is used and on other, seemingly more trivial, contingencies of the interview. We rely on construal level theory (CLT; Trope \& Liberman, 2010) to develop and test the construal compatibility effect hypothesis: Concrete and direct types of self-promotion constitute low-level construals and are more effective with close spatial distance. Abstract and indirect types of self-promotion constitute high-level construals and work better with far spatial distance. In doing so, we build on the work by Proost, Germeys, and Schreurs (2012), who demonstrated that concrete IM tactics work better when interviewers have a shorter time horizon (i.e., wanting to fill a job vacancy within a month), whereas abstract tactics work better with interviewers having a longer time horizon (i.e., wanting to fill a job vacancy within a year).

In contrast to Proost et al. (2012) who focused on temporal distance, we focus on spatial distance, and we do so for the following reason: Increasingly more job interviews are taking place through technologically advanced media where the interviewer and applicant are physically separated from each other. Examples of such technology trends are webcam tests, online interviews, and communication via social media (Chapman \& Webster, 2003; König, Klehe, Berchtold, \& Kleinmann, 2010; Recruiter.com, 2015). Due to these technological advancements, applicants may be located anywhere in the world at the time of the job interview. We aim to demonstrate that such seemingly trivial aspects of the job interview can have more far-reaching consequences than initially expected, both for the applicant as well as the organization.

We investigate the construal compatibility effect hypothesis in two experiments. In the first experiment, spatial distance is operationalized as the degree of home place detachment between the applicant (i.e., located in the Netherlands) and interviewer (i.e., located in the US) during a video-chat (i.e., Skype) job interview. In the second experiment, spatial distance is operationalized as the degree of separation between the applicant and interviewer in the interview room (i.e., distance in centimeters across the table). With both experiments together, we want to collectively show that interviewers are susceptible to how applicants present themselves during the job interview, and more importantly, that the same IM tactic is weighed differently depending on the spatial distance to the applicant.

Our study contributes to the literature in several ways: First of all, we advance current research on IM, and more specifically self-promotion, by investigating the effect of 
spatial distance as a boundary condition, likely to impact IM effectiveness during job interviews. Through this, we aim to shed more light on the previously found mixed findings linking self-promotion use to job interview ratings. We also add to research on personnel selection by postulating that decision-making in personnel selection is not always a rational process but can also be driven by subtler and less explicit aspects. By investigating a trivial contextual factor like spatial distance during the job interview together with the type of self-promoting used therein, our study attempts to disentangle in more detail the scope of selection biases taking place during job interviews. The hypothesized model is shown in Figure 2.1.

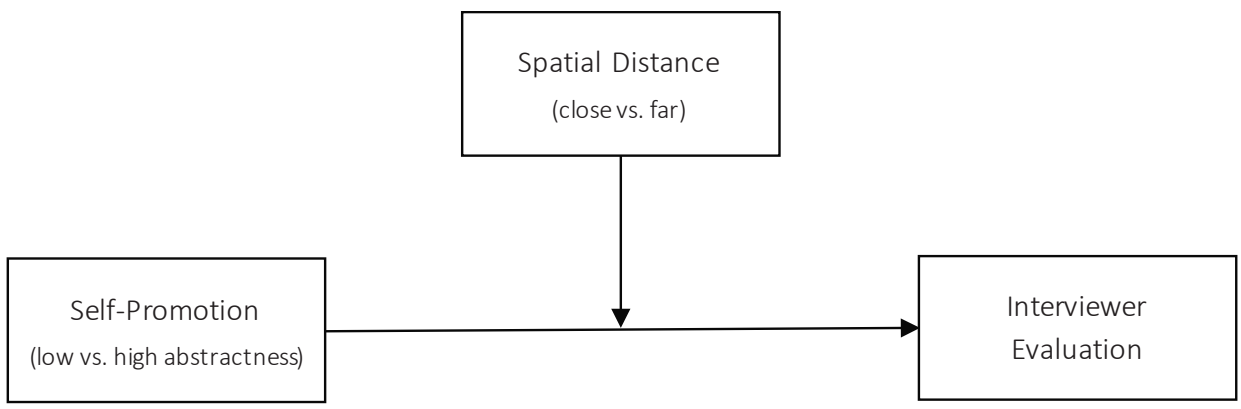

Figure 2.1 The hypothesized model.

\subsection{Theoretical Background and Hypotheses}

\subsubsection{Self-Promotion in the Selection Context}

IM tactics are frequently used in the area of personnel selection. IM can be defined as the process through which people attempt to influence the image others have of them (Rosenfeld, Giacalone, \& Riordan, 1995). During selection, the applicants' primary motive to use IM tactics is to create the most positive impression possible (Fletcher, 2013). Previous studies have shown that the engagement in IM typically leads to more favorable interview outcomes, such as higher perceived competence or increased hiring chances (Higgins, Idson, Freitas, Spiegel, \& Molden, 2003; Kacmar, Delery, \& Ferris, 1992; Kristof-Brown, Barrick, \& Franke, 2002; Leary \& Kowalski, 1990; Proost, Schreurs, De Witte, \& Derous, 2010). One exception originates from the self-promotor's paradox, showing that the use of IM and self-promotion does not always lead to more favorable interview outcomes (Berman et al., 2015).

IM research typically differentiates between five main tactics, namely self-promotion, ingratiation, exemplification, intimidation, and supplication, of which the former three classify as assertive and the latter two as defensive tactics (Turnley \& Bolino, 2001). Assertive tactics are used in order to acquire and promote favorable impressions (Tedeschi \& Norman, 1985), whereas defensive tactics are used to protect or repair one's image 
(Higgins, Snyder, \& Berglas, 2013). We concentrate on assertive IM tactics, which can be broken down into three main tactics: Ingratiation, exemplification, and self-promotion (Jones \& Pittman, 1982). According to Jones' and Pittman's taxonomy, ingratiation can be defined as a form of other-focused IM tactic (flattery doing and giving compliments, i.e. toward one's authority figure or supervisor), exemplification as a job-focused tactic (being dedicated at work, i.e., arriving early, leaving late) and self-promotion as a selffocused IM tactic (demonstrating one's competencies, i.e., appearing skillful at work). Especially, self-promotion, alongside ingratiation and exemplification, is directed toward increasing the assessment of competence (Jones \& Pittman, 1982; Rudman, 1998). This is a feature primarily relevant to the job interview context and we therefore concentrate on self-promotion as the primary point of interest in our study.

The way in which one can publicly advertise one's qualities can take on different forms. One differentiation can be made between the use of direct versus indirect selfpromotion. Direct self-promotion serves to draw the audience's attention to one's own qualifications and skills. When using direct self-promotion, people present detailed and favorable descriptions of themselves, which should lead observers (i.e., recruiters) subsequently to have a concrete and detailed representation of the person. When using indirect self-promotion, people try to convey a good impression by highlighting connections to successful others. This behavior is also referred to as "basking in reflected glory" (BiRG, Cialdini et al., 1976). BiRG can be considered as being more indirect because it relies mainly on showcasing links to other people or institutions (i.e., the university an individual went to) as an attempt to look more competent rather than highlighting one's own skills. Following from this, we anticipate that indirect self-promotion leads observers (e.g., recruiters) to have an abstract and general representation of the person.

Self-promotion can also vary with respect to language use. Self-promotion can be either concrete or abstract (Cialdini \& De Nicholas, 1989). Whereas concrete selfpromotion mainly deals with situation-specific, personal experiences, abstract selfpromotion refers to more unobservable, global competencies. Like direct selfpromotion, also concrete self-promotion mainly arises out of competences tied to an individual person and is much more specific in nature (i.e., stressing unique skills and competences). Indirect as well as abstract self-promotion, both arise out of competences that can be associated with, but do not directly originate from, the individual and are thus more general in nature (i.e., stressing unobservable and global traits). In our study, we combine the direct and the concrete, and the indirect and the abstract dimension into two distinct forms of self-promotion: Low versus high abstractness of selfpromotion.

More particularly, we propose that low abstractness of self-promotion is most effective when interviewer and applicant are spatially close. In contrast, we expect high abstractness of self-promotion to be most effective when interviewer and applicant are spatially distant. We use CLT as the basis to develop our hypotheses. 


\subsubsection{Construal Level Theory and the Construal Compatibility Effect in Personnel Selection}

CLT describes how psychological distance to objects or events affects the level of abstractness when thinking about such objects or events. When objects or events are removed from one's direct experience, psychologically, people tend to construe these objects or events in more abstract ways. In comparison, psychologically close objects or events are construed in more concrete ways (Fujita, Eyal, Chaiken, Trope, \& Liberman, 2008; Fujita, Henderson, Eng, Trope, \& Liberman, 2006). Abstract, high-level construals consist of schematic, prototypical summaries that capture the essence of the subject of interest. Concrete, low-level construals, in contrast, are relatively unstructured, contextualized representations that include secondary or incidental features of events (Fiske \& Taylor, 1991). When moving from a concrete representation of an object ("a cellular phone") to a more abstract representation ("a communication device"), central features of the object are preserved whilst features perceived as less important are neglected (Trope \& Liberman, 2003; Trope, Liberman, \& Wakslak, 2007).

CLT distinguishes between four psychological distance dimensions, namely time, space, social distance, and hypotheticality, implying that an object can be removed from one's own direct experience in time, space, social distance, or in terms of the likelihood that it will occur. According to CLT, all of the four distance dimensions evoke a feeling of psychological proximity (tomorrow, nearby, we, sure) versus psychological distance (next year, far away, others, maybe) in the observer.

When the level of construal is in line with the abstractness of a certain stimulus, the result is a subjective experience of construal congruence (Bar-Anan, Liberman, \& Trope, 2006; Henderson, Fujita, Trope, \& Liberman, 2006; Trope et al., 2007). One example could be an election taking place next year versus next month. If the election took place next year (month) and was promoted in an election campaign very abstractly (concretely), a voter would be more likely to vote for the corresponding candidate in the end. Based on this theory, it is suggested that congruent as opposed to incongruent information attracts more attention (Nussbaum, Trope, \& Liberman, 2003), is judged to be more credible (Hansen \& Wänke, 2010), as well as more persuasive and favorable (Kim, Rao, \& Lee, 2009; Trope \& Liberman, 2003). This is also referred to as 'construal compatibility' (Yang, Ringberg, Mao, \& Peraccio, 2011). The construal compatibility effect (CCE) implies that congruence between the level of the construal mindset and the linguistic abstraction of language used affects the way people process and evaluate information.

Most studies have looked at the phenomenon of construal compatibility in the area of marketing and consumer behavior, and found effects on judgments, decision-making processes, attitudes, as well as behavioral changes (Fiedler, 2007; Trope et al., 2007; Tsai \& McGill, 2011; White, MacDonnell, \& Dahl, 2011). For instance, Kees (2011) looked at product advertisements that either focus on the abstract level (i.e., being 
healthy) or on the concrete level (i.e., avoiding fatty food). Whereas 'being healthy' focuses on the end goal and is more abstract, 'avoiding fatty food' focuses on the means to achieve the goal (i.e., eating healthy), and thus is more concrete. Based on $\mathrm{CLT}$, individuals in an abstract mindset (i.e., through having received a general product description beforehand) would prefer the advertisement focusing on the ends (i.e., 'being healthy') whereas individuals in a concrete mindset (i.e., having received a detailed product description) would prefer the advertisement focusing on the means (i.e., 'avoiding fatty food'). The interplay of the level of construal mindset and the advertisement was found to have an effect on customers' actual buying behavior (Kees, 2011).

In the current paper, we suggest that another domain susceptible for construal compatibility is personnel selection. An applicant may try to impress the interviewer by using either high or low abstractness of information. It is plausible that the message is perceived and evaluated differently according to whether or not the interviewer's mindset is in correspondence with the abstraction of language used by the applicant i.e. whether or not the interviewer is in tune with the message. We base our idea on previous research findings, which showed that events taking place in a distant location are construed on a more abstract and general level compared to nearby locations being construed on a more concrete and detailed level (Fujita et al., 2006). Results indicated that participants used more abstract language to recall spatially distant events, compared with near events. These findings can also be of particular relevance to the context of personnel selection (i.e., job interviews) given that nowadays, due to both global mobility and technological advancements, there is not only an increased need to conduct job interviews from dispersed locations (i.e., on-site versus off-site job interviews) but also in different ways (i.e., online interviews, webcam tests, social media).

Initial support for construal compatibility in personnel selection comes from Proost et al. (2012), who looked at the psychological distance dimension of time. They found that an applicant's abstractness of self-promotion used interacts with the interviewer's time horizon (i.e., filling a job vacancy within a month versus within a year). More specifically, self-promotion associated with low levels of abstractness leads to more positive evaluations in the case of the recruiter trying to fill a vacancy within a month, whereas highly abstract self-promotion leads to more favorable evaluations when trying to fill a job vacancy within a year.

We therefore contend that also spatial distance affects the mindset of the interviewer such that different messages tend to be favored over others (i.e., low versus high abstractness of self-promotion) as a consequence. It is hypothesized that for a close spatial distance (i.e., a small physical separation between applicant and interviewer), the interviewer is likely to favor low abstractness of self-promotion. In contrast, in a recruiting situation with a greater spatial distance (i.e., large physical separation between applicant and interviewer), it is anticipated that the interviewer would react more favorably to high abstractness of self-promotion expressed by the applicant. Both 
cases are anticipated to translate into increased hiring chances for the applicant. This leads to the following hypotheses:

Hypothesis 1. The use of low abstractness of self-promotion during job interviews is more positively evaluated by the interviewer when the spatial distance between the applicant and the interviewer is close rather than far.

Hypothesis 2. The use of high abstractness of self-promotion during job interviews is more positively evaluated by the interviewer when the spatial distance between the applicant and the interviewer is far rather than close.

We operationalized spatial distance in two ways: The degree of home place detachment between the applicant (i.e., located in the Netherlands) and interviewer (i.e., located in the US) during the interview (Experiment 1) and the degree of separation between applicant and interviewer in the interview room (i.e., distance in centimeters across the table; Experiment 2). The use of two different manipulations of spatial distance helps to establish the generalizability of the findings (from distance across the globe to distance in seats) and attests to the validity of the phenomenon.

\subsection{Experiment 1}

We manipulated spatial distance by creating two fictitious hiring conditions. In one condition, participants were told that an applicant had been invited to their office in Amsterdam, in the Netherlands, in which they were working as an interviewer. For this condition, the interview was presented as taking place via a face-to-face interview in one of the organization's interview rooms. Besides the descriptive text, a picture was presented to participants, showing two interviewers and a job applicant sitting in an interview room (close spatial distance condition) (see Picture 2.1). In the other condition, participants were told that they were about to conduct a job interview with an applicant via Skype. Participants also learned that the applicant was currently situated in New York (USA). Next to a picture of two interviewers sitting in front of a screen on which a job applicant was displayed, also a map was presented to participants. The map showed the spatial distance between Amsterdam and New York, which was graphically represented by an arrow linking both locations (far spatial distance condition) (see Picture 2.2). 


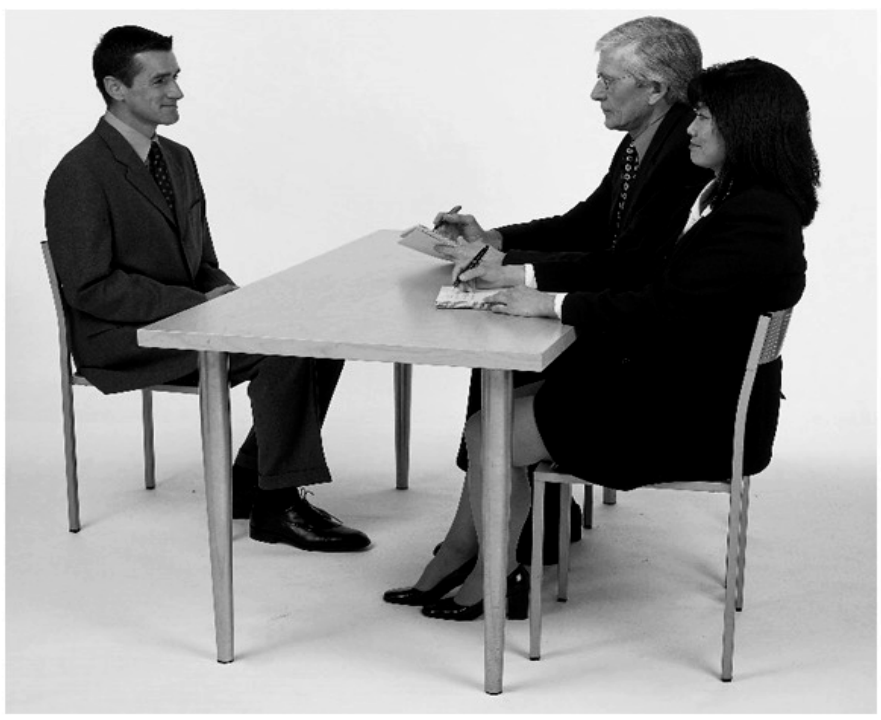

Picture 2.1 Close Spatial Distance Manipulation

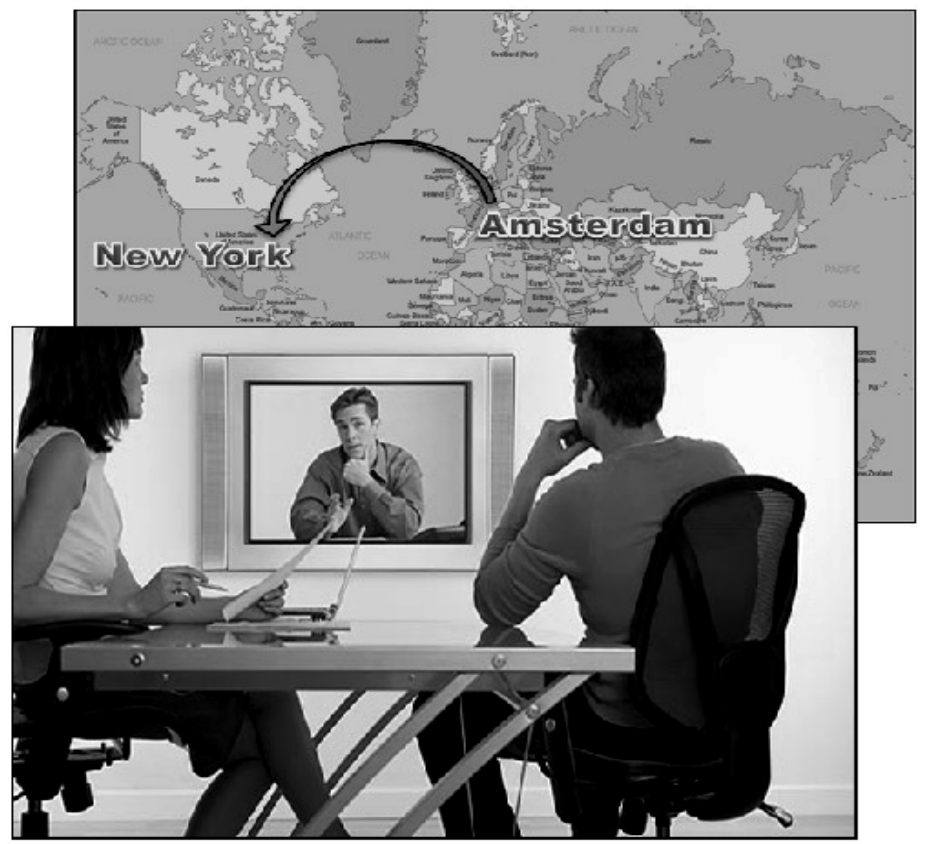

Picture 2.2 Far Spatial Distance Manipulation

Self-promotion level of abstractness was manipulated as follows: Firstly, by using direct versus indirect references to one's competences (i.e., referring to one's own versus 
linkages to successful others), and secondly, by the use of abstract versus concrete language (i.e., global and unobservable versus unique and specific).

\subsection{Method}

\subsubsection{Participants}

Seventy-six employees (35 males, 33 females, 8 unspecified) participated in the experiment. The mean age was 34 years $(S D=5.63)$. Some participants indicated having prior experience in the field of personnel selection, whereby roughly half of them had acted as a personnel interviewer before. $24 \%$ of the participants had never acted as a personnel interviewer, $21 \%$ had rarely acted as a personnel interviewer, $14 \%$ once or a few times per month, and $41 \%$ had acted as a personnel interviewer at least once a week or more.

\subsubsection{Procedure}

The experiment was conducted online and the sample consisted of alumni contacts of a Dutch University living and working in the surroundings of Amsterdam. Participants received an invitation to take part in the experiment via e-mail. At the beginning of the experiment, participants were instructed to take the role of the interviewer and to participate in the entire experiment in one go, if possible (i.e., without interruption). After having received a short introduction to the experiment, participants were given the task of hiring a sales specialist. Participants received a short job description in the form of a curriculum vitae of the fictitious male applicant. Through this, overall applicant qualifications were kept constant (i.e., previous working experience). After that, participants received a transcript of the job interview including interview questions posed and answers provided by the applicant. McCormack (2000) and Kiesinger (1998) referred to job candidate responses in the form of interview texts formulated as personal narratives as a realistic setting to study job interview outcomes. In line with the studies' results, short personal narratives by applicants were provided to participants, based on the different interview questions used.

After having read the interview, participants were asked to evaluate the applicant by completing an online-questionnaire. Finally, participants were thanked and debriefed via an online administered, funnelled debriefing (Bargh \& Chartrand, 2000); no participant pointed out suspicion regarding the experiment's purpose.

\subsubsection{Design}

The experimental procedure was a $2 \times 2$ factorial between subject design, with selfpromotion level of abstraction (low versus high) and spatial distance (close versus far) as independent variables. Participants were randomly assigned to the different condi- 
tions by the online questionnaire program, such that the number of participants per condition was held constant. The interview scenarios were based on the self-promotion manipulations developed by Proost et al. (2010). The authors had used extended extracts from a fictitious job interview. We adapted these extracts and included them as job interviews in the respective scenarios of the experiment. The interview consisted of five questions: "Tell me what you know about this company"; "Why should we hire you for this position?"; "Tell me about what role you usually assume in a team setting"; "What are you most proud of accomplishing in your life so far?"; and "What three things are you bringing that no-one else would?" In the low level of abstraction condition, the applicant replied by referring to his own and to behavioral indicators of competencies. The positive qualities could be tied directly to the applicant and the selfpromotional language referred to unique, situation-specific examples. In the high level of abstraction condition, the applicant replied by referring to connections to other successful people or networks. The positive qualities were non-personal traits and the language referred to unobservable, global competencies (for a more detailed overview of interview questions and responses, see Appendix A).

Spatial distance was manipulated as follows: In one condition, participants were instructed to imagine having a face-to face job interview in their office in Amsterdam (close spatial distance condition). In the other condition, participants were instructed to imagine that they were having a Skype interview with a job applicant currently situated in New York (large spatial distance condition).

\subsubsection{Measures}

Interviewer Evaluation. In line with Proost et al. (2012) three items were used to measure the evaluation by the interviewer. These items read as follows: "I would invite the applicant for a second interview", "I would offer the applicant a job", and "I would send the applicant a rejection letter" (reverse coded). All three items were measured by means of a 5-point Likert scale ( 1 = definitely not; 5 = definitely yes) and afterwards, were averaged to form one scale. The Cronbach's alpha was .73.

Manipulation Checks. The level of abstractedness manipulation check consisted of two items (from 1 = strongly disagree to 5 = strongly agree), asking participants whether "the applicant was talking on a concrete level" and whether "the applicant was talking on an abstract level"). The spatial distance manipulation check consisted of three bipolar items: "The spatial distance between the applicant and interviewer was: " 1 = short to $5=$ long", " 1 = close to 5 = far", and " 1 = small to $5=$ large"." The items were averaged to obtain a close versus far spatial distance scale.

Control Variables. Previous studies (Goldberg, 2005; Graves \& Powell, 1995) have shown that interviewer sex may influence applicant evaluations. For example, Goldberg (2005) found that interviewers tend to give higher ratings to applicants of the opposite sex. 
This is especially likely for male interviewers, primarily rating female applicants more favorably compared to males. For female interviewers, no distinction was made between male and female applicants. Taking these findings into consideration, we presumed that applicant sex could have a confounding effect and we therefore decided to include sex ( 1 = male, 2 = female) as a control variable.

Analyses. A 2 (self-promotion level of abstractness: low versus high) x 2 (spatial distance: close versus far) between-groups ANOVA was conducted to examine the differences between the four conditions with regard to the dependent variable 'interviewer evaluation'. Abstractness of self-promotion and spatial distance were entered as the independent variables. As recommended by Aiken and West (1991), we effect-coded self-promotion level of abstractness (low $=-1$ and high $=1$ ) and spatial distance (close = -1 and far =1). Univariate analyses of variance (ANOVAs) were conducted to analyze whether the manipulations of self-promotion and spatial distance had been successful.

\subsection{Results}

\subsubsection{Manipulation Checks}

The results of a 2 (level of abstractness: low versus high) x 2 (spatial distance: distant versus close) ANOVA on level of abstractness showed a main effect of speech type, $F$ $(1,72)=10.00, p<.01, \eta^{2}=.13$. Participants in the low abstractness condition perceived the job interview to be less abstract $(M=2.40, S D=1.00)$ than those in the high abstractness condition $(M=3.14, S D=0.99)$. Neither the main effect of spatial distance, $F$ $(1,72)=0.95, p=.34, \eta^{2}=.01$ nor the interaction effect between abstractness and spatial distance was significant, $F(1,72)=1.50, p=.23 \eta^{2}=.01$. The same analysis on spatial distance showed a main effect of spatial distance, $\mathrm{F}(1,72)=81.59, p<.001, \eta^{2}=.56$ (see Table 2.1). Participants in the spatially close condition estimated the distance to the applicant to be closer $(M=2.09, S D=0.99)$ than those in the spatially distant condition $(M=4.32, S D=1.07)$. Neither the main effect of level of abstractness, $F(1,72)=$ $0.42, p=.53, \eta^{2}=.01$ nor the interaction effect between abstractness and spatial distance was significant, $F(1,72)=3.00, p=.09, \eta^{2}=.04$. More information on the mean values of experimental manipulations is provided in Table 2.1. The results indicate that the manipulations worked as intended.

Correlations between all variables in this study are reported in Table 2.2. From all variables of interest, only abstractness of self-promotion use was significantly related to $\operatorname{sex}(r=.27, p<.05)$. All other correlations were insignificant. 
Table 2.1 Mean Values of Items Measuring Adequacy of Experimental Manipulations

\begin{tabular}{llllllllr}
\hline & Low/close & SD & Low/far & SD & High/close & SD & High/far & SD \\
\hline $\begin{array}{l}\text { Abstractness of } \\
\text { self-promotion }\end{array}$ & & & & & & & & \\
Low & $\mathbf{3 . 4 7}$ & 1.01 & $\mathbf{3 . 0 0}$ & 1.20 & 2.40 & 1.20 & 2.30 & 1.13 \\
High & 2.65 & 1.00 & 3.22 & 1.00 & $\mathbf{3 . 6 7}$ & 1.00 & $\mathbf{3 . 4 5}$ & .95 \\
Spatial distance & & & & & & & & \\
Close vs. far & 2.35 & 1.01 & $\mathbf{4 . 1 9}$ & 1.08 & 1.76 & .89 & $\mathbf{4 . 4 5}$ & 1.08 \\
\hline
\end{tabular}

Note: The mean values indicate that self-promotion and spatial distance have been manipulated adequately under the different conditions.

Table 2.2 Intercorrelations Between the Variables in This Study

\begin{tabular}{llll}
\hline & 1 & 2 & 3 \\
\hline 1. Sex & -- & & \\
2. Spatial distance & $-.12 / .04$ & -- & \\
3. Low vs. high abstractness of self-promotion & $.27 * / .12$ & $.03 / .00$ & -- \\
4. Interviewer evaluation & $.05 /-.17$ & $-.21 /-.07$ & $-.00 / .10$ \\
\hline
\end{tabular}

Note: Results for Experiment 2 are in italics.

Sex $(1=$ male, 2 = female).

$* p<.05 ; * * p<.01 ; * * * p<.001$.

\subsubsection{Hypotheses Testing}

Our hypotheses were tested using an ANCOVA. Interviewer evaluation was entered as the dependent variable, the effect-coded conditions as independent variables, and sex as a covariate. ANCOVA results can be found in Table 2.3. The results show an interaction between self-promotion and spatial distance on interviewer evaluation, $F(1,72)=$ 4.83, $p<.05, \eta^{2}=.07$. Neither the type of self-promotion main effect, $F(1,72)=0.12$, $p=.78, \eta^{2}=.00$ nor the spatial distance main effect, $F(1,72)=1.68, p=.20, \eta^{2}=.03$ were significant. The influence of sex on interviewer evaluation was not significant, $F$ $(1,72)=0.24, n s$. In order to facilitate interpretation of the significant interaction, we used planned contrasts analysis. The results revealed significant differences in interviewer evaluation between small $(M=3.25, S D=0.97)$ and large spatial distance $(M=$ $2.43, S D=0.85)$, when the applicant used low abstractness of self-promotion, Contrast $=0.82, F(1,72)=6.35, p<.05, \eta^{2}=.09$, Cohen's $d=0.69$. In contrast, for highly abstract self-promotion, no significant differences were found between large $(M=2.87, S D=$ 1.07) versus small spatial distance $(M=2.69, S D=0.88$ (see Figure 2.2), Contrast $=0.19$, $F(1,72)=0.33, p=.57, \eta^{2}=.01$, Cohen's $d=0.09$. Hence Hypothesis 1 , predicting the interaction effect of low abstractness of language used and close spatial distance, is supported whereas Hypothesis 2, predicting the interaction of high abstractness of language used and far spatial distance, is not. 
Table 2.3 Test of Between Subjects Effects

\begin{tabular}{llcc}
\hline & df & MS & F \\
\hline Intercept & 1 & 823.63 & $580.24^{* *}$ \\
Sex & 1 & .17 & .18 \\
Abstractness of self-promotion & 1 & .11 & .12 \\
Spatial distance & 1 & 1.54 & 1.68 \\
Abstractness of self-promotion*Spatial distance & 1 & 4.43 & $4.83^{*}$ \\
\hline
\end{tabular}

$* \mathrm{p}<.05 ; * * \mathrm{p}<.01 ; * * \mathrm{p}<.001$.

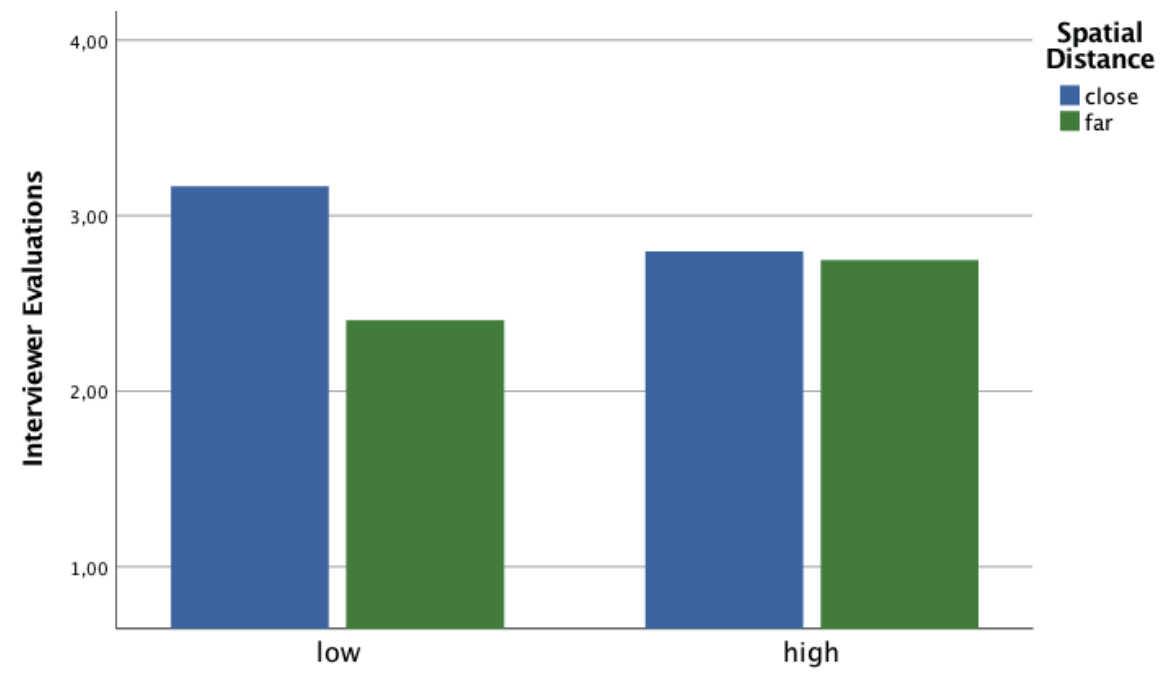

Abstractness of Self-Promotion

Figure 2.2 Bar charts with Abstractness of Self-Promotion (low versus high abstraction of language used) and Spatial Distance (close versus far) on Interviewer Evaluations.

\subsubsection{Conclusion and Discussion}

The purpose of Experiment 1 was to test the construal compatibility effect hypothesis in personnel selection by varying the degree of home place separation between the applicant and interviewer during the job interview. For low levels of abstractness, the results are supportive of the construal compatibility effect hypothesis: Direct and concrete selfpromotion is more effective when the psychological (i.e., spatial) distance to the applicant is small rather than large. The effect of indirect and abstract self-promotion did not differ according to spatial distance. Consistent with Proost et al. (2012), the results of Experiment 1 (i.e., especially Hypothesis 1) suggest that the outcome of the selection interview depends on whether applicants are capable of tailoring their language to fit the interviewer's mindset. In Experiment 1 the effect of self-promotion was tested in two different interview settings: A face-to-face interview and a Skype interview. One 
limitation of Experiment 1 is the inability to disentangle the effects of spatial distance and other characteristics of the communication medium. Face-to-face interviews differ from Skype interviews not only in terms of interviewer-applicant distance, but also in terms of degree of virtuality, technology, and richness of the information, etc. In Experiment 2 , in order to isolate the effect of spatial distance, we keep the setting constant and merely vary the seating distance between interviewer and applicant across the table in the interview room. Additionally, in order to increase the ecological validity of the experiment, participants are shown video fragments of the interviews instead of written interview extracts.

\subsection{Experiment 2}

We manipulated spatial distance by letting participants watch a video, which showed a job interview between a fictive interviewer and applicant. In one condition, the interviewer and applicant were sitting opposite each another at a small table (close spatial distance condition) (see Picture 2.3).

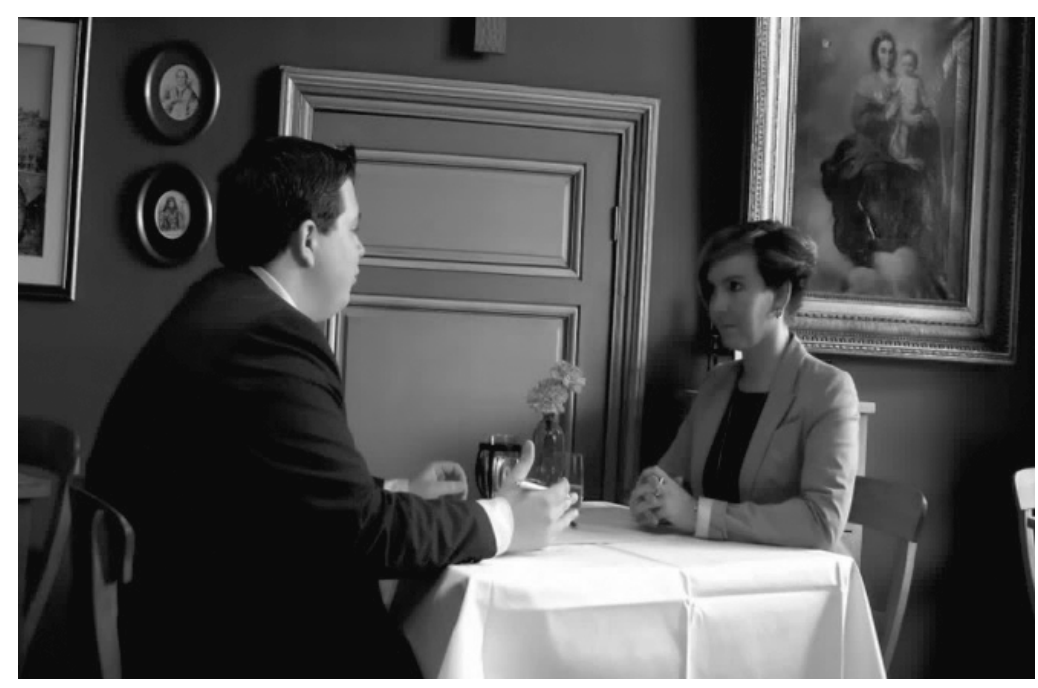

Picture 2.3 Close Spatial Distance Manipulation

In the other condition, the video showed the same job interview but with applicant and interviewer sitting far away from each other at a longer table (far spatial distance condition) (see Picture 2.4). 


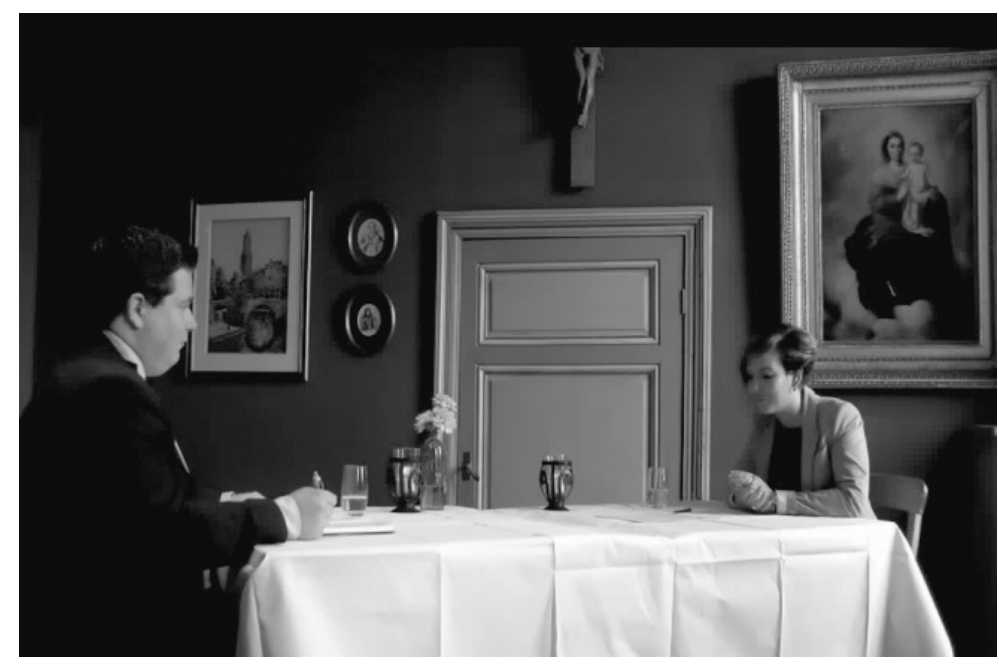

Picture 2.4 Far Spatial Distance Manipulation

As in Experiment 1, self-promotion was manipulated as follows: Firstly, by using direct versus indirect references to one's competences (i.e., referring to one's own versus linkages to successful others), and secondly, by the use of abstract versus concrete language (i.e., global and unobservable versus unique and specific).

\subsection{Method}

\subsubsection{Participants}

One hundred employees (48 males, 52 females) from an international hotel chain participated in the experiment. The mean age was 38 years $(S D=9.09)$. All participants worked in an area somewhat connected to personnel selection, though not all of them had acted as a personnel interviewer before. $10 \%$ of the participants had never acted as a personnel interviewer, $48 \%$ had rarely acted as a personnel interviewer, $24 \%$ had but only once or a few times per month, and $18 \%$ had acted as a personnel interviewer at least once a week or more.

\subsubsection{Procedure}

To start with, and similarly to Experiment 1, participants received a short introduction to the experiment, instructing them to take the role of the interviewer. Moreover, participants were given the task of hiring a Front Desk Manager of a hotel chain. Participants then received a short job description and a curriculum vitae of a fictitious female applicant, in order to keep overall applicant qualifications constant. Participants were 
randomly assigned to groups of eight to ten people, in which they collectively watched the videotaped interview. Moreover, participants were instructed to remain silent during this time. After watching the video, participants filled out the questionnaire individually. Upon completion of the questionnaire, participants were thanked and debriefed via an orally administered, funnelled debriefing (Bargh \& Chartrand, 2000); no participant indicated suspicion regarding the experiment's purpose.

\subsubsection{Design}

As in Experiment 1, the experimental procedure was a $2 \times 2$ factorial between subject design, with self-promotion level of abstraction (low versus high) and spatial distance (close versus far) as independent variables. Again, the interviews were based on the self-promotion manipulations developed by Proost et al. (2010). The authors used extended extracts from a fictitious job interview and we adapted these extracts into scenarios and asked semi-professional actors (with some experience in movie-making) to play the scenes as realistically as possible. Like in experiment 1, the interview consisted of five questions: "Tell me what you know about this company"; "Why should we hire you for this position?"; "Tell me about what role you usually assume in a team setting"; "What are you most proud of accomplishing in your life so far?"; and "What three things are you bringing that no-one else would?" In the low level of abstraction condition, the applicant replied by referring to her own and to behavioral indicators of competencies. The positive qualities could be tied directly to the applicant and the selfpromotional language referred to unique, situation-specific examples. In the high level of abstraction condition, the applicant replied by referring to connections to other successful people or networks. The positive qualities were non-personal traits and the language referred to unobservable, global competencies (for a more detailed overview of interview questions and responses, see Appendix A).

Spatial distance was manipulated as follows: In one condition, the video showed the applicant and interviewer sitting closely together at a short table (approximate distance of around 1 meter). In the other condition, the video showed the applicant and interviewer sitting far from each other at a longer table (approximate distance of around 2 meters).

\subsubsection{Measures}

Interviewer Evaluation. As in Experiment 1, three items were used to measure the evaluation by the interviewer. These items read as follows: "I would invite the applicant for a second interview", "I would offer the applicant a job", and "I would send the applicant a rejection letter" (reverse coded). All three items were measured by means of a 4point Likert scale ( 1 = definitely not; 4 = definitely yes) and were afterwards averaged to form one scale afterwards. In order to avoid a neutral point as was the case in Experiment 1, the scale was reduced from 5 to 4 Likert points. The Cronbach's alpha was .95. 
Manipulation Checks. The level of abstractness manipulation check consisted of two items (from 1 = strongly disagree to 5 = strongly agree), asking participants whether "the applicant was talking on a concrete level" and whether "the applicant was talking on an abstract level"). The spatial distance manipulation check consisted of three bipolar items: "The spatial distance between the applicant and interviewer was: " 1 = short to $5=$ long", " 1 = close to 5 = far", and " 1 = small to $5=$ large"." The items were averaged to obtain a close versus far spatial distance scale.

Analyses. We conducted an analysis of covariance (ANCOVA) to test the hypotheses using interviewer evaluation as our dependent variable. Abstractness of self-promotion and spatial distance were entered as the independent variables. As in Experiment 1, sex was entered as a covariate. In line with Aiken and West (1991), we effect-coded level of abstractness (low $=-1$ and high $=1$ ) and spatial distance (close $=-1$ and far $=1$ ). Multivariate analyses of variance (ANOVAs) were conducted to analyze whether or not the manipulations of self-promotion and spatial distance had been successful.

\subsection{Results}

\subsubsection{Manipulation Checks}

A 2 (self-promotive speech type: abstract versus concrete) $\times 2$ (spatial distance: great versus small) analysis of variance (ANOVA) on abstractness ratings showed a main effect of speech type, $F(1,96)=329.89, p<.001, \eta^{2}=.78$. Participants in the concrete speech condition perceived information to be less abstract $(M=2.00, S D=0.51)$ than those in the abstract speech condition $(M=4.03, S D=0.60)$. Neither the main effect of spatial distance, $F(1,96)=0.07, p=.78, \eta^{2}=.00$, nor the interaction between speech type and spatial distance were significant, $F(1,96)=0.65, p=.42, \eta^{2}=.01$. The same analysis on distance ratings showed a main effect of spatial distance, $F(1,96)=163.85, p<.001, \eta^{2}$ $=.63$. Participants in the small distance condition estimated distance as closer $(M=$ $2.37, S D=0.63)$ than those in the great distance condition $(M=4.11, S D=0.72)$. Neither the main effect of speech type, $F(1,96)=0.70, p=.41, \eta^{2}=.01$, nor the interaction between speech type and spatial distance were significant, $F(1,96)=0.32, p=.73, \eta^{2}=$ .00 . The results indicate that both manipulations were successful. For more information on the adequacy of experimental manipulations, see Table 2.4.

\subsubsection{Hypotheses Testing}

Our hypotheses were tested using an ANCOVA. Interviewer evaluation was entered as the dependent variable, the effect-coded conditions as independent variables, and sex as a covariate. ANCOVA results can be found in Table 2.5. Results showed an interaction between self-promotion and spatial distance on interviewer evaluation, $F(1,96)=$ 
$153.15, p<.001, \eta^{2}=.63$. Neither the type of self-promotion, $\mathrm{F}(1,96)=2.41, p=.12, \eta^{2}$ $=.02$ nor the spatial distance main effect $\mathrm{F}(1,96)=1.41, p=.24, \eta^{2}=.01$, were significant. The main effect of sex on interviewer evaluation was also not significant, $F(1,96)=$ 0.61 , ns.

Table 2.4 Mean Values of Items Measuring Adequacy of Experimental Manipulations

\begin{tabular}{lcccccccc}
\hline & Low/close & SD & Low/far & SD & High/close & SD & High/far & SD \\
\hline $\begin{array}{l}\text { Abstractness of } \\
\text { self-promotion }\end{array}$ & & & & & & & & \\
Low & $\mathbf{4 . 1 2}$ & .73 & $\mathbf{4 . 3 2}$ & .56 & 2.32 & .80 & 2.16 & .69 \\
High & 2.12 & .73 & 2.20 & .96 & $\mathbf{4 . 2 0}$ & .50 & $\mathbf{4 . 2 8}$ & .46 \\
Spatial distance & & & & & & & & \\
Close vs. far & 2.29 & .63 & $\mathbf{4 . 0 8}$ & .71 & 2.45 & .63 & $\mathbf{4 . 1 5}$ & .74 \\
\hline
\end{tabular}

Note: The mean values indicate that self-promotion and spatial distance have been manipulated adequately under the different conditions.

Table 2.5 Test of Between Subjects Effects

\begin{tabular}{llrr}
\hline & $\mathrm{df}$ & $\mathrm{MS}$ & $\mathrm{F}$ \\
\hline Intercept & 1 & 807.70 & $6038.01^{* * *}$ \\
Sex & 1 & .08 & .61 \\
Abstractness of self-promotion & 1 & .36 & 2.67 \\
Spatial distance & 1 & .18 & 1.33 \\
Abstractness of self-promotion*Spatial distance & 1 & 20.49 & $153.15^{* * *}$ \\
\hline
\end{tabular}

$* \mathrm{p}<.05 ; * * \mathrm{p}<.01 ; * * * \mathrm{p}<.001$.

To facilitate interpretation of the significant interaction we used planned contrasts (see Figure 2.3). The results revealed significant differences in interviewer evaluations between small $(M=3.30, S D=0.32)$ and large spatial distance $(M=2.28, S D=0.38)$, when the applicant used low abstractness of self-promotion, Contrast $=1.02, F(1,96)=91.82$, $p<.001, \eta^{2}=.49$, Cohen's $d=1.54$. In the same way, for large $(M=3.32, S D=0.31)$ versus small spatial distance $(M=2.48, S D=0.43)$ together with high abstractness of self-promotion, significant differences were found, Contrast $=0.84, \mathrm{~F}(1,96)=64.35, p<$ $.001, \eta^{2}=.40$, Cohen's $d=1.79$. Thus, both Hypotheses 1 and 2 are supported.

\subsubsection{Conclusion and Discussion}

Experiment 2 was designed to test whether self-promotion results in more favorable interviewer evaluations when there is congruence between the level of abstractness of self-promotion used by the applicant and the level of construal mindset of the interviewer (i.e., construal compatibility). The construal mindset was induced by varying the seating distance between the applicant and the interviewer. We found that construal 
compatibility positively biased the evaluation of applicants. Direct and concrete selfpromotion turned out to be more effective when interviewers were seated close to the applicant. Conversely, indirect and abstract self-promotion resulted in more favorable evaluations when interviewer and applicant were seated at a larger distance. Apparently, a seemingly trivial decision as where to seat the applicant can have far-reaching consequences. Unlike what we found in the first experiment, the CCE occurred also in the abstract self-promotion condition. Different from Experiment 1, in the second experiment we kept constant the communication medium (i.e., face-to-face) and increased the ecological validity by having participants watch video fragments instead of read interview excerpts. Overall, findings are in line with previous research examining the CCE in the fields of personnel selection (Proost et al., 2012), marketing, and consumer behavior (Fiedler, 2007; Trope et al., 2007; Tsai \& McGill, 2011; White et al., 2011).

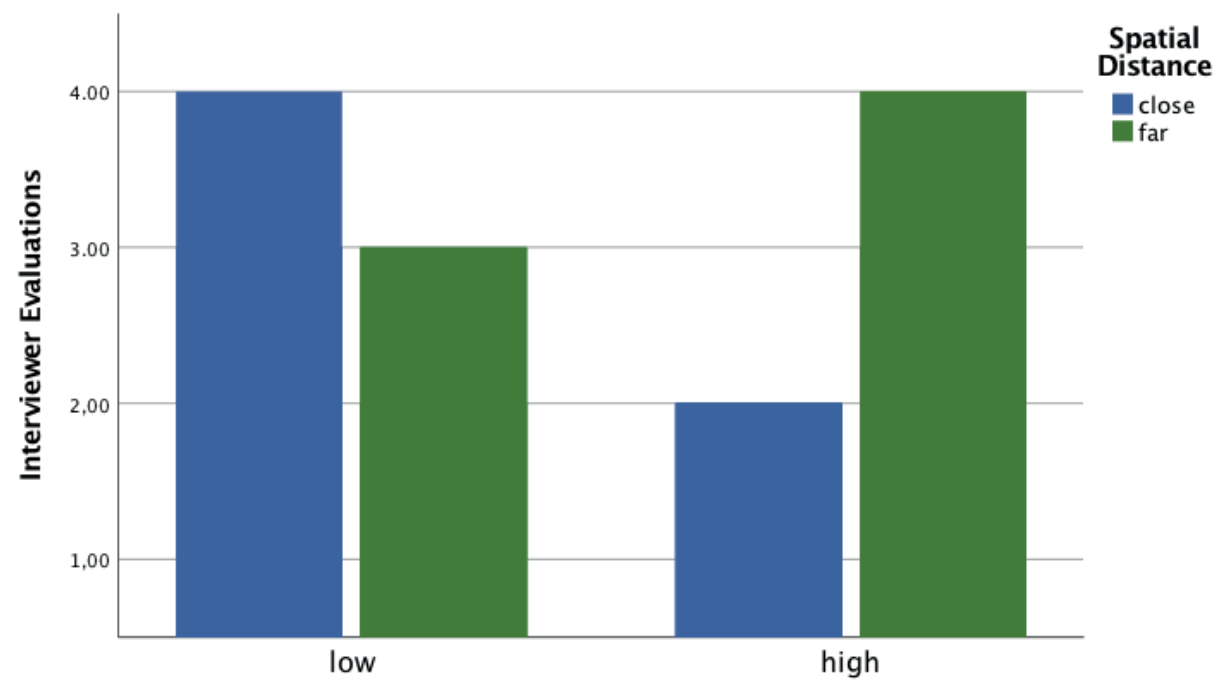

Abstractness of Self-Promotion

Figure 2.3 Bar charts with Abstractness of Self-Promotion (low versus high abstraction of language used) and Spatial Distance (close versus far) on Interviewer Evaluations.

\subsection{General Discussion}

Two experimental studies were conducted in order to examine the interactive effect of self-promotion and spatial distance between the interviewer and applicant on subsequent interviewer evaluations (i.e., the likelihood of being hired) during a simulated selection procedure. We used CLT, postulating that congruence between the level of 
the construal mindset and the linguistic abstraction of information used positively biases the way people process and evaluate information.

Our findings are mostly in line with the construal CCE hypothesis: Congruence between the interviewer's level of construal mindset and the abstractness of selfpromotion used by the applicants led interviewers (i.e., participants) to evaluate the applicant more favorably. In Experiment 1, partial support was found for the construal compatibility effect hypothesis, such that low abstractness of self-promotion combined with close spatial distance between the interviewer and applicant led to more favorable interviewer evaluations. No such effect could be found for high abstractness of selfpromotion together with a far spatial distance. Experiment 2 differed from Experiment 1 in terms of the physical interaction between the interviewer and applicant (i.e., as manipulated through the videotaped interview segments), which was not the case in Experiment 1. The results of Experiment 1 have shown that participants' evaluations of applicants did not differ significantly in the abstract self-promotional condition for close versus far spatial distance. It seems as if the highly abstract self-promotional language used (i.e., through paper-based interview scripts) was not affected differently by low versus high construal mindsets of the object (i.e., participant) evoked through close and far spatial distances. One potential reason for this may be that the distance manipulation of Experiment 1 (i.e., by showing an image of a face-to-face versus virtual interview taking place on screen) comprised much more than the spatial distance alone, such as the degree of virtuality, technology, and richness of the information. For high abstractness of self-promotional language used, this may have caused an overall loss of richness of information. Participants may have therefore reacted differently to low abstractness of self-promotional language used by the applicant with a close versus far spatial distance, whereas they have not reacted differently to high abstractness of language used for both types of distance.

\subsubsection{Theoretical Implications}

Our study makes several contributions to the literature. First, we provide evidence for the existence of the CCE in the area of personnel selection. Past studies investigated the CCE in the area of marketing and consumer behavior, and found effects on product judgments, decision-making processes (i.e., purchasing intentions), as well as behavioral changes (Fiedler, 2007; Trope et al., 2007; Tsai \& McGill, 2011; White et al., 2011). We have shown that the CCE also affects how interviewers perceive and evaluate information during job interviews.

Second, we advance research on IM by identifying a new boundary condition to the effectiveness of IM during job interviews. Until today, research typically found an overall positive effect of self-promotion on interviewer evaluations (e.g., Higgins \& Judge, 2004; Kristof-Brown et al., 2002; Proost et al., 2010). Another more recent stream of research assumed that when overusing, self-promotion can also backfire - also referred 
to as the self-promotor's paradox (Berman et al., 2015). In our research, we hypothesized that interviewer evaluations are the result of the interactive effect of the type of self-promotion used by the applicant and further contingencies of the job interview. In line with expectations, the effect of self-promotion depends on the psychological distance from the interviewer to the applicant: Interviewers are more positive when the applicant uses language that is 'in tune' with their state of mind which, in turn, is a consequence of the perceived distance between them and the applicant.

Psychological distance is dyadic by definition: It refers to the perceived distance between the self as a point of reference and another object, person or event, in this case the applicant. Past research has largely ignored the dyadic nature of the job interview. Self-promotion has mostly been studied in a vacuum without sufficient attention to the social structures of which it is part (i.e., the applicant-interviewer relationship). We have demonstrated that, in order to understand the effect of self-promotion, one needs to account for how perceived distance colors interviewers' interpretation of selfpromotion.

Third, the current paper adds to literature in the area of personnel selection (i.e., job interviews). Due to the global mobility of employees, as well as technological advancements, the variety of forms in which job interviews take place is increasing. We have shown that not only the spatial distance around the globe (i.e., different homelands of interviewer and applicant) interacts with abstractness of language use, but so does changing the physical separation between the interviewer and applicant across the table in the interview room; thus affecting job interview outcomes as evaluated by the interviewer.

Our findings suggest that, rather than recruitment-related decision-making being a rational and conscious process, it can be largely influenced by more automatic and subtler aspects (Purkiss, Perrewé, Gillespie, Mayes, \& Ferris, 2006). This is also in line with the dual process approach, stating that two distinct systems govern information evaluation and judgment (Chaiken \& Trope, 1999). Based on this approach, interviewers, on the one hand, engage in a deliberate, effortful, and thoughtful gathering of information, representing the more conscious part of decision-making. On the other hand, interviewers also engage in implicit and automatic processes, requiring less cognitive resources. According to the dual process approach, both processes come into play at different stages, and alternate each other throughout the selection process, thereby also influencing hiring decisions taken by the interviewer. Also Sekaquaptewa and Espinoza (2004) and Sherman, Stroessner, Conrey, and Azam (2005) found out that both implicit and explicit processes determine which of the presented information gets most attention and whether certain applicant behaviors are attributed more internally or externally. Following up upon this line of thought, the question arises as to how the implicit and automatic process, as influenced by the CCE, subsequently leads to more favorable interviewer evaluations. Further inquiry in this direction would provide new 
and more detailed insights into how the CCE eventually causes selection biases in personnel selection.

\subsubsection{Limitations and Suggestions for Future Research}

All in all, this paper at hand found support for the CCE in personnel selection. The question, however, arises as to which mechanisms underlie the effect of congruence or incongruence in the context of personnel selection, an aspect that is still underresearched. Since, at this stage, one can only speculate about the scope of subconscious aspects driving selection decisions, future research needs to further assess the underlying mechanisms driving the CCE. More particularly, there are several possible driving mechanisms, which may have caused the differences in outcomes: One underlying mechanism could be that congruence between the level of construal mindset and the information used facilitates how information is memorized and stored. Also, construal compatibility may have an impact on how easily information is processed and retrieved by the recipient. Evidence in favor of the processing fluency explanation has been found in the area of consumer behavior (Lee, Keller, \& Sternthal, 2010; White et al., 2011). Yet another explanation would be that congruence between the level of construal mindset and the linguistic abstraction of language used has an impact on how information is evaluated, i.e. by perceiving the applicant as more trustworthy, credible or persuasive. Future studies examining mediating mechanisms might help to uncover how construal level compatibility leads to differences in outcomes.

Finally, Liviatan, Trope, and Liberman (2008) discussed the assumption that social closeness may also arise as a consequence of spatial distance during evaluations, thus translating into an individual's (i.e., the interviewer's) search for similarities (i.e., in age, sex, and personal traits). The question arises as to whether it is indeed the perception of spatial distance alone that ultimately leads to differences in recruitment outcomes. Alongside differences in terms of spatial distance, also social distance may influence the interviewer in some way (Rand \& Wexley, 1975). However, the results of the second experiment hold out against this line of thought, as therein, spatial distance was manipulated more meticulously by altering the spatial distance between applicant and interviewer across the table (i.e., in a face-to face interview). This reduces the possibility of other psychological distance dimensions having impacted our results.

\subsubsection{Practical Implications}

Based on the results of these studies, practical implications arise for both the interviewer and the organization as a whole. Our results highlight the importance of different self-promotion tactics used by the applicant (i.e., low versus high abstractness of selfpromotion used) together with spatial distance (i.e., close versus far) on subsequent hiring outcomes. Our findings suggest that interviewers may benefit from receiving job interview trainings in order to become aware of likely selection biases that exist. First of 
all, it is important to reflect upon the way in which the job interviews typically take place (i.e., face-to-face versus virtual interviews). For on-site interviews, in particular, it is important to analyze the detailed setting of the interview room(s) used, potential differences that exist, and how interviewer and applicant are located therein. In doing so, interviewers not only get a better overview of the interview rooms at the firm's disposal but also of the effect these might have on overall decision-making.

Above that, organizations may want to actively influence the type of job interview employed. As our study showed, different aspects of spatial distance between applicant and interviewer (i.e., across the globe and in the interview room) can lead to biases in personnel selection. One important implication arising out of this is to keep the degree of spatial distance constant for all applicants reviewed for a specific job vacancy. In this context it might be worthwhile, in the first interview round, to let every potential job candidate be reviewed via a virtual tool (i.e., in the form of a webcam testing, such as Skype), and only then invite candidates for an on-site interview. Another solution might be using several interviewers as judges, who take on different psychological distances to the applicant and who need to come up with one, unanimous decision. The various above-mentioned interventions help to standardize the selection process, thereby minimizing the chance of selection biases to occur.

Furthermore, interviewers should be trained in their ability to identify the extent to which self-promotion tactics originate from the applicants themselves (low abstractness) and/or from linkages to successful others (high abstractness). One useful intervention for interviewers might hence be simulated job interviews with the intention of practicing how to formulate unambiguous and precise interview questions. This would presume posing both questions that refer to competencies arising directly from the applicants themselves as well as questions on competencies going beyond the applicants' personal skills and capabilities.

\subsection{Conclusion}

Prior IM research in the context of job interviews typically studied the direct effect of self-promotion on interviewer evaluations (i.e., the likelihood of being hired) and found primarily positive effects of applicant self-promotion use on job interview outcomes. An exception is what we refer to as the self-promotor's paradox suggesting that, when overdosing, self-promotion can also backfire. Given the inconsistencies in previous research results we presumed that the effect of self-promotion is also likely dependent on other seemingly trivial contingencies of the job interview. We conducted two experiments, in which we studied the interactive effect of type of self-promotion (low versus high abstractness of self-promotion used) and spatial distance between the interviewer and applicant (close versus far) on interviewer evaluations of the applicant. Based on the construal compatibility effect hypothesis, we found that low abstractness of self- 
promotion used is rated more favorably when combined with a close spatial distance and high abstractness of self-promotion used is rated more favorably when combined with a far spatial distance. The results demonstrate the effect that seemingly trivial decisions can have on job interview outcomes. 


\section{Chapter}

\section{Impressing to Preserve? \\ The Role of Threat Appraisal, Job Control, and Proactivity on Exemplification}

This chapter is based on the manuscript:

Schmitte, K., Segers, M., De Jong, S. B. Impressing to preserve? The role of threat appraisal, job control, and proactivity on exemplification. 



\subsection{Introduction}

In today's dynamic organizations, employees' appraisals of job threat are on the rise (Scheck \& Kinicki, 2000). Job threat, as perceived by employees, can arise due to changes in work processes, practices, and routines (Weick \& Quinn, 1999). Such work changes often require employees to use different competencies compared to before. Consequently, employees typically fear that their current job competencies might become obsolete, hence creating an overall concern over potential job feature loss, also referred to as job threat appraisal (Lazarus \& Folkman, 1984).

Previous research demonstrated that the appraisal of job threat deteriorates attitudes at work, such as job satisfaction and commitment, and simultaneously impedes well-being and health (for meta-analytic analyses, see Cheng \& Chan, 2008; Sverke, Hellgren, \& Näswall, 2002). Hence, the majority of studies have pointed to a negative relationship between job threat and task performance (Gilboa, Shirom, Fried, \& Cooper, 2008; Probst, 2005). However, there is a small but growing literature evidencing that job threat appraisal can also lead to increases in positive work behaviors. For example, recent studies found that, as a consequence of experiencing threat, employees are likely to work longer hours (De Cuyper, Bernhard-Oettel, Berntson, De Witte, \& Alarco, 2008), to make more use of voice behaviors (Sverke \& Hellgren, 2001), and to be more productive (Probst, Stewart, Gruys, \& Tierney, 2007).

Very recently, scholars have raised a cautionary note, as it has been suggested that these positive behaviors might not always be "true". This brings forward the alternative possibility that positive work behaviors are also used by employees in order to only "appear" working harder, with the actual intention of securing the job as it currently is, including presently held job features - a motivation referred to as job preservation (Shoss, 2017). As the above idea indicates, the motives of observable behaviors, such as working more hours, can be diverse and not that straightforward. In this vein, it is not clear if the finding of previous research is that employees experiencing job threat actually intend to increase positive work behaviors or if they instead react to perceptions of job threat by engaging in impression management (IM) behaviors (e.g., Huang, Zhao, Niu, Ashford, \& Lee, 2013; Kang, Gold, \& Kim, 2012). One concrete IM behavior relevant to the motivation for job preservation is exemplification - a type of job-focused IM, such as appearing to go above the call of duty in order to appear dedicated and hard-working at work (Tedeschi \& Melburg, 1984). Previous IM research demonstrated that exemplification could increase or decrease as a result of job threat. Whereas Huang et al. (2013) found a positive relationship between job threat and exemplification, Kang et al. (2012) concluded a negative relationship. The observed difference is puzzling, as both papers originated from proactivity theory (Griffin, Neal, \& Parker, 2007) and hypothesized that feelings of job threat initiate some form of proactive coping in individuals.

In the current study, the authors argue that this conundrum might be solved by departing from the counterparty view that exemplification is a proactive behavior, thereby 
arguing that it is a more reactive behavior in reaction to workplace stressors like appraised job threat. Conservation of resources theory (CoR; Hobfoll, 1989, 2001) postulates that people who experience job threat strive to protect themselves from resource loss by investigating in additional resources. The engagement in exemplification can be regarded as one such investment in additional resources - that is, a type of job preservation behavior to prevent job feature loss from occurring in the near future (Shoss, 2017). Using CoR theory, we reason that not every individual tries to retain current job features to the same extent, but only those who can protect and preserve their resources.

Hence, our first contribution to the IM literature is developing a novel and more reactive view on exemplification and being the first to bring CoR theory to this field. To further contribute to the IM literature, we provide more insights into the contextual effects which might shape who would engage in exemplification at the workplace, and who not, by proposing a "dual" view of control. In short, we argue that when employees perceive to be in control, they are more likely to feel that they can protect and preserve their resources (Park, Jacob, Wagner, \& Baiden, 2014). We propose a "dual" view of control, as the perception of control might, on the one hand, be given by the organization in the form of job control, and, on the other hand, might also come from more personal forms of control, such as the degree of proactivity held by a person. Job control is defined as an individual's evaluation of existing resources, through which a given threat can be counteracted (Ashford, 1988; Lazarus \& Folkman, 1984). Proactivity is defined as an individual's pre-dispositional state to initiate action aimed at influencing the environment of which someone is part (Bateman \& Crant, 1993). Thus, we investigate if especially individuals who feel in control of organizational possibilities and processes (i.e., are high in job control) and who have the general tendency to engage in behaviors trying to affect change outcomes (i.e., are high in proactivity) are anticipated to engage more in exemplification.

Although the idea of control is new to the field of IM, the role of job autonomy and decision latitude at work has already been established by previous CoR theory research (Chen, Westman, \& Eden, 2009). Job control seems to buffer the negative consequences of change, through reductions in perceived stress (Park et al., 2014). Yet, to our knowledge, no study looked at organizational and personal forms of control simultaneously, thus assessing their combination. We argue that introducing this dual view on control to the field of IM might resolve some of the previously contradictory findings linking threat appraisal to IM behavior (Huang et al., 2013; Kang et al., 2012). Individuals who do not have the power to control practices within the organization (i.e., are low in job control) but have the tendency to engage in behaviors with the intention to affect change outcomes at work (i.e., are high in proactivity), are unlikely to engage in exemplification because they are not able to have an impact on future outcomes. Likewise, individuals who have the freedom to control practices within the organization (i.e., are high in job control) but do not have the tendency to engage in behaviors intending to influence change outcomes (i.e., are low in proactivity), are unlikely to engage in exem- 
plification although they could potentially have an impact. We expect that both types of control are necessary, as only then individuals have both the behavioral repertoire to influence change outcomes and the perception that they can have the power to control events happening in the organization of which they are part. We thus anticipate high levels of job control and proactivity together to have a positive and reinforcing effect on the threat appraisal - exemplification relationship, thus hypothesizing a three-way interaction effect.

With our research model, we add to previous IM literature in the following ways: First, we aim to resolve the previously found mixed findings linking job threat appraisal to IM, and more specifically exemplification. We do so by offering an alternative theoretical rationale through which threat appraisal impacts exemplification. Second, we add to CoR theory in that we simultaneously look at job control (i.e., a form of control bestowed by the organization) and personal control (i.e., an individual's level of proactivity), thereby aiming to provide more information for whom the threat appraisal exemplification relationship is more pronounced. The hypothesized model of our study is depicted in Figure 3.1.

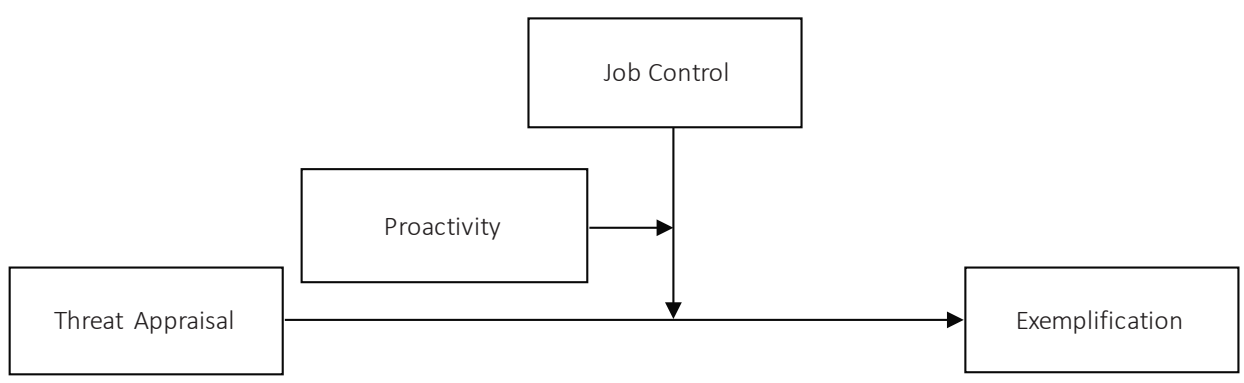

Figure 3.1 The hypothesized model.

\subsection{Theoretical Background and Hypotheses}

\subsubsection{The Relationship between Threat Appraisal and Exemplification}

CoR theory states that individuals experience stress when resources are threatened or lost or when invested resources do not lead to anticipated returns (Hobfoll, 1989, 2001). According to CoR theory, threat appraisal at work may constitute a violation against anticipated returns (i.e., the expectation of being engaged and committed at work in return for job safety; Hobfoll, 1989, 2001). For instance, having a job incorporates the resource of earning an income or living up social contacts next to family and friends. One basic assumption of CoR theory is that people strive to protect themselves from resource loss by using additional resources. On the contrary, individuals may also 
decide to remain more passive, by trying to protect existing resources and refraining from conserving additional resources. When confronted with feelings of job threat, we anticipate that individuals try to retain current resources by mobilizing additional resources. The concept of job threat appraisal, unlike job stability features alone such as the possibility of losing one's job in the future (i.e., being mostly beyond an individual's personal responsibility), incorporates a broader number of highly valued job features about which the individual and the organization can potentially do something (Fugate et al., 2012). It is therefore likely that employees experiencing job threat are motivated to mobilize additional resources by engaging in exemplification. The engagement in exemplification (i.e., a type of job-focused behavior), with the intention to go above the call of duty to appear dedicated and hard-working at work (Tedeschi \& Melburg, 1984), is thus regarded as a type of IM behavior attempting to retain current job features.

Traditional research on job threat appraisal has demonstrated that changes in work processes, practices, and routines, and the associated feelings of job threat, can have negative and detrimental outcomes for employees, including lower well-being and health (for a meta-analytical overview, see Cheng \& Chan, 2008; Sverke et al., 2002). Subsequent research added to this by showing that, when experiencing changes at the workplace, employees are also likely to demonstrate their worth to the organization by investing extra effort into behaviors that will be noticed and valued, through for example enhanced task performance, organizational citizenship, and voice behavior (Shoss \& Probst, 2012). Yet, very recent research by Shoss (2017) puts some of the above into question, as it wonders if positive work behaviors are always "true", arguing that job threat appraisal - a construct similar to qualitative job insecurity - also induces the motivation for job preservation behaviors, such as exemplification. Positive work behaviors differ from job preservation behaviors in one meaningful way: The motive of former behaviors is mainly to "do" good, e.g. by working longer hours (De Cuyper et al., 2008), increasing productivity (Probst et al., 2007), and engaging in voice behaviors (Sverke \& Hellgren, 2001). The motive of latter behaviors is mainly to "appear" good, e.g. by trying to come across as hard-working and engaged. In the current study we build on this recently emerged idea by postulating that exemplification is used to "appear" rather than to "do" good as a result of experiencing job threat.

For the core of our model, we consider threat appraisal at work as a trigger for exemplification. We argue that exemplification is likely to increase as a consequence of perceived job threat, as it initiates individuals to maneuver for desired outcomes and subsequently initiates some form of political behavior (Huang et al., 2013; Kreitner \& Kinicki, 2008). In the current study and, based on premises of CoR theory, we anticipate a positive relationship between threat appraisal and exemplification. We thus come up with the following first hypothesis:

Hypothesis 1. An employee's appraisal of job threat is positively related to exemplification. 


\subsubsection{The Moderating Role of Organizational and Personal Control}

Past research mainly focused on the association between job threat and exemplification and did not investigate whether and if so, to what extent, individual exemplification use differs as a function of contingency factors. Taking this shortcoming as a starting point, in the current paper, we presume that not every individual responds to feelings of job threat with exemplification behaviors to the same extent but that its effect is likely to depend on other contingencies. One such contingency factor is the extent to which individuals feel in control of the undergoing processes, practices, and routines. Previous research already stated that employees may end up putting few additional efforts into IM related behaviors when they feel both burned out and powerless as a result of work changes (Kang et al., 2012; Westman, Etzion, \& Danon, 2001). Similarly, Fugate, Kinicki, and Prussia (2008) demonstrated that negative appraisals, such as perceived job threats, are typically associated with reduced control and increased escape coping.

Looking at this idea from CoR theory research, previous studies already showed different types of job control, including skill discretion, and decision latitude at work, to act as contingency factors in stressor - strain relationships (Park et al., 2014). For example, Park and colleagues showed that high levels of skill discretion and decision latitude buffered the negative effect that workplace stressors have on strain outcomes, thereby leading to less negative outcomes. As another example, Kühnel, Sonnentag, and Bledow (2012) studied the contingency effect of job control in stressor - strain relationships. These authors looked at the relationship of time pressure on work engagement contingent on job control and found that, on days where employees perceived job control to be high, time pressure was positively associated with work engagement. On days where employees perceived job control to be low, time pressure was negatively associated with work engagement. Taken together, previous CoR theory - and threat appraisal research in general - demonstrated that perceptions of job control play a pivotal role in stressor - strain relationships (Halbesleben, Neveu, Paustian-Underdahl, \& Westman, 2014).

Based on previous research findings highlighting the important role of job control in different stressor - strain relationships, also we introduce job control as a contingency factor to the context of threat appraisal. Job control determines whether an individual believes in the existence of organizational resources to keep a potential threat of loss from translating into actual loss (Ashford, 1988). The more that individuals view threats in the organization as controllable, the more likely they are to take action in an attempt to avert those threats, thereby engaging in exemplification as a form of job preservation behavior (Shoss, 2017). As a result, we predict that especially employees, who hold high levels of job control, i.e. who believe that it is possible to counteract job threats associated with workplace change, engage more in exemplification behaviors (Jones, Jimmieson, \& Griffiths, 2005). We therefore develop the following hypothesis: 
Hypothesis 2. Job control moderates the relationship between an employee's appraisal of job threat and exemplification.

Drawing upon research on CoR from yet another field, we expect that the relationships stated in Hypothesis 2 might be further dependent on other contextual factors. For instance, Xanthopoulou, Bakker, Demerouti, and Schaufeli (2009) drew upon CoR theory to study the effects of so-called job as well as personal resources. Job resources refer to different aspects of the job that help to achieve professional goals, reduce job demands (and associated psychological costs), and stipulate personal growth and development (Demerouti, Bakker, Nachreiner, \& Schaufeli, 2001). Personal resources, in contrast, refer to a person's belief in the ability to control and have an impact on the environment of which someone is part (Hobfoll, Johnson, Ennis, \& Jackson, 2003). The authors not only hypothesized job resources (e.g., autonomy, social support) and personal resources (e.g., optimism, self-efficacy) together to impact work-engagement, but also hypothesized work-engagement to reciprocally affect both types of resources. The authors found support for the anticipated relationships. This is one reason why we expect that a "dual" view on control is necessary to understand why people perceiving threat at work engage in exemplification.

The need for a dual view is further strengthened when one looks at similar evidence by Parker (2000), who suggested that individuals are motivated to take initiative if they feel in control of both the situation (e.g., through control appraisals) and their own actions (e.g., through self-initiated behaviors) at the same time. Also Parker, Williams, and Turner (2006) tested a model in which personality (i.e., proactivity) and work environment antecedents (i.e., job autonomy, co-worker trust, and supportive supervision) together affect work behaviors such as idea implementation and proactive problem solving. When relating the above-described findings to our study's research model, job resources (i.e., being in control of the situation) seem to have much in common with our concept of job control, whereas personal resources (i.e., feeling in control of own actions) are closely related to our concept of personal control. Similar as to Parker et al. (2006), also we study proactivity and conceptualize it as a form of personal control, next to job control - conceptualized as a form of control bestowed by the organization.

In an earlier section, we deemed proactivity as a theoretical rationale to be inadequate in predicting the threat appraisal - exemplification relationship. Proactivity incorporates taking control and showing initiative rather than being passive observers and only reacting to the environment (Bateman \& Crant, 1993). Based on the different tendencies of proactive and reactive individuals to interact with the environment, proactivity influences how an individual confronts problems and copes with adversity.

We anticipate proactive personality to interact with the feeling of job threat, and especially for individuals already holding high levels of job control: Employees who are high in job control believe in the impact that they can have on the consequences of work change and the possibility that potential job feature loss can be counteracted 
(Park et al., 2014). Similarly, employees high in proactivity, can be considered to possess the natural tendency to engage in behaviors like exemplification in an attempt to influence future job outcomes. In the context of job threat, this presumes that proactivity affects the extent to which individuals try to influence potential negative consequences. When perceiving job threat, proactive, more than reactive, individuals try to retain current job features by engaging in exemplification, instead of getting anxious and not doing anything about the undergoing threat. Based hereupon, we presume that individuals high in job control and low in proactivity do not try to influence change outcomes through behaviors like exemplification although they could potentially have an impact, compared to how individuals high in both job control and proactivity would do.

Based on CoR theory, we therefore anticipate that holding high levels of job control (i.e., feeling in control over organizational processes) and high levels of personal control (i.e., feeling in control by being highly proactive) at the same time indicates that the individual has a higher total number of resources at disposal to protect and preserve job resources at stake (Ito \& Brotheridge, 2003; Vinokur \& Schul, 2002). We thus anticipate a three-way interaction effect between threat appraisal, job control, and proactivity on exemplification, leading to the following hypothesis:

Hypothesis 3. There is a three-way interaction effect such that proactivity moderates the relationship of threat appraisal, and job control on exemplification. More specifically, an employee's appraisal of job threat is most strongly and positively related to exemplification when employees are simultaneously high in job control and proactivity.

\subsection{Method}

\subsubsection{Sample}

The sample for this study was drawn from a total of 356 employees working in various organizations within the United States, including Retail \& Services ( $n=108$ ), IT \& Telecommunications ( $n=75)$, Construction \& Manufacturing $(n=45)$, Education \& Public Services $(n=39)$, Healthcare $(n=32)$, Hospitality, Food, \& Travel $(n=29)$, and Finance \& Accounting $(n=28)$. The sample consisted of 226 male and 130 female participants, whose age ranged from 21 to 62 years $(M=33.30, S D=8.80)$. Participants worked in their respective organization from less than 1 year to more than 30 years ( $M=3.43, S D$ $=3.63)$ and from less than 1 year to more than 30 years in the current position $(\mathrm{M}=$ 4.19, SD $=4.30$ ). 29 participants were part-time employed, whereas 327 participants were employed full-time. 93 participants held a temporary and 263 a permanent contract. The nationality of participants was primarily US-American $(n=294)$, and a minority of participants was Indian ( $n=47)$, Asian $(n=5)$, Spanish $(n=3)$, Portuguese $(n=2)$, Caribbean ( $n=2)$, Canadian ( $n=1)$, British $(n=1)$, and Russian $(n=1)$. 


\subsubsection{Research Setting and Procedure}

Data were collected through an online survey (i.e., Qualtrics) and administered through a market platform (i.e., Mturk). The survey description pointed out the importance that participants were currently holding a daily job, were not self-employed, and the daily job was characterized at least by some degree of resource threat. In order to guarantee that only suitable candidates participated in the research project, the three necessary conditions were implemented as funnel questions at the beginning of the questionnaire. Consequently, only participants who responded to all three questions with a 'yes' were directed to the beginning of the actual survey. Participants who did not respond as required to at least one of the three questions (i.e., who responded to one or more question(s) with a 'no') were thanked for their time and redirected to the end of the survey. Above that, four randomly distributed questions served as attention checks, making sure that participants read the questions carefully and responded accurately. Respondents who failed one or more of the four attention checks were sorted out from the final dataset. A total of 548 respondents participated in the survey, out of which, based on the two conditions described above, 356 usable cases could be generated. Participation during the entire survey was completely anonymous and voluntary.

\subsubsection{Measures}

Validated scales were used to measure constructs. All constructs were rated on a 5point Likert scale ranging from 1 to 5 representing "strongly disagree" to "strongly agree."

Threat Appraisal. Threat appraisal was measured with seven items from Fugate et al., 2012. The scale taps into the assessment of threat referring to a broad selection of work elements, including elements affecting the actual job stability and future prospective (i.e., job opportunities at the current employer, pay and benefits, and job stability), as well as a broad range of other features of the job (i.e., relationships with supervisors, relationships with coworkers, desirability of one's job, and general working conditions). Respondents were asked: "Due to changes in work routines, processes, and practices, to what extent do you feel that each of the following is threatened in your daily work"? Instructions of this type are also common in other threat appraisal research (e.g., Chandler, Kennedy, \& Sandhu, 2007). The Cronbach's alpha is .86.

Job Control. Job control as perceived by employees was measured with a three-item scale by Ashford, Lee, and Bobko (1989). Exemplary items are "In this organization, I can prevent negative things from affecting my work situation" and "I have enough power in this organization to control events that might affect my job". The Cronbach's alpha is .85 . 
Proactivity. Proactivity was measured with four items by Bateman and Crant (1993). Exemplary items are "No matter what the odds, if I believe in something I make it happen" and "If I believe in an idea, no obstacle will prevent me from making it happen". The Cronbach's alpha is .84.

Exemplification. Exemplification was measured with a five-item scale by Bolino and Turnley (1995). Exemplary items are "I try to appear like a hard-working, dedicated employee towards my supervisor" and "I arrive at meetings on time in order to look dedicated". The Cronbach's alpha is .71.

Control Variables. In our analysis, we controlled for the type of employment (part-time versus full-time), the type of contract (temporary versus permanent), as well as participants' age, and sex. Previous research has shown that different job-related background variables affected subjective perceptions of job insecurity as well as their health and well-being related outcomes. In this context, part-time employees often feel that they are not part of the organization to the same extent as full-time employees are, assuming that they do not feel treated as the traditional and core workforce (Barling \& Gallagher, 1996; Sverke, Gallagher, \& Hellgren, 2000). Similar findings exist for employees holding a temporary job contract such that temporary employees have been found to exhibit higher levels of threat appraisal compared to permanent employees (Sverke et al., 2000), thus also affecting threat appraisal outcomes. Beyond that, also employee age is likely to affect the threat-appraisal - exemplification relationship. Older employees have less alternative chances at the labor market (Van Hercke, De Cuyper, Peeters, \& De Witte, 2014) and therefore seem to be more tempted to engage in exemplification when the current job features are threatened. Finally, previous research found that men tend to engage in higher levels of job-focused IM, compared to women (Singh, Kumra, \& Vinnicombe, 2002).

\subsection{Convergent and Discriminant Validity}

After separately assessing the reliability of each scale, we further assessed the convergent and discriminant validity of our scales. For this, we tested whether the hypothesized measurement model consists of four distinct constructs: Threat appraisal, job control, proactivity, and exemplification, and performed a CFA analysis in R based on the maximum likelihood method. Following the recommendations of $\mathrm{Hu}$ and Bentler (1999) and Bentler (2007), and in order to test the overall model fit, we reported the SRMR as an absolute fit measure, in combination with two incremental fit measures the CFI and the TLI. For the incremental fit measures, i.e. the CFI and TLI, a common cutoff are values close to .90 (Hu \& Bentler, 1999), indicating that values close to .90 indicate a reasonable fit and values of and above .90 indicate a good fit. For the SRMR values below .08 indicate a good fit, values between .08 and .10 indicate a reasonable 
fit, and values above .10 indicate a poor fit (Browne \& Cudek, 1993; Hu \& Bentler, 1999). The confirmatory factor analysis of all constructs showed that our expected measurement model fitted reasonably to the data $\left(\chi^{2}[146]=594.43, p<.001 ;\right.$ SRMR $=$ .09; $\mathrm{CFI}=.86 ; \mathrm{TLI}=.84)$, and all factor loadings were above .50 and significant on a $1 \%$ level, indicating adequate convergent validity (see Table 3.1).

Table 3.1 Results of the Confirmatory Factor Analysis (CFA)

\begin{tabular}{|c|c|c|c|c|c|c|c|c|c|}
\hline Model & $x^{2}$ & d.f. & $\chi^{2} /$ d.f. & $\Delta$ d.f. & $\Delta \chi^{2}$ & sig. & SRMR & $\mathrm{CFI}$ & TLI \\
\hline Four factor hypothesized model: & 594.43 & 146 & 4.07 & - & - & $p<.001$ & .09 & .86 & .84 \\
\hline $\begin{array}{l}\text { Alternative Model 1: Job control } \\
\text { and proactivity as one factor }\end{array}$ & 1101.20 & 149 & 7.39 & 3 & 506.77 & $p<.001$ & .12 & .71 & .67 \\
\hline $\begin{array}{l}\text { Alternative Model 2: Threat } \\
\text { appraisal, job control, and } \\
\text { proactivity as one factor }\end{array}$ & 2010.24 & 151 & 13.31 & 5 & 1415.81 & $p<.001$ & .17 & .43 & .36 \\
\hline $\begin{array}{l}\text { Alternative Model 3: All on one } \\
\text { factor }\end{array}$ & 2473.36 & 152 & 16.27 & 6 & 1878.93 & $p<.001$ & .19 & .30 & .21 \\
\hline
\end{tabular}

Note: sig. = level of significance.

To provide more insights into the factor structure we also performed an EFA, which can be found in Appendix B. As demonstrated in the appendix, four items of the exemplification measure show a decent factor loading whereas the fifth and last item does not. Yet, and due to theoretical reasons (i.e., including the well-established measurement), the exemplification measure was kept as it is including all five items.

Next, we inspected the discriminant validity of our measures by investigating three additional model specifications. We assessed whether a three-factor model, in which job control and proactivity loaded on one factor, fitted worse than our hypothesized four-factor model. The results showed that this was the case $\left(\Delta \chi^{2}[3]=506.77, p<.001\right.$; SRMR $=.12 ; \mathrm{CFI}=.71 ; \mathrm{TLI}=.67$ ). We then assessed whether a two-factor model (in which threat appraisal, job control, and proactivity loaded on one factor) fitted worse to our data, compared to the four-factor model. Again, the alternative model fitted significantly worse than the hypothesized four-factor model $\left(\Delta \chi^{2}{ }^{2}{ }_{5]}=1415.81, p<.001\right.$; SRMR $=.17 ; \mathrm{CFI}=.43 ; \mathrm{TLI}=.36)$. Lastly, we assessed a one-factor model, in which all items loaded on one construct. This model also fitted significantly worse than our original four-factor model $\left(\Delta \chi^{2}[6]=1878.93, p<.001 ; \mathrm{SRMR}=.19 ; \mathrm{CFI}=.30 ; \mathrm{TLI}=.21\right)$. Overall, the results demonstrate that a four-factor measurement model fits our data best and that the measures of interest, next to being theoretically distinct, are empirically distinct. 


\subsection{Results}

\subsubsection{Descriptive Statistics}

Table 3.2 shows the means, standard deviations, bivariate correlations, and the internal consistencies of the scales included in the analyses. As to our key variables, type of employment ( 1 = part-time versus 2 = full-time) and type of contract ( 1 = temporary versus 2 = permanent) negatively and significantly relate to threat appraisal, indicating that individuals who are employed full-time $(r=-.10, p<.05)$ and who hold a permanent contract $(r=-.15, p<.01)$ feel less threatened at work. Age negatively relates to job control $(r=-.17, p<.001)$, indicating that older people feel less in control of work processes and practices. Sex ( 1 = male, 2 = female) negatively relates to job control $(r=-$ $.11, p<.05)$, suggesting that females feel less in control of their jobs compared to males. Threat appraisal significantly and negatively relates to job control $(r=-.17, p<$ $.001)$ and positively and significantly relates to exemplification $(r=.25, p<.001)$. Job control significantly and positively relates to proactivity $(r=.23, p<.001)$ and proactivity significantly and positively relates to exemplification $(r=.15, p<.01)$.

Table 3.2 Descriptive Statistics: Means, Standard Deviations, and Correlations

\begin{tabular}{lrrrrrrrrr}
\hline Variable & M & SD & 1 & 2 & 3 & 4 & 5 & 6 & 7 \\
\hline 1. Type of employment & 1.92 & .27 & -- & & & & & & \\
2. Type of contract & 1.74 & .44 & $.17^{* * *}$ & -- & & & & & \\
3. Age & 33.30 & 8.80 & -.04 & $.14^{* *}$ & -- & & & & \\
4. Sex & 1.37 & .48 & .05 & -.04 & $.11^{*}$ & -- & & & \\
5. Threat appraisal & 3.21 & .91 & $-.10^{*}$ & $-.15^{* *}$ & .02 & -.05 & -- & & \\
6. Job control & 2.76 & .99 & .04 & .08 & $-.17^{* * *}$ & $-.11^{*}$ & $-.17^{* * *}$ & -- & \\
7. Proactivity & 3.75 & .81 & .07 & .03 & .01 & .00 & -.07 & $.23^{* * *}$ & -- \\
8. Exemplification & 3.31 & .74 & -.04 & -.04 & -.05 & -.01 & $.25^{* * *} .04$ & $.15^{* *}$ \\
\hline
\end{tabular}

Note: $\mathrm{N}=356$.

Type of employment $(1=$ part-time, 2 = full-time), Type of contract $(1=$ temporary, 2 = permanent $), \operatorname{Sex}(1=$ male, 2 = female).

$* p<.05 ; * * p<.01 ; * * p<.001$.

\subsubsection{Hypothesis Testing}

In line with the stepwise approach of moderation models in ordinary least squares regression analysis (e.g., Aiken \& West, 1991), we first specified a model with only control variables included. We then examined the main effect in a separate model, followed by the two-way interactions, and finally the three-way interaction effect (see Table 3.3). As Model 1 of Table 3.3 shows, none of the demographic control variables, i.e. type of employment, type of contract, age, and sex, relate significantly to exemplification. Yet, and in order to improve the external validity of our results, the demographic control variables are still included for the remaining models to be tested. Model $2\left(\Delta \mathrm{R}^{2}=.09, p\right.$ 
$<.001$ ) includes the main effect and demonstrates that, as was predicted in Hypothesis 1 , there is a positive and significant direct relationship of threat appraisal on exemplification $(B=.20, p<.001)$.

Hypothesis 2 anticipated that the relationship of threat appraisal on exemplification is moderated by job control, such that the relationship is more positive when job control is high compared to low. As can be seen from Model 3, the addition of the two-way interaction of threat appraisal and job control, when controlling for the other two-way interaction effects, significantly improved the total amount of variation explained $\left(\Delta R^{2}=\right.$ $.02, p<.05)$. Consequently, Hypothesis 2 can also be supported $(\theta=.07, p<.05)$, indicating that individuals who feel in control of the processes and outcomes affected by change engage more in exemplification.

Table 3.3 Results of Hypothesis Testing

\begin{tabular}{|c|c|c|c|c|c|c|c|}
\hline Step & & Variable & Model 1 & Model 2 & Model 3 & Model 4 & VIF \\
\hline \multirow[t]{4}{*}{1.} & Controls & Type of employment & -.03 & -.02 & -.02 & -.03 & 1.05 \\
\hline & & Type of contract & -.02 & .01 & .01 & .02 & 1.09 \\
\hline & & Age & -.04 & -.05 & -.05 & -.05 & 1.08 \\
\hline & & Sex & .00 & .02 & .02 & .02 & 1.04 \\
\hline \multirow[t]{3}{*}{2.} & Main effects & Threat appraisal & & $.20 * * *$ & $.16 * * *$ & $.13^{* *}$ & 1.32 \\
\hline & & Job control & & .03 & .01 & .04 & 1.25 \\
\hline & & Proactivity & & $.12^{* *}$ & $.14^{* * *}$ & $.17 * * *$ & 1.26 \\
\hline \multirow[t]{3}{*}{3.} & 2-way interactions & Threat appraisal x Job control & & & $.07 *$ & .01 & 1.61 \\
\hline & & Threat appraisal x Proactivity & & & .06 & $.08^{*}$ & 1.42 \\
\hline & & Job control x Proactivity & & & .03 & .01 & 1.29 \\
\hline \multirow[t]{3}{*}{4.} & 3-way interaction & $\begin{array}{l}\text { Threat appraisal x Job control x } \\
\text { Proactivity }\end{array}$ & & & & $.11^{* *}$ & 1.69 \\
\hline & & $\mathrm{R}^{2}$ & .01 & .10 & .12 & .14 & \\
\hline & & $\Delta \mathrm{R}^{2}$ & .01 & $.09 * * *$ & $.02 *$ & $.02 * *$ & \\
\hline
\end{tabular}

Note: $N=356$.

Type of employment ( 1 = part-time, 2 = full-time), Type of contract $(1=$ temporary, 2 = permanent $), \operatorname{Sex}(1=$ male, 2 = female).

$* p<.05 ; * * p<.01 ; * * p<.001$.

Finally, Hypothesis 3 predicted that there is a three-way interaction effect among threat appraisal, job control, and proactivity such that the relationship of threat appraisal on exemplification is most pronounced for high levels of both proactivity and job control. Model 4 demonstrates that adding the three-way interaction effect significantly improved the total amount of variance explained in the model $\left(\Delta R^{2}=.02, p<.01\right)$. Also the regression coefficient of the three-way interaction shows that, when experiencing job threat, high levels of job control (i.e., a form of control bestowed by the organization) and proactivity (i.e., a personal form of control) together have a positive and reinforcing effect on exemplification ( $B=.11, p<.01$ ). Variance inflation factors (VIFs) for the varia- 
bles in the fourth model are all below values of 4 , indicating that multicollinearity was not a problem in the performed analysis (e.g., Langfred, 2004; Miles \& Shevlin, 2001).

The three-way interaction of threat appraisal with job control and proactivity is graphically depicted in Figure 3.2. with Jeremy Dawson's tool for interpreting interaction effects. Figure 3.2 shows that, in support of Hypothesis 3, the interaction between threat appraisal and job control is most pronounced when proactivity is high rather than low, displayed by highest levels of exemplification with increases in threat appraisal (see condition 1). The plot also seems to suggest that job control and proactivity act as two reinforcing moderating factors, such that high levels of both job control (i.e., a form of control bestowed by the organization) and proactivity (i.e., a personal form of control) together have a positive and reinforcing effect on exemplification behaviors displayed at work.

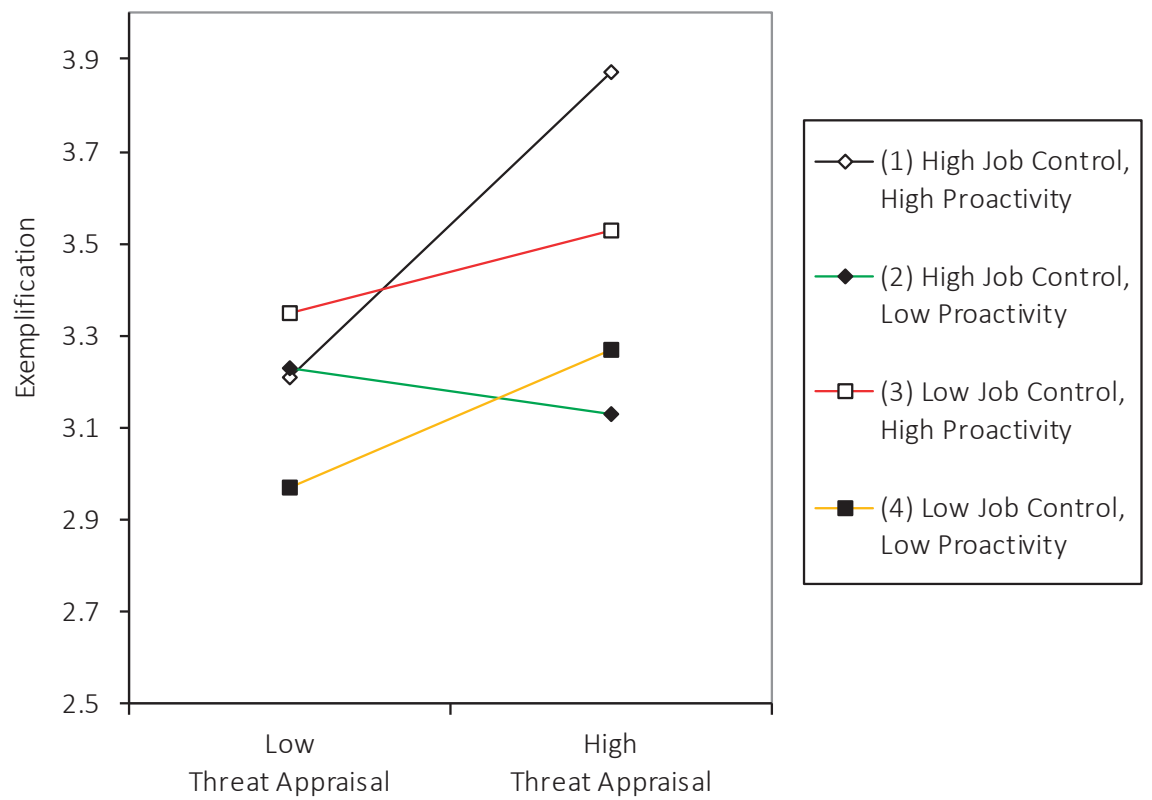

Figure 3.2 Three-way interaction plot of Threat Appraisal, Job Control, and Proactivity on Exemplification.

To further examine the three-way interaction effect, we used the method by Dawson and Richter (2006) to examine whether the pairs of individual slopes are significantly different from each other. The simple slopes and slope difference tests relating to Figure 3.2 are presented in Table 3.4. In line with the theoretical arguments described above, the results of the simple slopes test show that the relationship of threat appraisal and exemplification is only significant for both high levels of job control and proactivity (condition 1: $b=.33, p<.001$ ). In contrast, when individuals hold low levels of job control, and/or low levels of proactivity (conditions 2, 3, and 4), the effect on exemplifi- 
cation becomes statistically insignificant. Next to the simple slopes test, the analysis of simple slope differences indicates that the interaction of threat appraisal and proactivity is significant when job control is high (slopes 1 and $2 ; t=3.47, p<.001$ ) and the relationship between threat appraisal and job control is significant when proactivity is high (slopes 1 and $3 ; t=3.80, p<.001$ ). These results further support Hypothesis 3 .

Table 3.4 Simple Slope Comparisons for Three-Way Interactions

\begin{tabular}{lcc}
\hline Simple slopes & Slope & sig. \\
\hline 1. High job control, high proactivity & .33 & $* * *$ \\
2. High job control, low proactivity & -.05 & n.s. \\
3. Low job control, high proactivity & .09 & n.s. \\
4. Low job control, low proactivity & .15 & n.s. \\
Pairs of comparisons & & t \\
slopes 1 and 2 & $3.47^{* * *}$ \\
slopes 1 and 3 & $3.80^{* * *}$ \\
slopes 1 and 4 & & 1.42 \\
slopes 2 and 3 & & -1.11 \\
slopes 2 and 4 & & -1.41 \\
slopes 3 and 4 & & -.55 \\
\hline
\end{tabular}

Note: $\mathrm{N}=356$.

$* \mathrm{p}<.05 ; * * \mathrm{p}<.01 ; * * * \mathrm{p}<.001$

Numbers correspond to numbers listed in Fig. 1, tests based on Dawson and Richter (2006).

\subsection{Discussion}

In line with recent research moving away from investigating the detrimental consequences that change can have for health-related outcomes, we looked at more positive work behaviors (i.e., increases in productivity, working hours, and voice) resulting out of job threat appraisal (De Cuyper et al., 2008; Probst et al., 2007; Sverke \& Hellgren, 2001). Yet, we argued that such positive behaviors may not be driven out of proactivity alone but more out of the motivation for job preservation - i.e. the attempt to prevent job feature loss in the near future (Shoss, 2017). Individuals, when fearing that resources might be threatened or lost in the future, try to retain current resources (Hobfoll, 1989, 2001), i.e. through the engagement in exemplification. Consequently, and as predicted in Hypothesis 1 , the appraisal of job threat is positively and significantly related to exemplification behaviors. In Hypothesis 2, and based on premises of CoR theory (Hobfoll, 1989, 2001), we introduced job control, the feeling of control over the resources affected by change (i.e., control bestowed by the organization), as a moderator to the threat appraisal - exemplification relationship. Our results show that Hypothesis 2 could also be supported, indicating that feelings of job control, indeed, strengthen the threat appraisal - exemplification relationship. In Hypothesis 3, we further predicted 
this to be conditional on an employee's level of proactivity (i.e., a personal form of perceived control), hence hypothesizing a three-way interaction effect between threat appraisal, job control, and proactivity on exemplification. Hypothesis 3 was supported as well, demonstrating that high levels of both job control and proactivity act as two reinforcing moderating factors in the threat appraisal - exemplification relationship. Our results indicate that individuals who feel that they can have an impact on outcomes affected by workplace change (i.e., are high in job control) and who have the general tendency to engage in behaviors to influence future outcomes (i.e., are high in proactivity) engage most in exemplification.

\subsubsection{Theoretical Implications}

With our research model we add to previous research in the following ways: We first contributed to the IM literature by developing a novel and more reactive view on exemplification and by connecting this idea to CoR theory. In doing so, we add to the currently mixed findings linking threat appraisal and IM (e.g., Kang et al., 2012; Huang et al., 2013). Drawing from proactivity theory, both Kang et al. (2012) and Huang et al. (2013) studied the effect that job threat appraisal has on IM behaviors. While Kang et al. (2012) found a negative relationship, Huang et al. (2013) concluded a positive relationship. At the same time, when experiencing job threat, individuals most likely do not engage in IM behaviors out of a proactive motivation alone. Based on CoR theory (Hobfoll, 1989, 2001), the idea that people who experience job threat strive to protect themselves from resource loss, we offered an alternative theoretical rationale as to why individuals engage in exemplification behaviors. By referring to exemplification as a type of job preservation behavior (Shoss, 2017), we aimed to bring more clarity into the previously found mixed findings linking threat appraisal to IM.

Our findings also add to the current threat appraisal conversation, in that they show that, in the context of work change, there seem to be multiple reasons for observable work behaviors such as working more hours. We showed that next to the proactive rationale for (change-related) behavior, also the preserving rationale is likely to affect reactions to appraised threat. This finding opens up new questions, including, but not limited to, possible contingencies of when which type of rationale prevails. Above that, and as an explanation for the negative relationship found, Kang et al. (2012) developed the argument that employees experiencing some form of job threat do not tend to believe in the impact that they can have on the potential positive outcomes. Our study adds to this idea by demonstrating that the conflicting prior findings might be understood from the "dual" perspective on control this paper takes.

Second, our paper also contributes to CoR theory itself in that it studies different types of control. Previous CoR theory research already established the mitigating contingency effect of organizational forms of control (i.e., job autonomy and decision latitude) on threat appraisal - outcome relationships (Chen et al., 2009; Kühnel et al., 
2012; Schmidt \& Diestel, 2012). At the same time, studies examining the contingency effect of personal and organizational factors together, likely to exacerbate the effect of threat appraisal on actual work behaviors, is lacking. We advance CoR theory research because we demonstrate that different resources, a form of control bestowed by the organization (i.e., job control), and a personal form of control (i.e., proactivity), can have a reinforcing and exacerbating effect on $\mathrm{IM}$. This raises the question of whether, next to the organizational resource of feeling in control, and the individual resource of proactivity, there exist more contingencies helping employees to deal with the consequences of change at work. Moreover, the question unfolds whether there are also situations in which the existence of organizational and personal resources together leads to a buffering, instead of exacerbating, effect.

\subsubsection{Limitations and Suggestions for Future Research}

As any other study, also this study has limitations. First, our study might, at least to some degree, be source of common method bias given that all measures were based on individuals' self-ratings (Podsakoff, MacKenzie, \& Podsakoff, 2012). Therefore, and in order to verify whether different levels of job threat are objectively related to greater IM use, prospective research may benefit from ratings stemming from multiple sources (i.e., an external rating of exemplification through the supervisor).

Moreover, cross-sectional data have been used for the study at hand. More specifically, this suggests that the research model might potentially be subject to reversecausality concerns (Zapf, Dormann, \& Frese, 1996). For the concrete research model chosen this would suggest that exemplification rouses feelings of job threat, a direction that, based on previous and current theoretical perspectives (i.e., proactivity and CoR theory), seems very counterintuitive. Yet, and to fully overcome this shortcoming, future research should attempt to replicate this research idea by making use of either longitudinal or some degree of nested data.

Another limitation stems from the non-nested, non-hierarchical structure of the data. Due to this single-level, single source data structure, the results are not easily generalizable across populations and industries (McAleer, 1995). Yet, as the focus of attention of the paper at hand lay on subjective perceptions of threat appraisal, feelings of threat did not manifest themselves out of the respective industry the employees worked in.

The statistical model used in the study did not fit the data very well, yet resulted in an acceptable model fit. One potential reason could emerge from the exemplification measure (i.e., in particular the fifth and last item). When re-running the CFA excluding the fifth item, the incremental fit measures (i.e., the CFI and TLI) slightly improved (CFI= $.87 ; \mathrm{TLI}=.85$ ), yet still below the commonly accepted cut-off value of .90 . Next to the theoretical arguments (i.e., including the well-established measure) for keeping all items, a supplementary analysis leaving out the last item, indicated a loss with respect to data richness and results, including a partly insignificant slope difference test (i.e., 
slopes 1 and $3 ; t=1.67, p>.05)$. Hence, the measure was kept in its original form for further analysis.

Fifth, a market platform (i.e., Mturk) has been used to collect the study's data, implying that participants (i.e., internet users) were younger, in our case with a mean of 33 years, and more liberal compared to the overall population (Paolacci \& Chandler, 2014). At the same time, Paolacci and Chandler (2014) suggest that Mturk may be used by researchers for any study that is feasible to be conducted online, given that it adheres to overall quality standards. Beyond that, a major strength of Mturk for our study was that we as researchers had some degree of control over our participants, i.e. ensuring that individuals are currently employed with a daily job, and are not self-employed; two important criteria for our research model. Nevertheless, and in order to be able to generalize findings to the broader population, future research should try to replicate a similar study by looking for participants in respective organizations.

Lastly, we would like to note that a large proportion of scholars studying workplace change referred to job insecurity, defined as the "perception of a potential threat to continuity" in one's current job (i.e., also referred to as quantitative job insecurity; Hellgren, Sverke, \& Isaksson, 1999). The current paper focused on the concept of threat appraisal - that is the consequences of workplace change on overall job features, thereby moving above and beyond studying job stability features alone (Heaney, Israel, \& House, 1994). Therefore, in our study, we studied threat appraisal as a concept similar to qualitative job insecurity and referred to it as a broad set of resources at stake, including relationships to co-workers and supervisors, general working conditions, desirability of one's job, future job opportunities, as well as job stability related aspects (Hellgren et al., 1999).

\subsubsection{Practical Implications}

Our study bears several implications for practice. When experiencing potential job feature loss, individuals strive to protect themselves from resource loss. One way of doing so is to engage in exemplification behaviors, implying that exemplification helps individuals to keep current job features. Especially individuals who feel that they can have an impact on future outcomes (i.e., who are high in job control) strive to protect themselves from potential job feature loss through the use of exemplification behaviors. It therefore is important that firms clearly articulate the extent to which their employees can influence work processes and practices and possible ways to do so. Above that, organizations should train individuals in their general tendencies to engage in behaviors attempting to affect future change outcomes (i.e., their proactivity). Like that, they can increase awareness that employees are possibly able to influence future outcomes. 


\subsection{Conclusion}

Previous research suggested that, as a result of experiencing workplace change, employees are likely to work longer hours, to make more use of voice behaviors, and to be more productive. At the same time, previous research overlooked that such behaviors might not solely be driven out of proactivity but might also be used to preserve current job features - a motivation referred to as job preservation. Based on CoR theory, we found that individuals who experience threats and are high in job control and high in proactivity engage most in exemplification. As such, our findings support the hypothesized three-way interaction effect. Our findings shed light on the previously found controversial findings linking threat appraisal at work to positive behaviors like going above the call of duty such as working more hours (Huang et al., 2013; Kang et al., 2012). 


\section{Chapter}

\section{Within-Subject Variability in Ingratiation as a Function of Self-Esteem and Time: A Dynamic Perspective}

This chapter is based on the manuscript:

Schmitte, K., Segers, M., Schreurs, B., \& Jawahar, I. M. (forthcoming). Within subject variability in ingratiation as a function of self-esteem and time: A dynamic perspective. Journal of Personnel Psychology.

An earlier version of the manuscript has been presented as:

Schmitz, K., Segers, M., \& Schreurs, B. A dynamic perspective on ingratiation as an upward-hierarchy influence behavior across undergraduate bachelor students. Proceedings of the 2016 Conference of the Society of Industrial and Organizational Psychology, Anaheim, CL, April, 2016. 



\subsection{Introduction}

Impression management (IM), the process whereby individuals seek to influence the image others have of someone (Rosenfeld, Giacalone, \& Riordan, 1995), is critical to social influence and is a fact of social life (Vohs, Baumeister, \& Ciarocco, 2005). Ingratiation, a specific form of $I M$, is one of the most commonly used social influence tactics by employees who are highly dependent on their supervisors to achieve their personal career objectives (Higgins \& Judge, 2004). The practical value of ingratiation is illustrated by quotes, such as "Everybody likes a compliment" (Mark Twain) and "Flattery will get you everywhere" (Mae West). Meta-analytic findings showing that flattery, the most common tactic of ingratiation, impacts liking (Gordon, 1996) validate these quotes. In fact, the impact of ingratiation on liking holds even when targets are aware that the flatterer's praise is based on inaccurate information (e.g., Byrne, Rasche, \& Kelley, 1974), and driven by ulterior motives (Drachman \& Insko, 1978). Evidence for the association between ingratiation and liking is important as liking is considered one avenue through which ingratiation impacts work outcomes.

Previous research has demonstrated that ingratiation, defined as flattering behaviors used with the intention to appear likeable (Jones \& Pittman, 1982) influences many important work outcomes (for reviews, see Ferris \& Hochwarter, 2011). For instance, ingratiation is associated with higher performance ratings (e.g., Ferris, Judge, Rowland, \& Fitzgibbons, 1994; Higgins, Judge, \& Ferris, 2003), higher ratings of citizenship behaviors (Bolino, Varela, Bande, \& Turnley, 2006), hiring recommendations (Ellis, West, Ryan, \& De Shon, 2002; Kristof-Brown, Barrick, \& Franke, 2002), salary progressions (Gould \& Penley, 1984), promotion decisions (Thacker \& Wayne, 1995), career success (Judge \& Bretz, 1994; Sibunruang, Garcia, \& Tolentino, 2016), and board appointments (Stern \& Westphal, 2010).

A review of the aforementioned and other studies indicates that extant research on ingratiation has exclusively taken a between-person perspective - examining if individuals who ingratiate more enjoy more positive benefits than those who engage in ingratiation less. This exclusive focus on the between-person perspective has resulted in the complete neglect of the within-person perspective necessary for understanding when and why individuals increase or decrease ingratiatory behaviors over time. By taking a within-person perspective, the authors address this important gap in knowledge of when and why individuals engage in more or less ingratiation over time.

It is clear that people ingratiate more in some situations than in other situations. For instance, think of the yearly performance appraisal meeting. To get good evaluations, employees may engage in ingratiation, and we can expect some employees to engage in ingratiation more than others. Previous research is supportive of this between-person perspective. In contrast to this research, we take a dynamic perspective and posit that as the appraisal interview gets closer, the more salient it becomes, eliciting increasing levels of ingratiation. By taking a within-person perspective, we show that ingratiation increases with an approaching salient event. Thus, we investigate the possibility that 
ingratiation exhibits significant within-individual variability and that individuals will increase their ingratiatory behaviors as the appraisal event gets closer.

Drawing on behavioral plasticity theory (BPT) (Brockner, 1988), we further contend that self-esteem, defined as an individual's overall sense of worthiness of oneself (Rosenberg, 1979), is able to explain between-individual differences in within-individual increases in ingratiation. BPT postulates that individuals with low, compared to high levels of self-esteem respond more strongly to environmental cues or events (Brockner, 1988; Pierce, Gardner, Dunham, \& Cummings, 1993). This idea also suggests that individuals low in self-esteem are more strongly influenced by conditions in the environment (Inceoglu \& Warr, 2011; Li, Fan, \& Zhao, 2015). We extend BPT to a more "dynamic" BPT, by accounting for changes in individual behavior over time. We do so by theorizing that low self-esteem individuals are likely to react more strongly to environmental increases in salience over time and ingratiate more compared to their high self-esteem counterparts. Hence, we propose that over time - as the appraisal event draws closer, low self-esteem individuals will ingratiate more relative to high self-esteem individuals. We test these ideas using data collected in three waves across a time span of six weeks.

Our study contributes to the literature in two specific ways. First, unlike previous research that examined ingratiation from a between-person perspective, we take a within-person perspective and track how ingratiation increases as a salient event draws closer. Thus, we not only contribute to ingratiation research, but also offer a new paradigm that can be used to study when and why other upward influence attempts, such as rational persuasion and consultation increase or decrease with time. Second, we extend Brockner's (1988) BPT from a stable to a dynamic form by showing that not only do low self-esteem individuals ingratiate more than high self-esteem individuals, but their rate of increase in ingratiation is much steeper than that of high self-esteem individuals as the salient performance appraisal event draws closer. The idea that environmental pressures activate individual differences such that manifestations of such individual differences are accentuated over time can be applied to study behaviors in several other domains.

The hypothesized model of our study is shown in Figure 4.1.

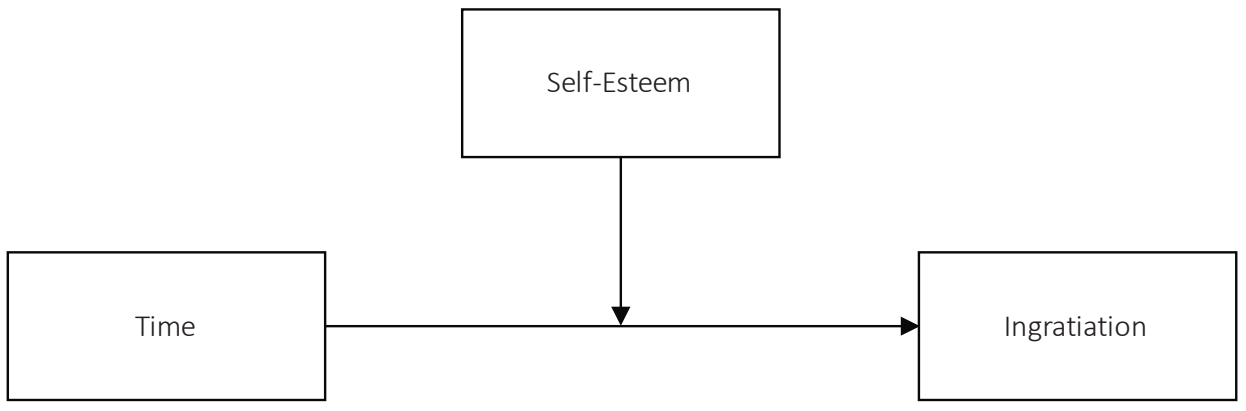

Figure 4.1 The hypothesized model. 


\subsection{Theoretical Background and Hypotheses}

\subsubsection{Ingratiation from a Within-Person Perspective}

Tedeschi and Melburg (1984) refer to ingratiation as a set of assertive tactics used by individuals to gain the approval of authority figures controlling significant rewards for them. A behavioral example of ingratiation is engaging in flattery, such as giving compliments. According to Jones and Pittman's (1982) IM classification, ingratiation is a form of other-focused IM tactic along with self-promotion (i.e., a form of self-focused IM, such as pointing out one's skills and abilities) and exemplification (i.e., a form of jobfocused IM, such as appearing dedicated and hard-working at work).

Previous research conceptualized IM, including ingratiation, as a stable construct and investigated antecedents of ingratiation as well as conditions under which ingratiation is more or less effective. Different personality traits such as emotional stability (van Iddekinge, McFarland, \& Raymark, 2007), self-esteem (Huang, 2013), and need for power (Kacmar et al., 2004) have been found to predict ingratiation use. In addition, self-monitoring (Turnley \& Bolino, 2001), political skill (Harris, Kacmar, Zivnuska, \& Shaw, 2007), person-job fit (Kristof-Brown et al., 2002), and perceived similarity (Wayne, Kacmar, \& Ferris, 1995) have been found to modify the effectiveness of ingratiation, such that ingratiation was more effective when self-monitoring, political skill, person-job fit, and perceived similarity were high. Extant research has taken a betweenperson perspective neglecting the within-person perspective that is crucial for understanding factors influencing when individuals might increase (or decrease) their ingratiatory behaviors and if there are individual differences in the tendency to do so.

The majority of previous studies assumed that ingratiation is used in high-stake situations (i.e., involving important consequences), such as performance appraisal situations (Wayne \& Kacmar, 1991; Wayne \& Liden, 1995), job interviews (Ellis et al., 2002; McFarland, Ryan, \& Kriska, 2003) or in supervisor-subordinate meetings (Wayne \& Kacmar, 1991; Wayne \& Liden, 1995). In these high-stake situations, it is argued that employees are motivated to convey a good impression at that particular point in time (e.g., Harris et al., 2007; Wayne \& Ferris, 1990; Wayne, Liden, Graf, \& Ferris, 1997). IM studies, in the realm of performance appraisals, therefore focused on understanding how the use of IM tactics at a high-stake one-time encounter (i.e., with the supervisor) translate into enhanced performance appraisals (Ferris et al., 1994; Higgins et al., 2003).

We postulate that $\mathrm{IM}$, and more specifically ingratiation, may not only be used at one point in time, but actually may be used over an extended period of time. Thus, there is not only between-person variation in the use of ingratiation, but also variation in ingratiation use within-persons over time. When experiencing a high-stake situation, people are not, at all times, equally motivated to make a good impression. More particularly, there may be moments in which making a good impression and gaining the ap- 
proval of others is perceived as more important compared to other moments (Schlenker \& Weigold, 1992).

In the current study, we bring forward the idea that an individual's motivation to demonstrate a particular image and thus the extent to which the individual engages in ingratiation across time is likely to change as a function of the temporal distance to the performance appraisal event. Both the perceived goal relevance of one's impressions (i.e., the degree to which making a particular impression will facilitate the achievement of the desired goal), and the value of the desired goal (i.e., the importance of achieving the goal) (Leary \& Kowalski, 1990) increase the perceived salience of achieving the goal; hence contributing to ingratiatory behavior. An example of how an increase in perceived salience translates into an increase in IM behaviors can be seen in how politicians behave as the election draws closer. The closer the election date gets, the more motivated a politician becomes to make a good impression, engaging more in IM behaviors. This example illustrates that IM behaviors increase over time as a result of increases in salience.

Yet, the majority of previous studies assumed that the extent to which individuals engage in IM and ingratiation across the studied time frame stays constant. An exception is the study by Bolino, Klotz, and Daniels (2014). In their study, the authors investigated how performance appraisals by the supervisor develop over time as a result of the continuous use of ingratiation behaviors (i.e., how frequently IM was used by an employee) across the measured time frame. The study is valuable because it informs us that, next to using ingratiation only once, it can also be used continuously, and to different extents over a longer period of time. Nonetheless, the study's focus lay on the effectiveness (i.e., performance evaluations) of using ingratiation over time and not on within-individual fluctuations in ingratiation use itself (Bolino et al., 2014).

Our study is unique in that we try to explain why ingratiation varies over time. As the temporal distance to the performance appraisal event decreases, the appraisal event becomes more salient, leading individuals to increasingly use ingratiatory behaviors to achieve desired positive evaluations. Hence, we offer the following hypothesis:

Hypothesis 1. As the performance appraisal date draws closer, the use of ingratiation tactics increases (over time).

\subsubsection{Individual Differences in Within-Person Variation of Ingratiation use: The Role of Behavioral Plasticity Theory}

As previously proposed, individuals are likely to increase ingratiatory behaviors as a function of increases in salience due to the performance appraisal event drawing closer. At the same time, we acknowledge that not every individual will react to increases in salience in a similar way. We believe that the magnitude of the effect that salience has on ingratiatory behavior is also likely dependent on individual characteristics, such as self-esteem. Originated on behavioral plasticity theory (BPT) (Brockner, 1988), low self- 
esteem individuals are anticipated to seek contextual cues to validate feelings of selfworth more so than those high in self-esteem (Caesens, Marique, \& Stinglhamber, 2014; Wille, Van Hoye, Weijters, Rangarajan, \& Carpentier, 2018). As a matter of (in)validating feelings of self-worth, it is presumed that low self-esteem individuals react more strongly (i.e., are more susceptible) to situational factors, thereby leading to greater adjustments in behavior (Amrein \& Berliner, 2002).

Extant research on BPT has only focused on static interpersonal differences - variations in behaviors between different individuals as a function of self-esteem (Saks \& Ashforth, 2000). To date, behavioral plasticity research has not attempted to explain how individual behaviors differ over time as a function of self-esteem, thereby predicting intrapersonal differences (in ingratiation) as time passes. In this study, we extend BPT to a more "dynamic" form of BPT; we do so by investigating how ingratiatory behaviors of an individual change over time in response to increases in salience as the performance appraisal event draws closer in time (Leary \& Kowalski, 1990).

According to Brockner (1988), relative to individuals with high self-esteem, individuals with low self-esteem: 1 ) tend to engage in social comparison processes more due to feelings of uncertainty; 2) tend to seek social approval by conforming attitudinally and behaviorally with others' expectations and social norms to boost one's image; and 3) are more susceptible to self-diagnosis. We argue that as the temporal distance to the performance appraisal event decreases and perceived salience increases, an individual's motive for social comparison, social approval, and self-diagnosis is likely to increase. First, the closer the appraisal event gets, the more likely low self-esteem individuals will engage in some form of social comparison in order to estimate their current performance (i.e., relative to others) towards the final performance appraisal event. Second, as the appraisal event draws closer, low self-esteem individuals' desirability for social approval (i.e., being liked by the target) is likely to increase. Third, with decreasing temporal distance to the appraisal event, an individual's desire for self-diagnosticity (i.e., a reflection of own past behavior) is likely to increase. For these reasons, and proportional with increases in perceived salience, we expect low self-esteem individuals relative to high self-esteem individuals to engage in increasingly more ingratiation as the temporal distance to the appraisal event decreases. This leads to the following hypothesis:

Hypothesis 2. Self-esteem moderates the effect of time on ingratiation, such that the rate of change in ingratiatory behaviors is expected to be steeper and more positive for individuals with low compared to high self-esteem. 


\subsection{Methods}

\subsubsection{Research Setting/Context}

Data were collected from undergraduate students studying in a mid-sized Dutch university. The university is well-known for its problem-based learning (PBL) pedagogy that emphasizes interactive experiential learning in small tutorial groups (Moust, Berkel, \& Schmidt, 2005). Each tutorial group consists of one instructor (i.e., tutor) and between 12 to 14 students.

Students enrolled in a course titled "Entrepreneurship and Human Resource Management" served as participants. In this course, 50\% of the course grade is based on a final exam. The tutor is responsible for leading discussion in the tutorial group, for the continuous development of students, and is responsible for assigning the remaining $50 \%$ of the course grade, based on individual course assignments. In the Dutch University system, the general grade range is from 1 to 10 . Values equal to and higher than a 5.5 (up to 10) count as pass. Values equal to a 5.0 and below count as fail.

Just as in organizations where supervisors and subordinates interact frequently, students and tutors are also interacting frequently with students taking advice and directions from tutors. And, just as performance appraisals conducted in organizations have real consequences for employees, so do evaluations of students by tutors. Tutors assign grades to students and grades are important to students. For instance, getting a good grade in this first year second semester course is extremely important because in the Dutch educational system, students need to secure the so-called positive binding study advice (i.e., the permission to continue with the bachelor studies) after the completion of the first two bachelor semesters. Therefore, we feel that the student sample does not provide any disadvantage and is appropriate for testing our hypotheses.

\subsubsection{Sample}

The sample for this study were 376 students enrolled in the course. In total, 32 tutorial groups from nine tutors participated. The course coordinator was responsible for managing these tutors. Participation in the longitudinal study varied over the three consecutive measurements. At time 1, 349 responses were collected, 277 responses were collected at time 2, and 272 responses at time 3. The dropout group of 77 individuals did not differ in any significant way in terms of demographics and study constructs relative to the sample for whom complete data were available. Consequently, data provided by all 349 individuals were included in further data analysis. An analysis of the available demographics revealed that $54.14 \%$ of participants were male and $45.86 \%$ female. The average age of participants was 20.93 years with a minimum of 18 and a maximum of 28 years. Overall, $20.68 \%$ of participants came from the Netherlands, $51.50 \%$ from Germany, 7.14\%, from Belgium and 20.68\% from other countries. 
In spite of repeated assurances from the researchers, some participants (i.e., $29.30 \%$ ) fearing loss of anonymity did not respond to questions about demographics, such as their sex, age, and nationality.

\subsubsection{Data Collection Procedure}

Course coordinators are responsible for overseeing tutors. A few weeks prior to the start of the course, the course coordinator was contacted to seek approval and support for this research project. After securing his approval, the respective tutors for the course were invited to participate in the research project. Before each tutorial meeting, printed questionnaires were distributed to the tutors. Tutors then distributed the printed questionnaires amongst their students and students completed these questionnaires during class time.

The course was structured as follows: Students had to submit two individual course assignments during weeks two and four of this seven-week course. At the end of week six an additional assignment was due, in which students submitted a complete case report about a real-life HRM case. The two preceding assignments served as intermediate and preparatory tasks towards the final case-analysis report. Final grades for every student including individual subgrades for the different assignments were assigned by the tutor at the end of the course (i.e., during week seven). Data were collected to coincide with these assignments, namely during weeks two, four, and six, to capture the high-stake moments, in which students were primarily concerned about performing well and getting a good grade. Grades were assigned respectively by the tutor with the help of a grading rubric developed for each course assignment.

During all three waves, participants were assured anonymity in terms of personal responses through the use of a box installed in the classroom, where participants dropped their completed questionnaires. As with any longitudinal study, individual responses needed to be matched across the three measured time points for data analysis. Therefore, we asked participants to generate an anonymous code.

\subsubsection{Measures}

Validated scales were used to measure constructs. Slight wording changes were made to the items to reflect the educational and tutorial setting as well as to the tutorstudent relationship. The constructs were measured on a 5-point Likert scale ranging from 1 to 5 representing "strongly disagree" to "strongly agree."

Self-Esteem was measured once (at the first measurement moment) with the 10-item Self-Esteem Scale by Rosenberg (1979), which is a widely used measure of self-esteem and has demonstrated appropriate validity in empirical research (Crandall, 1973; Scheier, Carver, \& Bridges, 1994). The scale was originally developed to measure the self-esteem of high-school students and was later adapted for other groups. Sample 
items were "I feel that I am a person of worth" and "I take a positive attitude towards myself". In this study, the scale yielded a Cronbach's alpha of .85.

Ingratiation was measured three times with the 5-item scale developed by Bolino and Turnley (1999), based on the five IM tactics identified by Jones and Pittman (1982). Wording changes were made to the items in such a way that ingratiation behavior towards the tutor rather than colleagues was measured. Sample items included "I take an interest in my tutor's personal life so that he or she sees me as likable" and "I use flattery and favors towards my tutor to make him or her like me more". The Cronbach's alphas for this scale for time 1, 2, and 3, were .89, .91, and .93.

Control Variables. Political skill was measured once (at the first measurement moment) with a six-item scale developed by Ahearn, Ferris, Hochwarter, Douglas, and Ammeter (2004). Some authors use the terms IM and influence tactics interchangeably, one concrete behavioral example of influence tactics being political skill (e.g., Higgins \& Judge 2004; Judge \& Bretz, 1994; Wayne \& Ferris, 1990). Given the conceptual similarity to IM, we included political skill as a covariate. In addition, a study by Harris and colleagues (2007) showed that individuals with high levels of political skill achieved more desirable supervisor ratings as a result of impression management, and ingratiation use, compared to those low on political skill. Hence individuals high on political skill are more inclined to use ingratiation, compared to their counterparts. Sample items included, "I find it easy to envision myself in the position of others", and "I am able to make most people feel comfortable and at ease around me." The Cronbach's alpha for this scale was .80. Given the relatively high non-response rate with respect to participants' age, sex, and nationality, no demographics have been included as additional control variables.

\subsection{Results}

\subsubsection{Descriptive Statistics}

Descriptive statistics and correlations between study variables are reported in Table 4.1. Political skill relates positively to self-esteem, suggesting that individuals higher in political skill tend to hold higher levels of self-esteem $(r=23, p<.001)$. Self-esteem is negatively related to ingratiation at time 1 ( $r=-.09, p>.05), 2(r=-.24, p<.001)$ and 3 $(r=-.27, p<.001)$, indicating that individuals with low levels of self-esteem engage more in ingratiatory behaviors over time. Moreover, and as expected, ingratiation at time 1 is positively related to ingratiation at time $2(r=.51, p<.001)$ and $3(r=.48, p<$ .001). Ingratiation at time 2 is positively related to ingratiation at time $3(r=.70, p<$ .001), underlining the anticipated non-independent structure of our data. 
Table 4.1. Descriptive Statistics: Means, Standard Deviations, and Correlations

\begin{tabular}{|c|c|c|c|c|c|c|}
\hline & M & SD & 1 & 2 & 3 & 4 \\
\hline 1. Political Skill & 3.90 & .52 & -- & & & \\
\hline 2. Self-Esteem & 3.89 & .58 & $.23 * * *$ & -- & & \\
\hline 3. Ingratiation_T1 ${ }^{a}$ & 1.71 & .70 & .04 & -.09 & -- & \\
\hline 4. Ingratiation_T2 b & 2.06 & .79 & -.01 & $-.24 * * *$ & $.51^{* * *}$ & -- \\
\hline 5. Ingratiation_Т3 ${ }^{c}$ & 2.25 & .88 & .05 & $-.27 * * *$ & $.48 * * *$ & $.70 * * *$ \\
\hline
\end{tabular}

Note: $N=349$.

$* \mathrm{p}<.05 ; * * \mathrm{p}<.01 ; * * * \mathrm{p}<.001$.

a, b, c Ingratiation measured at time 1, 2, and 3 .

\subsubsection{Hypotheses Testing}

A random coefficient modeling (RCM) approach was chosen for analyzing the hierarchical growth model. A major benefit of RCM is its ability to examine change, both within-person (i.e., level 1) and between-person (i.e., level 2) over time. Bliese and Ployhart's (2002) guide for growth modeling by using RCM served as an orientation and provided the basis for a five-step model estimation approach. All analyses were conducted in $\mathrm{R}$ (version 3.2.0).

As a first step in the progression from a regression to a growth model, the so-called baseline model was set. This model does not comprise of any random effects and thus serves as a baseline for further analyses.

As a second step, a random intercept model was built. Here, we examined the properties of the dependent variable, ingratiation. First, we calculated the ICC1, which refers to the proportion of variance that resides at the between-person level (Bliese \& Ployhart, 2002). An ICC1 of (.34/.27+.34) implies that roughly $56 \%$ of variance in ingratiation is due to between-person differences whereas $44 \%$ is due to within-person variability. The considerable proportion of within-person variance provides support for the use of a random intercept multilevel growth model approach $(\Delta-2 * \log$ Lik: $220.56, p<.001)$ (see Model 1, Table 4.2). We also calculated the proportion of variance residing at the tutor level. An ICC1 of (.05/.57+.05) demonstrated that only $8 \%$ of variance in ingratiation is due to groups having the same tutor. For this reason, we decided not to include tutor level in the analysis.

In step 3, we determined whether there is significant slope variation among respondents by comparing two models, one in which the slope of time does not vary among respondents (random intercept, fixed slope model) and one in which the slope of time does vary (random intercept, random slope model). Results show that a random intercept, random slope model fits the data significantly better than a random intercept fixed slope model does ( $\Delta-2 * \log$ Lik: 40.99, $p<$.001) (see Model 2, Table 4.2). This finding confirms that there is significant variance in ingratiation use over time both within and between individuals. Given that a time-based random intercept random slope model fits the data best, the validity of the within-person design was evidenced. 
The results also show that time was positively associated with ingratiation (estimate = 0.26, $p<.001$ ), supporting Hypothesis 1 , that, as performance appraisal events draw closer, ingratiation use increases.

Table 4.2 Fixed and Random Effects for Models Predicting Ingratiatory Behaviors over Time

\begin{tabular}{|c|c|c|c|c|}
\hline & Null Model & Model 1 & Model 2 & Model 3 \\
\hline \multicolumn{5}{|l|}{ Fixed Effects } \\
\hline Intercept & $1.73^{* * *}(.04)$ & $1.73^{* * *}(.04)$ & $1.70 * * *(.05)$ & $1.74 * * *(.04)$ \\
\hline \multicolumn{5}{|l|}{ Main Effects } \\
\hline Time & & & $.26 * * *(.03)$ & $.26^{* * *}(.02)$ \\
\hline Self-Esteem & & & & $-.17 * *(.06)$ \\
\hline Political Skill & & & & $.06(.04)$ \\
\hline \multicolumn{5}{|l|}{ Two-way interaction } \\
\hline Time*Self-Esteem & & & & $-.11 * *(.04)$ \\
\hline \multicolumn{5}{|l|}{ Random Effects } \\
\hline $\begin{array}{ll}\text { Level 2: } & \text { intercept/intercept } \\
& \text { time/intercept } \\
& \text { time/time }\end{array}$ & & .34 & .27 & .17 \\
\hline Level 1: intercept/intercept & & .27 & .21 & .30 \\
\hline$-2 * \log$ Lik & 2123.68 & 1903.12 & 1862.13 & 1746.94 \\
\hline$\Delta-2 * \log$ Lik & 2123.68 & $220.56 * * *$ & $40.99 * * *$ & $115.19 * * *$ \\
\hline
\end{tabular}

Note: $\mathrm{N}=349$.

Numbers in parentheses are robust standard errors.

$* p<.05 ; * * p<.01 ; * * * p<.001$.

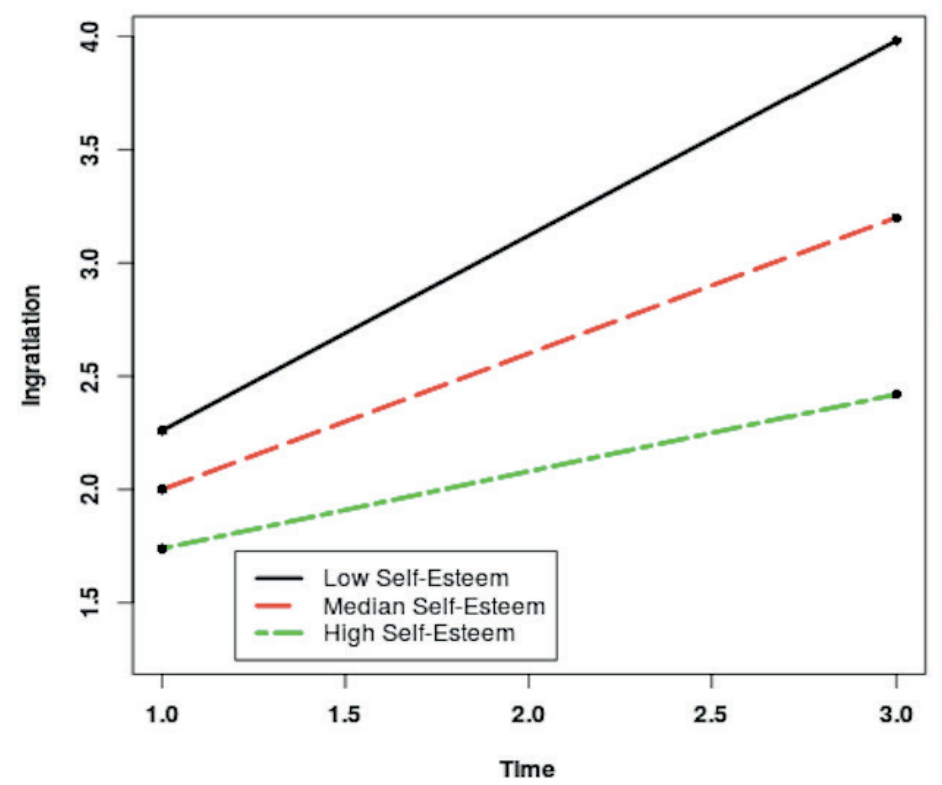

Figure 4.2 Interaction plot of Time and Self-Esteem on Ingratiation. 
In step 4, we investigate the degree of autocorrelation and heteroscedasticity within the sample, in order to account for the within-person error structure in the dataset. The fit of both models slightly improved compared to the previous model. Whereas the change in log Lik is not significant at the $5 \%$ significance level $(\Delta-2 * \log$ Lik: $0.82, p=.36)$ for autocorrelation, the change is significant at the $5 \%$ significance level $(\Delta-2 * \log$ Lik: $4.55, p<.05)$ for heteroscedasticity. Consequently, the error structure adjustment for heteroscedasticity was considered in the subsequent model.

In the final step, we added to the model the covariate political skill in conjunction with the interaction term time* self-esteem (Model 3, Table 4.2). In support of Hypothesis 2, results show a significant time* self-esteem interaction effect ( $\Delta-2 * \log$ Lik: 115.19, $p<.001$ ). The coefficient of political skill was only significant at $p<.10$ (estimate $=0.06$, $p=.07$ ), indicating that individuals with high levels of political skill make more use of ingratiation.

Figure 4.2 graphically shows the interaction effect. The figure graphically displays that self-esteem determines the rate of change in ingratiatory behaviors among individuals, such that individuals with low levels use more ingratiatory behaviors as time passes relative to their high self-esteem counterparts.

\subsection{Discussion}

In contrast to previous IM research examining ingratiation only as a between-individual construct, in our study, we conceptualized ingratiation as a within-individual construct by investigating the possibility that it also varies substantially within individuals. Based on Leary and Kowalski's (1990) proposition that IM changes as a function of changes in motivators, we argued that individuals engage in more ingratiation over time as the time to the performance appraisal event decreases. In line with our hypothesis, ingratiation use increased over time with approaching performance appraisals. In addition, based on premises of behavioral plasticity theory (BPT), we hypothesized that individuals with low levels of self-esteem make more use of ingratiation as salience increases.

\subsubsection{Theoretical Implications}

We extended BPT to 'dynamic' BPT by predicting that low self-esteem individuals are more susceptible to environmental events (i.e., approaching performance appraisals), leading to steeper increases in ingratiatory behaviors across time. As predicted, individuals with low levels of self-esteem used more ingratiatory behaviors as the performance appraisal event drew closer relative to their high self-esteem counterparts.

Our results have two theoretical implications, first for IM and ingratiation research, and second for behavioral plasticity theory (BPT). With respect to IM research, our data show that $44 \%$ of the variance in ingratiation occurred at the within-person level indi- 
cating that it is meaningful and important to examine ingratiation as an episodic behavior. The within person-variability in ingratiation suggests that individuals are not equally motivated to engage in ingratiation all the time but autonomously decide when to increase (or decrease) use of ingratiatory behaviors.

Furthermore, our results demonstrate that impending appraisals serve as instigators for individuals to gradually increase ingratiating behaviors. Individuals become more occupied with making a good impression as the appraisal gains in salience. Past research has primarily focused on studying individuals' 'peak' ingratiation during the focal event (e.g., job interview, performance appraisal). Our study draws attention to the fact that individuals already engage in ingratiation (and probably other types of IM) long before the focal event. This type of anticipatory IM has been neglected or has escaped the attention of researchers. Whereas a large body of knowledge has accumulated on predictors and outcomes of 'peak' ingratiation, very little is known about the dynamics leading up to it. Yet, it is important to identify the dynamic features of organizational phenomena, such as IM and to study changes of temporal parameters, as such an approach may lead to theoretical innovations and to a substantial expansion of possibilities for intervention (Roe, 2008). To the best of our knowledge, this study is the first to investigate dynamic features of ingratiation (or any other type of IM for that matter), and to identify factors that predict individual differences in change patterns.

Second, our study adds to BPT. According to BPT, contextual cues are likely to have a more significant effect on individuals with low (as opposed to high) self-esteem. Various contextual cues have been studied in this regard, including leadership (Avey, Palanski, \& Walumbwa, 2011), team characteristics (Duffy, Shaw, \& Stark, 2000), and myriad of work stressors (Ferris, Lian, Brown, Pang, \& Keeping, 2010; Jex \& Elacqua, 1999; Pierce et al., 1993; Saks \& Ashforth, 2000). These studies, in accordance with the original theory, focus on individuals' responses to (stable) contextual factors. Our study takes a different approach, by also accounting for time-sensitive elements in the environment (i.e., approaching performance appraisal events). As such, we aim to extend the original theory, and propose that self-esteem also influences behavioral responses to dynamic features in the environment. Our reasoning is that low self-esteem individuals, because they feel less equipped to deal with environmental cues, are more susceptible to and react more strongly to situational factors in the environment. Our study is a first step in testing this dynamic version of BPT, but clearly more work is needed to better understand when and why low and high self-esteem individuals respond differently to dynamic features in their environment.

\subsubsection{Limitations and Suggestions for Future Research}

Like any research, our study has some limitations that highlight areas for future research. First, our sample, comprising of Western European students pursuing a course taught using the problem-based learning pedagogy, may prompt external validity con- 
cerns. While the use of student subjects is not an inherent problem to research investigating psychological processes (Druckman \& Kam, 2011; Greenberg, 1987), behavioral plasticity theory has mainly been tested with working adults. Since self-presentational behaviors in an academic setting might be somewhat different from those of employees in an organizational setting, future research should therefore seek to replicate our study with a sample of working adults.

In a similar vein, it is possible that self-presentational behaviors of older people differ from those of younger people. In our sample, students are of a younger age compared to employees from a comparable organizational sample. From a theoretical perspective, older individuals are likely to engage in self-promotional behaviors more compared to younger individuals. Sturman (2003), in a meta-analysis, found employee age to relate to job performance, such that employees of an older age show lower task performance (e.g., because of a decline in productivity and motivation), compared to employees of a younger age. Relatedly, older employees can be anticipated to engage more in self-promotional behaviors in an attempt to counterbalance this reduction in productivity and motivation. As a result, higher average levels of ingratiation use could potentially be found in a working sample, compared to our student sample used. A replication study using organizations and employees helps to provide more detailed insights hereof.

Third, in this paper we developed the notion that ingratiatory behaviors are likely to increase over time with decreasing temporal distance to the performance appraisal event. This rationale is based on the idea that, as the appraisal event draws closer, the desirability of getting good evaluations increases, promoting increased use of ingratiatory behaviors. Despite this compelling reasoning, future research should investigate individual ingratiation behaviors in the absence of clear end goals, i.e. getting good evaluations. Doing so rules out the alternative suggestion that low self-esteem individuals simply engage more in ingratiation as the length of the relationship to the authority figure increases or that low self-esteem individuals learned such behaviors to be overly beneficial.

Fourth, the data for this study were collected over a relatively short period, six weeks in three bi-weekly measurements. The distinct measurement moments chosen across the six weeks coincided with when major assignments and case analyses were due; thus, enhancing the salience of receiving a good grade and motivating ingratiatory behaviors. It is possible that the relatively short time period may have impacted fluctuations observed in ingratiatory behaviors. Studying ingratiatory behaviors over a longer period may result in fluctuations in ingratiatory behaviors different from what we observed in this study. Future research would benefit from a replication study, examining how ingratiation behavior develops when studied over longer durations.

Fifth, common method bias is a concern as all measures were based on solely students' self-ratings, rather than on objective measures. However, Podsakoff, Mackenzie, and Podsakoff (2012) observed that this concern may be attenuated when constructs are measured over time and interaction effects are included, as was the case in our research. 


\subsubsection{Practical Implications}

Results of our study have several implications for practice. As the performance appraisal event draws closer, salience increases, leading to more ingratiatory behavior from low self-esteem individuals, suggesting that low self-esteem individuals use ingratiation as a coping mechanism. Low self-esteem individuals doubt their capabilities for achieving desired goals; thus, organizations should encourage supervisors to provide more mentorship to individuals with low levels of self-esteem. Such mentorship could lead to high quality relationships with supervisors precluding the necessity to engage in ingratiation. In addition, organizations could train low self-esteem individuals to learn more productive coping mechanisms that over time enhance self-esteem. Finally, a climate where on-going feedback is encouraged and practiced (instead of a once-a-year feedback), the yearly performance appraisal interview becomes less important taking away the motivation to engage in ingratiatory behaviors. Above that, such an environment offers employees, particularly those with low self-esteem, more opportunities to boost their selfesteem (Edwards \& Peccei, 2010).

\subsection{Conclusion}

Unlike previous research that studied ingratiation almost exclusively from a betweenperson perspective, we took a within-person perspective to theorize why the use of ingratiation increases over time and for whom. We found that the use of ingratiation increased as time to the performance appraisal event decreased, and consistent with behavioral plasticity theory (BPT), low self-esteem individuals ingratiated more as time progressed relative to high self-esteem individuals. Results highlight the need to study phenomena from both between and within-person perspectives in order to find out when and why behaviors such as IM, and other upward influence attempts, increase or decrease over time. 
Chapter

General Discussion and Conclusion 



\subsection{Introduction}

Previous impression management (IM) research has mainly investigated individual IM use on subsequent performance evaluations received, i.e. during the job interview or as an employee at work, by taking a cross-sectional perspective. Next to examining antecedents of IM use, another research stream studied the role of different contingencies, attempting to reduce the positive effect that IM has on performance ratings received. Whilst contingencies originating from structural formats of the interview have been investigated in different ways, knowledge on the effect that seemingly more trivial and subconscious contingencies of the interview can have on the favorableness of evaluations received is lacking.

Second, previous research typically investigated IM used by employees at the workplace by taking a retention of the current job, including current job features, as a given. In doing so, scholars somewhat suggested that IM is primarily used to make progress in the current job, that is for career development purposes, by being evaluated in a positive way. At the same time, IM can also be used by employees for other purposes, for instance when current job features are perceived to be at stake. As a result of changes in work processes, practices, and routines, employees may also be urged to engage in IM to retain current job features at stake.

Third, research, until today, presumed that individuals use IM at one particular highconsequence moment in time. Although a few longitudinal studies on IM exist, the focus lay on the development of IM outcomes (i.e., performance evaluations of supervisors) over time, resulting out of an individual's repeated IM use. In doing so, previous research overlooked that IM can also be used to different extents over a period of time such that there are moments in which an individual engages more or less in IM. The main objective of the dissertation was to advance current research on assertive IM tactics in the three above-mentioned ways by:

1) examining the interactive effect of different forms of IM used during the job interview and the spatial distance between the applicant and interviewer as a seemingly more trivial and subconscious contingency, affecting interviewer evaluations of the respective applicant

2) investigating IM use for another purpose at work next to increasing subsequent performance evaluations received, namely the attempt to retain current job features at stake caused by threat appraisal at the workplace

3) studying IM over time, as a function of increases in salience to achieve good evaluations, thereby suggesting that IM use also varies considerably within and not only between individuals over time.

Each of the three empirical chapters of the dissertation focused on one particular objective and thus contributed in different and unique ways to the research gaps stated 
above. Referring back to the introductory framework presented in the beginning of this dissertation (Figure 1.1, p. 25), IM acted as an independent variable in Chapter 2, whereas it acted as a dependent variable in Chapters 3 and 4 . Chapters 2 built the bridge between the individual and organizational level by studying an individual aspect such as the type of self-promotion used together with an organizational factor such as the spatial distance between the interviewer and interviewee. Similarly, also Chapter 3 bridged the individual and organizational level and studied a person's level of proactivity as an individual factor together with perceived control bestowed by the organization as an organizational factor. Chapter 4 took an individual-level perspective to examine within-person variation in IM use over time, contingent on an individual's level of selfesteem.

As the previous paragraph demonstrates, the dissertation approached three different assertive IM tactics (i.e., self-promotion, exemplification and ingratiation) as an integrative and dynamic concept which is not only employed by individuals in different contexts but also across time. In an attempt to answer the research questions, a variety of research designs have been used, ranging from experimental designs, to field studies, and growth modelling analysis. Below, the main findings of the different empirical chapters are summarized. Next, theoretical contributions of the different empirical chapters as well as the relations between those chapters are discussed. After that, practical implications for both targets and senders of IM are elaborated upon. Finally, limitations and evolving suggestions for future research are discussed.

\subsection{Summary of Main Findings}

In Chapter 2, the first empirical chapter, I examined the combined effect of selfpromotion (i.e., low versus high abstractness of language used) and spatial distance (i.e., close versus far) between the applicant and interviewer on the likelihood of being hired as rated by the interviewer. Based on premises of construal level theory (CLT) (Trope \& Liberman, 2010, I posited that low abstraction of self-promotion used is rated more favorably for a close spatial distance, whereas high abstraction of self-promotion used is rated more favorably for a far spatial distance. Results of both experiments were mainly in line with predictions of CLT. The results suggest that also subtler, and less conscious aspects can have a great impact on the favorableness of assessment made by the interviewer (i.e., the likelihood of being hired). The finding therefore points to an important and new boundary condition of self-promotional effectiveness, i.e. the spatial distance between the applicant and interviewer in the interview room.

In Chapter 3, the second empirical chapter of the dissertation, I studied IM, and more particularly exemplification, in a currently under-researched work context. Changes in work processes, practices, and routines cause employees to perceive current job features to be at stake (i.e., also referred to as job threat appraisal). Contrary to 
previous research, I presumed that, when experiencing an environmental trigger such as threat appraisal at work, employees are unlikely to engage in behaviors mainly out of a proactive motivation. Instead, employees may also display behaviors such as working longer hours for the sake of only "appearing" hard-working and committed at work, that is for IM purposes. The idea that individuals engage in behaviors to retain current resources at stake is also referred to as job preservation motivation (Shoss, 2017). Based on conservation of resources theory (CoR; Hobfoll 1989, 2001) stating that, when confronted with feelings of job threat, individuals strive to preserve current features (i.e., resources), an alternative theoretical rationale was offered as to why individuals engage in IM, and more specifically exemplification. To understand individual differences in exemplification use, a "dual" view of control was introduced: Job control (i.e., a form of control bestowed by the organization) and proactivity (i.e., a personal form of control), anticipating a three-way interaction effect. The results confirmed the hypothesized three-way interaction, such that perceptions of job threat are positively related to exemplification behaviors and that individuals feeling in control both of the job and themselves personally engage most in exemplification.

In Chapter 4, the third and last empirical chapter of the dissertation, I studied IM (i.e., ingratiation) as a construct that varies over time both within and between individuals throughout the progression of an academic course at university. Based on Leary and Kowalski (1990), I argued that, as the performance appraisal event is coming closer, individual goals (i.e., the desirability of achieving good evaluations) and values (i.e., the importance of achieving good evaluations) increase. It was hypothesized that, as the time to the appraisal event decreased, leading to increases in salience to achieve good outcomes, individuals started to engage more in ingratiation towards the target (i.e., the person responsible for final course evaluations). Further to that, and originating from behavioral plasticity theory (BPT) (Brockner, 1988), self-esteem was introduced as a contingency factor explaining inter-individual differences in intra-individual changes in the use of ingratiation. Results showed that the use of ingratiation increased as time to the performance appraisal event decreased, and showed this effect to be more pronounced for individuals low, relative to high, in self-esteem.

\subsection{Theoretical Implications}

The three empirical chapters added to current IM research by 1) studying a seemingly more trivial contingency factor affecting job interview outcomes, 2) studying IM in a less researched work context, and 3) studying IM as a behavior that is not only likely to vary between but also within individuals over time. The subsequent section elaborates in more detail how the three empirical chapters relate, by integrating the different theoretical perspectives used, hence discussing advancements in current IM research. 


\subsubsection{New Insights into Psychological Distance Driving Impression Management Use and Effectiveness}

The first empirical chapter (Chapter 2) of the dissertation studied spatial distance between the applicant and interviewer on selection biases. The chapter pointed out the importance of a seemingly more trivial factor, i.e. next to the structural format of the interview (e.g., interview structure; Tsai, Chen, \& Chiu, 2005, and interview length; Ellis, West, Ryan, \& DeShon, 2002), on subsequent performance evaluations of the applicant. In line with the construal compatibility effect (CCE), the chapter concluded that, whether more implicit or explicit information governs assessments made, seems to be a function of whether the information received (i.e., the abstractness of self-promotion used) is in congruence with the person receiving it (i.e., the spatial distance between the interviewer and the interviewee).

Chapter 4 studied temporal distance as another psychological distance dimension on individual IM (i.e., ingratiatory) behaviors over time. It was hypothesized that ingratiation varied considerably within individuals and that individuals increased ingratiatory behaviors over time with decreasing temporal distance to the performance appraisal event. Moreover, this effect was anticipated to be contingent on an individual's level of self-esteem, such that individuals holding low compared to high levels of self-esteem increased ingratiatory behaviors more steeply over time. The findings of Chapter 4 demonstrated that, as a result of temporal distance to the performance appraisal event, i.e. characterized by increases in salience to achieve good evaluations, an individual's motivation to engage in IM increases. The results were thus supportive of Leary's and Kowalski's (1990) idea that, with increases in values (i.e., the importance of achieving an outcome) and goals (i.e., the desirability of achieving an outcome), individuals engage increasingly more in ingratiation over time.

CLT has been used as a basis for Chapter 2 because the theory is able to predict IM effectiveness based on congruence (versus mismatch) between different forms of IM tactics used in combination with differences in spatial distance between the interviewer and interviewee. BPT has been employed as a backbone in Chapter 4 because the focus lay on individual IM use - that is behavioral responses, contingent on an individual's level of self-esteem with decreases in temporal distance to the performance appraisal event over time.

When integrating the findings of Chapters 2 and 4 , it becomes apparent that Chapter 2 mainly focused on IM effectiveness whereas Chapter 4 focused on IM prevalence. Chapter 2 has demonstrated that IM used by an applicant is more effective when the type of IM used is in congruence with the spatial distance to the object (i.e., participant). Chapter 4 has demonstrated that individual IM use (i.e., frequency) increases with decreasing temporal distance to the performance appraisal event. Applying CLT to Chapter 4, one might predict that not only IM frequency, as was demonstrated, but also the type of IM used and its subsequent impact on targets will change as the appraisal 
event draws closer. When applying the main premises of CLT to Chapter 4, one can therefore speculate about the overall IM effectiveness with decreasing distance to the appraisal event. The findings taken together seem to suggest that with decreasing distance to the actual performance evaluation, more direct and concrete (i.e., as opposed to more indirect and abstract) IM tactics result in more favorable performance evaluations. One expectation is that individuals would switch towards using more specific, selfpromotional speech as the course unfolds. I would also expect that targets (i.e., supervisors) evaluate self-promotional IM use more natural when it comes from individuals who are familiar with supervisors (i.e., who are in the inner circle).

\subsubsection{New Insights into Threat and Performance Appraisal Related to Impression} Management over Time

Chapter 3 of the dissertation studied IM in the context of job threat appraisal, triggered by changes in work processes, practices, and routines. Previous studies assumed that individuals who engage in positive behaviors, such as working more hours, do so mainly out of proactive motivation (Huang, Zhao, Niu, Ashford, \& Lee, 2013; Kang, Gold, \& Kim, 2012). Chapter 3 questioned this idea and argued that, once future job features are perceived to be at risk (i.e., typically leading to more rigid behaviors), an individual is more likely to engage in IM out of a job-preservation, and not proactive, motivation alone (Shoss, 2017). The results of Chapter 3, and in line with CoR theory, indicated that employees' threat appraisals at work trigger exemplification use, in an attempt to retain current resources at stake. More specifically, this relationship was contingent on the degree to which an individual felt in control of work processes and practices (i.e., was high in job control) and on an individual's pre-dispositional state aimed at influencing the environment of which the person is part (i.e., was high in proactivity).

Also Chapter 4 was based on the idea of performance appraisals, by arguing that ingratiation varies considerably within individuals and that individuals increase ingratiatory behaviors with impending performance appraisal events. Moreover, and in line with BPT, it was hypothesized that, in particular, low self-esteem individuals, because they feel less equipped to deal with environmental cues, are more sensitive to situational factors in the environment and thus react more strongly to dynamic features in the environment over time. The results confirmed the new and dynamic idea of BPT, such that individuals do not only engage in IM at the peak of the focal event (e.g., the actual performance appraisal event) but already prior to it. In this context, aspects such as approaching performance appraisals seem to act as instigators for IM use, and individuals with low, as opposed to high, self-esteem react more strongly to approaching performance appraisal events.

CoR theory in Chapter 3 has been used to connect perceived threat appraisal with the attempt to retain resources at risk, through the engagement in IM behaviors. BPT has been used in Chapter 4 to connect approaching performance appraisals to IM be- 
haviors over time, contingent on individual levels of self-esteem. Both findings together seem to suggest that threats throughout an individual's professional life can take different facets and forms, ranging from performance-related aspects (i.e., performance appraisals) to much broader aspects, comprising task responsibilities and relationships at stake (i.e., job threat appraisals), hence likely to influence individual IM behaviors in different ways.

When integrating the findings of Chapters 3 and 4, and applying CoR theory to Chapter 4 , the question arises as to whether decreasing temporal distance to the actual performance appraisal event would increase the perceived necessity to retain current resources at stake, that is the engagement in IM behaviors. By taking a longitudinal approach where the threat becomes more imminent over time, I would expect individuals to engage increasingly more in IM over time. Moreover, and in line with a paper by Schreurs, van Emmerik, Notelaers, and De Witte (2010), both self-esteem and control (i.e., including job control on the one hand and personal control on the other) are expected to act as buffers of uncertainty. As a consequence of reductions in perceived uncertainty, I would expect less IM use with higher levels of perceived control over time - opposed to what I found in Chapter 3 of the dissertation. Future research investigating this idea both cross-sectionally and over time would help to provide new insights into these controversial predictions.

\subsection{Limitations and Directions for Future Research}

The three empirical studies (Chapters 2, 3, and 4) of the dissertation, despite their strengths, also come along with limitations and potential areas for future research. First of all, out of the three empirical chapters of the dissertation, the data of one field study were cross-sectional, hence inferring the possibility of reverse-causality (Chapter 3) (Zapf, Dorman, \& Frese, 1996). At the same time, the theoretical justification (i.e., when experiencing job threats, individuals attempt to preserve current resources by investing in additional resources) provided in this chapter makes the idea that job threat appraisal impacts exemplification and not vice versa of lesser concern.

Second, Chapter 2 demonstrated, in the form of two experiments, that both spatial distance (i.e., between the applicant and the interviewer) and self-promotion used by the applicant (i.e., the abstractness of language used) in combination impact recruiter performance evaluations of the applicant. At the same time, the study did not take into consideration possible mediating mechanisms which may have caused the differences in performance evaluations. Relatedly, one possibility is that CLT impacts how information is memorized and stored. Alternatively, construal compatibility may influence the ease at which information is processed and retrieved by the interviewer. Preliminary evidence supporting the idea of processing fluency comes from research in the field of consumer behavior (Lee, Keller, \& Sternthal, 2010; White, MacDonnell, \& Dahl, 
2011). A third possibility for mediation is that construal compatibility impacts how information is evaluated such that congruent information is perceived as more credible, trustworthy or persuasive. In order to find out which of the distinct mediators eventually causes differences in performance evaluations, more future research is needed.

Third, the dissertation studied three distinct and specific contexts prone for individual IM use. Especially at the workplace, the reasons to engage in IM can be diverse. Chapter 3 of the dissertation demonstrated that, as a result of threat appraisal at work, employees also make use of IM out of a reactive (if not proactive) motivation. Similar as for the context of job threat appraisal, future research needs to consider the possibility of yet other purposes to engage in IM by moving away from the over-researched contexts of IM to a broader array of work contexts in which IM is used by individuals but also by organizations as a whole.

Fourth and finally, the third empirical chapter (Chapter 4) investigated individual IM use longitudinally, i.e. across a period of time, by proposing that there are moments in which an individual uses IM more or less. This idea opens up a completely new field of research in that it assumes that individuals already start to engage in IM long before the high-risk, focal event. Consequently, a number of new research questions unfold, including but not limited to how long before the focal event individuals start to engage in IM; how IM develops in the absence of a clear end goal (i.e., the salience to achieve good outcomes); the contingency effect of other personality characteristics of the individual next to the level of self-esteem or the possibility of classification into different risk stages during the development of the high-risk event (e.g., low, mid, high risk stage). A devotion of future IM research to the research questions stated above would provide new insights into the within-person variation of IM use over time.

\subsection{Practical Implications}

In life, and particularly in professional life, the skill to manage impressions is vital. Throughout an individual's professional life, IM can be used to boost subsequent performance appraisals and hence overall career chances. Yet, IM may pose benefits and risks for individuals and organizations. For the person evaluating (i.e., the target) and hence the organization, the result may be over-ratings of individual performance. Therefore, targets (i.e., including recruiters and supervisors) need to become increasingly aware of the effect that individual IM use can have on a variety of consequential decisions.

Several organizational interventions to overcome selection biases during job interviews exist, based on the effect that IM has on subsequent performance appraisals. Based on the findings of Chapter 2, interventions can range from interview trainings, teaching the interviewer how to pose more unambiguous and precise questions during the job interview, to overall standardizations of interview procedures. With respect to 
interview standardization, one intervention to reduce decision biases during job interviews is to balance out close and far spatial distances between the recruiter and applicant in the interview room. One concrete way of doing so may be to have a first round of interviews in the form of a virtual interview (i.e., via skype) in which recruiters get to know the applicant, and only then invite the applicant to the office for an on-site interview. Another intervention to reduce selection biases during job interviews is to have multiple recruiters assess the applicant who take different distances to the applicant in the interview room and who come up with one unanimous decision in the end.

Moreover, the findings of Chapter 3 stress the important role that organizations have when undergoing changes in work processes, practices, and routines. When work processes and practices are likely to change, organizations need to clearly articulate how current work processes and practices are affected and how employees can be an active part in this process. Besides that, and referring to the feeling of personal control, organizations can disburden individuals to cope when dealing with changes at the workplace. One way of doing so is to train employees in their general tendencies to engage in behaviors attempting to affect future change outcomes, that is by increasing their levels of proactivity. Another way is to invest time and effort in organizational communication with the intention to update employees about current work changes and to inform employees about the role they can take in this process. Based on the results of Chapter 4, organizations should also try to establish an active feedback climate, i.e. through regular performance appraisal meetings instead of once or twice-ayear performance appraisal meetings. Through this, the stake associated with performance appraisal meetings is reduced, on the one hand precluding the possibility to engage in IM and on the other hand creating a climate to develop individual levels of self-esteem.

IM also has important consequences for individuals using it. In this respect, using IM behaviors helps to retain current resources at stake, e.g. as a result of changes in work processes, practices, and routines. In line with the results of Chapter 3, in particular, individuals who feel in control of organizational processes and practices engage in jobpreserving behaviors such as IM. Above that, Chapter 4 has shown that IM acts as a catalyst for individuals with low levels of self-esteem in that it helps them to overcome personal feelings of doubt (i.e., the perceived capability to achieve desired goals). The results of Chapter 4 have demonstrated that especially individuals holding low levels of self-esteem increasingly engage in IM as the performance appraisal event approaches over time. Despite the positive effect that IM use can have for individuals to achieve their professional goals, there exist more productive mechanisms both for individuals themselves (i.e., engaging in speaking up/voice behaviors) and the organization (e.g., developing mentorship and training programs), helping individuals to reduce feelings of doubt, that is to develop their levels of self-esteem, and to take an active part in organizational work changes. 


\subsection{Conclusion}

The dissertation examined IM throughout an individual's professional life and identified three distinct contexts in which individual IM use is likely to impact future career outcomes, i.e. as an applicant during the job interview, as an employee at work, and with approaching performance appraisal events over time in an educational context. The dissertation, first of all, advanced our current knowledge about IM in that it studied the contingency effect of a seemingly more trivial and subconscious aspect of the job interview. I demonstrated that the spatial distance between the interviewer and applicant can have far-reaching consequences for interviewer evaluations of the respective applicant. Second, the dissertation has shown that employees do not only engage in IM to boost subsequent performance evaluations but also for other purposes; one being the retention of current job features at stake as a consequence of changes in work processes, practices, and routines. Third, I found strong support for the idea that individuals, next to using IM only once, also engage in IM over an extended period of time with decreasing temporal distance to the performance appraisal event. I thereby demonstrated that individuals do not only use IM in order to influence high-consequence situations at its peak, i.e. the actual performance appraisal event, but already engage in IM before the high-consequence event takes place. The latter idea also suggests that individuals autonomously decide when and to what extent to engage in IM. By adding to IM research in the named-above three ways, I not only emphasized the necessity to examine individual IM use in a variety of contexts but also longitudinally. The dissertation at hand represents a considerable pathway in these important movements. 

Valorization Addendum 



\section{Relevance}

During every-day life, and more particularly professional life, individuals constantly try to manage impressions because individuals are constantly appraised by others. The strategic use of behaviors to influence the image others have of someone is called impression management (IM) (Rosenfeld, Giacalone, \& Riordan, 1995). Targets of IM are typically influential others (i.e., supervisors) higher up the hierarchy (Rao, Schmidt, \& Murray, 1995). At the same time, the use of IM already starts before the actual performance appraisal evaluation - that is before the focal, high-stake event - and can go beyond the attempt to favorably influence supervisor evaluations. In this vein, individuals may also engage in IM to deal with threats at the workplace, such as the prevention of potential job feature loss from occurring in the near future.

We, as human beings, share some kind of value system, that is, a list of commonly accepted positive and negative personal values. Examples of positive values are, among others, to be a skillful, competent or likeable person. Examples of negative values are to be a lazy, stubborn or lonely person. Originated on the positive values mentioned (i.e., being skillful, competent or likeable), it is not surprising that one often-researched, high-stake context throughout the professional life is personnel selection, and more precisely the job interview (Bolino, Kacmar, Gilstrap, \& Turnley, 2008). This dissertation departed from the context of the job interview, and demonstrated that IM effectiveness, next to more structural formats of the interview, also depends on seemingly more trivial aspects of the job interview like the spatial distance between the interviewee and interviewer. The dissertation moved on by demonstrating that IM is, in fact, used in many more contexts and for different purposes than to boost subsequent performance evaluations received, e.g. as an employee at the workplace to counteract potential future job feature loss. Lastly, the dissertation took a longitudinal view and showed that individuals already start to engage in IM long before the actual high-stake event (i.e., the performance appraisal) takes place.

The findings show that engaging in IM behaviors throughout an individual's professional life does not only affect subsequent hiring chances and performance evaluations but also organizations and individuals more widely. For instance, IM use impacts how individuals deal with different types of job threats as a result of changes in work processes, practices, and routines, helping individuals to preserve resources at stake. IM use can therefore also improve overall employee well-being at the workplace and to reach attained professional goals. On the other hand, IM use can also impact overall organizational functioning by influencing how employees deal with both performance appraisal events and organizational work changes. 


\section{Target Groups}

The findings of this dissertation are valuable to recruiters, organizations, and individuals using IM, next to the academic community for whom this work is clearly valuable. For recruiters, IM use is connected to both opportunities and risks. On the one hand, IM use helps recruiters to identify who is fit for the job and who is not. However, the use of IM also comes along with downsides. In this vein, using IM tactics during the job interview increases the chance of selection biases, that is hiring a candidate who eventually turns out to be suboptimal for the job. IM use also affects organizations during later stages that is when used by employees at the workplace, to reduce feelings of job threat due to job features at stake. When undergoing changes in work routines, processes, and practices, organizations need to clearly communicate these changes, so that employees feel that they can be an active part in this process. For the individuals themselves, using IM can help to achieve attained goals and to get remedy by trying to retain current resources at stake and trying to actively influence future outcomes. Next to these target groups (i.e., organizations, recruiters, and individuals), the findings of IM research are also relevant for career coaches, and personal coaches. For instance, career coaches can use insights from IM research to simulate fictive job interviews and to prepare their clients for an effective job interview, thereby maximizing the chances of being hired for the job position. Personality coaches can use insights from the current dissertation to help individuals with personal development and in dealing with challenges related to work life (i.e., that is developing individual skills and work strategies to reach professional as well as personal goals).

\section{Implications}

Professional life is exposed to a variety of situations, in which creating a favorable impression is highly important. This part will focus on the most significant target groups, that is organizations, recruiters, and individuals using IM.

IM, first of all, has consequences for the organization as a whole, including overall organizational functioning (Giacalone \& Rosenfeld, 1991). One has to do with the standardization of interview procedures, including fixed interview formats, such as the presence of multiple assessors and the standardization of psychological distance (i.e., including but not limited to spatial distance) across the interview room. The dissertation has shown that seemingly trivial aspects such as the spatial distance between the interviewer and interviewee can have important consequences for who will be hired for a vacant job position. At the same time, the dissertation has shown that IM use is not only associated with risks for organizations during job interviews but also during later stages, that is, when used as an employee at the workplace. IM is typically used by employees at the workplace to affect future outcomes at stake (i.e., different job resources such as 
task responsibilities, general working conditions, as well as future job stability). In order to preclude employees from using too much IM at the workplace, it is important that firms clearly communicate current organizational work changes, and openly articulate if and what extent employees can take an active part in this process.

For recruiters, IM use is connected to both opportunities and risks (Weiss \& Feldman, 2006). On the one hand, IM use helps recruiters to identify who is fit for the job and who is not. However, the use of IM also comes along with downsides. That being said, using IM tactics during the job interview increases the chance of selection biases to occur. In doing so, the possibility of hiring a candidate who eventually appears to be suboptimal for the vacant job position in terms of required skills and competences increases. In order to circumvent or at least minimize the risks associated with selection biases, interviewers need to be able to identify the risks of possible selection biases during the job interview. In doing so, interviewers need to clearly observe the interview room and possible differences that exist between interview rooms. Above that, interviewers need to be able to identify whether IM, and more specifically, self-promotion tactics originate from the applicants themselves (i.e., low abstractness) and/or from linkages to successful others (i.e., high abstractness).

Finally, IM has consequences for the individuals using it (i.e., the senders). As outlined in the introductory part, individuals typically engage in IM behaviors because they want to achieve a desired image, such as being skillful or competent, e.g. during the job interview (Barrick, Shaffer, \& DeGrassi, 2009). At the same time, the achievement of desired images goes far beyond the job interview context and also depends on individual characteristics of the person using it. Especially for individuals who doubt their own capabilities (i.e., who are low in self-esteem), engaging in IM can help to achieve desired images in others. This, in turn, helps individuals to foster and develop their own individual levels of self-esteem. Another situation prone for individuals to engage in IM are contexts, in which individuals are surrounded by unstable working conditions (i.e., characterized by changes in work processes, practices, and routines). Once job features are likely to change in the future, engaging in IM can mean remedy, such that using IM not only means a way to retain current resources at stake but can also be a way to actively influence future outcomes.

\section{Innovative Activities}

The results of the current dissertation have shown that IM is not only used across different work contexts and for different motivational purposes, next to increasing performance evaluations received, but that IM is already used long before the actual highstake (i.e., performance appraisal) event takes place.

The dissertation departed from the context of job interviews and has demonstrated that spatial distance between the interviewer and interviewee impacts subsequent 
hiring decisions. As a consequence, one concrete intervention focuses on the standardization of interview procedures. One possible approach to achieve this is to first have a virtual interview for all candidates and only then invite interviewees for an on-site interview to the office. Another concrete solution is to establish a fixed committee of interview judges, who need to come up with one, unanimous decision, thereby cancelling out the effect of seemingly trivial aspects like the spatial distance to affect final interview outcomes.

Another starting point for possible interventions originates from training recruiters. Especially for on-site interviews (i.e., in interview rooms at the office), recruiters need to analyze the detailed setting of the interview room(s) used, potential differences, as well as the spatial separation between the interviewer and applicant therein. Furthermore, interviewers should receive trainings developing their ability to identify to what extent self-promotion tactics originate from the applicants themselves (i.e., low abstractness) and/or from linkages to successful others (i.e., high abstractness). This could, for instance, be practiced through simulated job interviews with the intention of practicing how to formulate unambiguous and precise interview questions, including posing detailed and experience-based questions (i.e., asking about previous job experiences) rather than situational questions (i.e., asking about an imaginary job-relevant situation).

IM has also been shown to affect organizations at later stages, that is when working at the organization as an employee, as employees may decide to engage in IM to preserve current job resources at stake. One concrete organizational intervention therefore pertains to fostering a transparent communication system, as this is especially meaningful to reduce employees' feelings of threat connected to changing work processes, practices, and routines. Another way to decrease perceived job threats of employees is to train individuals in their general beliefs and ability to affect future change outcomes by developing a sense of proactivity and self-esteem in employees, subsequently decreasing the necessity to use IM at the workplace. Concrete interventions to achieve this are mentorships, specifically targeted at individuals low on proactivity and self-esteem, and the creation of a regular feedback climate (i.e., including more regular and frequent performance appraisal meetings), taking away employees' perceived stake associated with performance appraisal events.

Finally, IM has implications for the individuals using IM themselves. This dissertation has shown that individuals use IM to retain current resources at stake, e.g. due to changes in work processes, practices, and routines. In particular, individuals who feel in control of organizational processes and practices (i.e., are high in job control) and who are highly proactive (i.e., are high in personal control) make more use of IM behaviors. Likewise, individuals low on self-esteem also use IM to gain security at the workplace. Although IM use can have positive effects for individuals to achieve professional goals, individuals should not alone trust in IM behaviors to achieve professional goals, but should simultaneously look out for more productive workplace behaviors, such as the engagement in speaking-up (e.g., voice) behaviors. By raising voice, employees can 
bring in constructive suggestions what organizations can do to reduce insecurity at the workplace, to improve communication during times of organizational work changes, and to make employees an active part in this process.

\section{Planning and Realization}

The findings of the dissertation can be traced by means of different monitorings. First, organizations, and personnel selection departments, in particular, can implement a yearly monitoring system to evaluate past years' hiring decisions and the quality of hired candidates. Indicators of high-quality decisions incorporate, but are not limited to, the hired candidate's overall performance (i.e., including total revenues generated), work presence and absenteeism, as well as turnover (intentions). Moreover, recruiters, in particular, should be briefed with respect to their perceived effectiveness of hiring decisions, including the identification of talented and suitable candidates. By reflecting on the effectiveness of current hiring processes, the necessity of required future job interview trainings connected to personnel selection can be identified.

Another measurement pertains to a yearly (or bi-yearly) monitor of organizational functioning, including organizational communication. Especially departments characterized by recent work changes including changes in work processes, practices, and routines, greatly benefit from such measures to keep track of how employees feel throughout the change process. These monitors should involve feelings and attitudes of the management direction on the one hand and feelings and attitudes of individual employees on the other. In terms of employees' feelings and attitudes, feedback on the perceived necessity to engage in behaviors such as IM as a remedy to deal with urgent job threats, serves as one indication of how the organization's communication structure is currently working.

A third realization plan for organizations is the implementation of a more active feedback climate, including more frequent performance evaluation meetings, than the nowadays common once or bi-yearly supervisor meetings. Employees worry about performance appraisal events long in advance, given that these meetings also affect opportunities for future promotions. As a result, individuals are likely to engage in behaviors such as IM already long before the actual appraisal event is taking place. The implementation of a more open feedback climate, and the execution of more regular and frequent (e.g., quarterly) performance appraisals help to reduce the stake of these events; hence also reducing the motivation to engage in behaviors like IM to increase subsequent performance appraisals received. 

Summary of the Dissertation 

The impressions we make on other people are important in every-day life, and especially in professional life. Throughout the professional life, individuals are constantly evaluated by others. The targets of IM are typically influential others, like e.g. supervisors higher up in the hierarchy (Rao, Schmidt, \& Murray, 1995). Therefore, individuals, during professional lives, constantly try to manage their own impressions, hoping to receive favorable assessments as a result. This phenomenon is referred to as impression management (IM), defined as the process whereby individuals seek to influence the image other people have of them (Rosenfeld, Giacalone, \& Riordan, 1995).

The dissertation at hand investigated IM during three distinct contexts across an individual's professional life, by also moving away from the mere motivation for IM - that is to solely increase performance evaluations received. The first empirical study looked at a job interview context, and examined how applicants' engagement in IM during a job interview affected interviewer evaluations of the respective applicant. The second empirical study investigated an organizational context, and examined the effect that perceived threat appraisal as a result of work changes had on individual IM use at work. The third empirical study originated from an educational context and examined the extent to which individuals throughout the progression of an academic course at university used increasingly more IM over time with decreasing temporal distance to the performance appraisal event.

With the three contexts studied, the dissertation added to previous IM research in three ways: First, IM research in the job interview context, until today, mainly looked at the effect of structural formats of the job interview, such as interview structure (Tsai, Chen, \& Chiu, 2005), and length (Peeters \& Lievens, 2006), and the use of multiple assessors (Ellis, West, Ryan, \& DeShon, 2004). At the same time, knowledge on the effect of less structural and seemingly more trivial contingency factors during the job interview is missing. Second, the majority of past IM research in the context of work took a retention of the actual job, including currently held job features, as a given. Next to the aim to boost performance evaluations received, employees at the workplace might also decide to engage in IM behaviors to retain current job features at stake in the near future (Fugate et al., 2012). This motivation is also referred to as job-preservation motivation (Shoss, 2017). Third, scholars, up to today, considered IM as behavior that fluctuates between, and not necessarily between, persons. As a result, only a very small amount of research examined the effect that individual IM use has over time, i.e. from a longitudinal perspective (Bolino, Klotz, \& Daniels, 2014; Wayne \& Liden, 1995), yet all focusing on subordinates' (repeated) IM use and the effect on supervisor evaluations over time.

The first empirical study of the dissertation examined two forms of self-promotion (i.e., direct/concrete and indirect/abstract) used by the applicant during the job interview in interaction with spatial distance (close and far) on subsequent performance evaluations by the interviewer. Originated on construal level theory (CLT), direct/concrete self-promotion was evaluated more favorably with a close spatial distance 
and indirect/abstract self-promotion was evaluated more favorably with a large spatial distance between the applicant and interviewer. The findings point to a trivial contingency, affecting the favorableness of final assessments made and hence the chance of being hired for a vacant job position. Based on the study's results, several interventions follow on the level of the interviewer and the organization as a whole. First of all, trainings with the intention to train interviewers in their abilities to identify possible selection biases (e.g., an analysis of the interview room) during the interview, seems an obvious starting point. Above that, interviewers should receive training on how to use unambiguous interview techniques, that is by focusing on detailed and experiencebased questions (i.e., asking about previous job experiences) rather than situational questions (i.e., asking about an imaginary job-relevant situation). At the same time, also organizational interventions such as overall standardizations of job interview processes, e.g. using multiple assessors who take different spatial distances in the interview room, and who need to come up to one, unanimous decision, provide a meaningful avenue.

The second empirical study investigated IM at work, and more specifically in the context of employees' job threat appraisal, triggered by changes in work processes, practices, and routines. In line with conservation of resources theory (CoR) the results showed that appraised job threat triggered subsequent exemplification use by the employee, in an attempt to retain current resources at stake. This relationship was found to be contingent on the extent to which the individual felt in control of work processes and practices (i.e., job control) and on the person's own pre-dispositional state aimed at influencing the environment (i.e., proactivity). Individuals high in both job control and proactivity were thus most likely to engage in exemplification. The study's results highlight the responsibilities organizations have when undergoing changes in work processes, practices, and routines. Organizations, on the one hand, need to communicate how current work processes and practices are affected and, on the other hand, what employees can do to become an active part in this process. With reference to the second contingency factor, i.e. personal control, organizations can help employees to cope with changes at the workplace, by developing their general tendencies to engage in behaviors to affect future change outcomes, that is by increasing their proactivity.

The third empirical chapter looked at IM in an educational context and postulated that individual IM use is likely to increase with decreasing temporal distance to the performance appraisal event. As appraisal events come closer in time, individual goals (i.e., the desirability of achieving a good outcome) and values (i.e., the importance of achieving a good outcome) increase. Based on premises of behavioral plasticity theory (BPT), a dynamic element was added, finding support for the idea that individuals with low rather than high self-esteem engaged in more ingratiatory behaviors as the performance appraisal approached. One concrete intervention following from the study's results is to establish an active feedback climate, i.e. through regular performance appraisal meetings instead of focusing on once or twice-a-year performance appraisal meetings. In doing so, organizations can reduce the stake associated with performance 
appraisal meetings. Above that, organizations should try to create a climate allowing employees to develop individual levels of self-esteem, hence reducing the necessity for individuals to engage in IM.

The dissertation has shown that individuals do not only engage in IM in different contexts throughout their professional lives but also across time. By applying a number of different theories, the dissertation has shown that threat is a prevailing factor during professional life which can take on different facets and forms, including performancerelated aspects but also more general aspects such as job features at stake. The dissertation also revealed the effect that different forms of psychological distance, such as spatial and temporal distance, can have on individual IM use on the one hand and IM effectiveness as rated by its targets on the other hand. 

Appendices 



\section{Appendix A}

\section{Overview of interview questions and answers}

"My first question for you: Tell me what you know about this company."

The abstract answer included reasons such as the "good reputation" and wanting to be "...part of the great atmosphere..." - which refers to emphasizing social connections and referred to reasons why the person made a certain claim, for example "...in order to make clients'(guests') purchasing experience (vacation) memorable". In contrast, the concrete response explained information about the company by also referring to the applicant's concrete skills and experiences and how these would be of value, for example, "I would like to share my experience and add value to this company. Since, I have good communication skills and know how to pamper clients (guests)".

"Why should we hire you for this position?"

The abstract answer mentioned the applicant having "a broad social network" and making general statements such as: "In my last job, I always fulfilled my tasks with passion, and would do my utmost to achieve the best outcomes". The concrete answer mentioned more individual explicit qualifications "I am qualified with both a bachelor's and a master's degree in organization" and explained how "...specific knowledge and expertise that I have about leadership and in teaching will help me guide associates within this company".

"Tell me about what role you usually assume in a team setting"

The abstract version stated the answer in general terms such as "I have great leadership and communication skills" and went on to conclude "I usually found myself taking charge of the situation". The concrete answer started with this conclusion and then gave a specific example of such a situation "In a project, I took charge early on and helped our group set deadlines, and I helped to keep everyone accountable for their own part of the project"

"What are you most proud of accomplishing in your life so far?"

The abstract answer mentioned the reputation of the organization ".... working at a university that has over 15,000 students, and this university received a Triple Crown accreditation, and the master's program in international business is ranked as one of the top 25 business programs in the world" and "...their well-skilled professors and teachers, and students who earn high grades...". The concrete answer discussed an internship and explained what specific tasks the applicant had done successfully "I had to prepare the reports and present the results in front of the board of directors. When the project was over, they asked me whether I would like to be the team leader for the upcoming project". 
"What three things are you bringing that no-one else would?"

The abstract answer gave general statements about the person's characteristics, "I have a lot of energy" and "I'm flexible" and mentioned social connections, "My family says I have a good sense of humor". The concrete answer mentioned things like "I know how to..." (e.g., talk to a large group of people) and "I can explain things in a clear way, so others understand easily what I expect from them". 


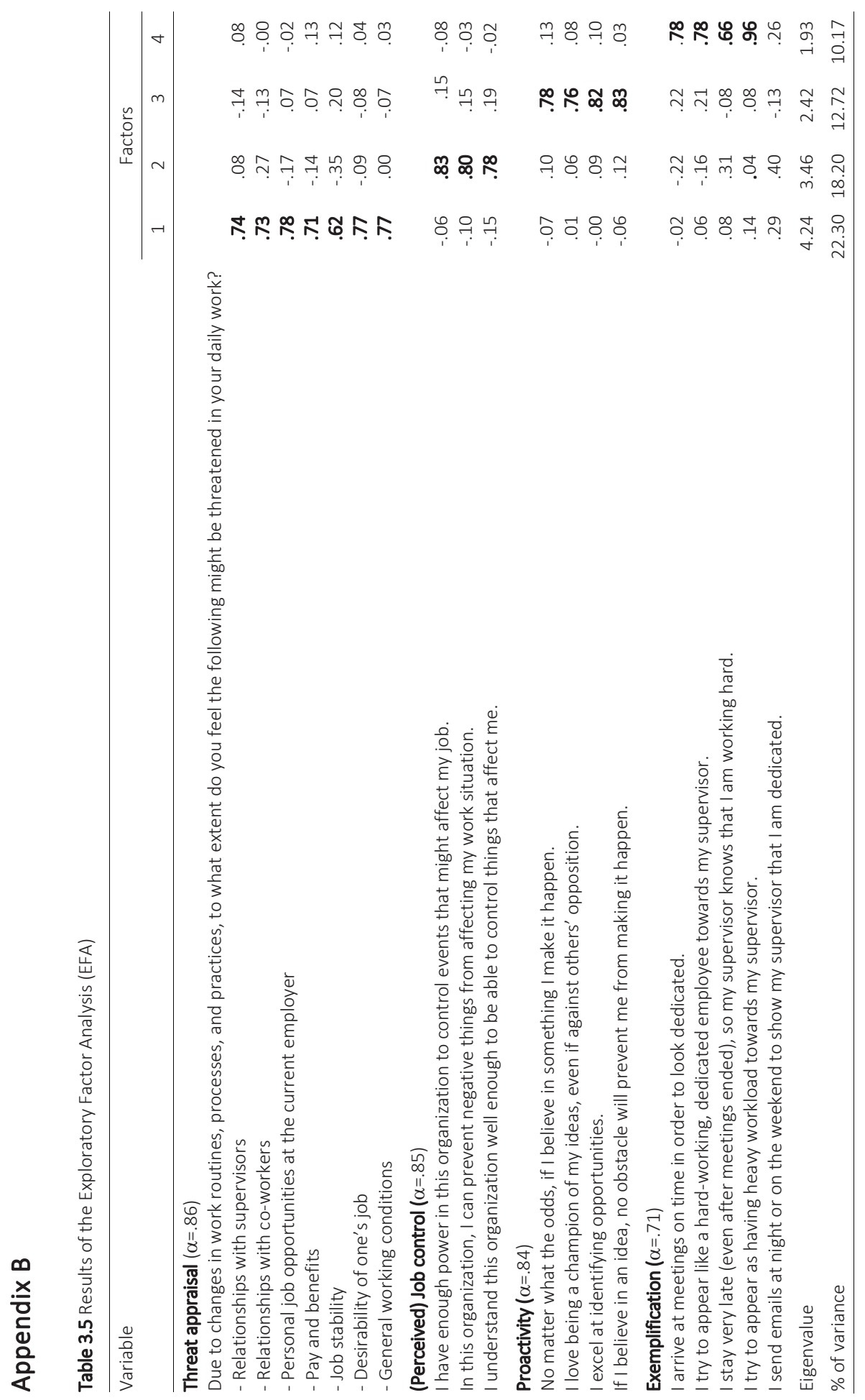





\section{References}

Ahearn, K. K., Ferris, G. R., Hochwarter, W. A., Douglas, C., \& Ammeter, A. P. (2004). Leader political skill and team performance. Journal of Management, 30(3), 309327. https://doi.org/10.1016/j.jm.2003.01.004

Aiken, L. S., \& West, S. G. (1991). Multiple regression: Testing and interpreting interactions. New York, NY: Sage.

Amrein, A. L., \& Berliner, D. C. (2002). High-stakes testing \& student learning. Education Policy Analysis Archives, 10(18), 1-74. https://doi.org/10.14507/epaa.v10n18.2002

Andrews, M. C., \& Kacmar, K. M. (2001). Discriminating among organizational politics, justice, and support. Journal of Organizational Behavior, 22(4), 347-36. https://doi.org/10.1002/job.92

Ashford, S. J. (1988). Individual strategies for coping with stress during organizational transitions. The Journal of Applied Behavioral Science, 24(1), 19-36. https://doi.org/10.1177/0021886388241005

Ashford, S. J., Lee, C., \& Bobko, P. (1989). Content, cause, and consequences of job insecurity: A theory-based measure and substantive test. Academy of Management Journal, 32(4), 803-829. https://doi.org/ 10.5465/256569

Ashford, S. J., \& Northcraft, G. B. (1992). Conveying more (or less) than we realize: The role of impression-management in feedback-seeking. Organizational Behavior and Human Decision Processes, 53(3), 310-334. https://doi.org/10.1016/07495978(92)90068-I

Avey, J. B., Palanski, M. E., \& Walumbwa, F. O. (2011). When leadership goes unnoticed: The moderating role of follower self-esteem on the relationship between ethical leadership and follower behavior. Journal of Business Ethics, 98(4), 573-582. https://doi.org/10.1007/s10551-010-0610-2

B

Bar-Anan, Y., Liberman, N., \& Trope, Y. (2006). The association between psychological distance and construal level: Evidence from an implicit association test. Journal of Experimental Psychology, 135(4), 609-622. https://doi.org/10.1037/00963445.135.4.609 
Bargh, J. A., \& Chartrand, T. L. (2000). The mind in the middle. In H. Reis \& C. Judd (Eds.), Handbook of Research Methods in Social and Personality Psychology, 253-285. New York, NY: Cambridge University Press. https://doi.org/10.1017/CBO978 0511996481

Barling, J., \& Gallagher, D. G. (1996). Part-time employment. In C.L. Cooper \& I.T. Robertson (Eds.), International Review of Industrial and Organizational Psychology (pp. 241-277). Chichester, UK: Wiley

Barrick, M. R., Shaffer, J. A., \& DeGrassi, S. W. (2009). What you see may not be what you get: Relationships among self-presentation tactics and ratings of interview and job performance. Journal of Applied Psychology, 94(6), 1394-1411. https://doi.org/10.1037/a0016532

Bateman, T. S., \& Crant, J. M. (1993). The proactive component of organizational behavior: A measure and correlates. Journal of Organizational Behavior, 14(2), 103-118. https://doi.org/10.1002/job.4030140202

Beal, D. J., Weiss, H. M., Barros, E., \& MacDermid, S. M. (2005). An episodic process model of affective influences on performance. Journal of Applied Psychology, 90(6), 1054-1068. https://doi.org/10.1037/0021-9010.90.6.1054

Becker, T. E., \& Martin, S. L. (1995). Trying to look bad at work: Methods and motives for managing poor impressions in organizations. Academy of Management Journal, 38(1), 174-199. https://doi.org/10.5465/256732

Bentler, P. M. (2007). Can scientifically useful hypotheses be tested with correlations? American Psychologist, 62(8), 772-782. https://doi.org/10.1037/0003066X.62.8.772

Berman, J. Z., Levine, E. E., Barasch, A., \& Small, D. A. (2015). The braggart's dilemma: On the social rewards and penalties of advertising prosocial behavior. Journal of Marketing Research, 52(1), 90-104. https://doi.org/10.1509/jmr.14.0002

Bliese, P. D., \& Ployhart, R. E. (2002). Growth modeling using random coefficient models: Model building, testing, and illustrations. Organizational Research Methods, 5(4), 362-387. https://doi.org/10.1177\%2F109442802237116

Bolino, M. C., Kacmar, K. M., Turnley, W. H., \& Gilstrap, J. B. (2008). A multi-level review of impression management motives and behaviors. Journal of Management, 34(6), 1080-1109. https://doi.org/10.1177/0149206308324325

Bolino, M., C. Klotz, A., \& Daniels, D. (2014). The impact of impression management over time. Journal of Managerial Psychology, 29(3), 266-284. https://doi.org/10.1108/JMP-10-2012-0290

Bolino, M., Long, D., \& Turnley, W. (2016). Impression management in organizations: Critical questions, answers, and areas for future research. Annual Review of Organizational Psychology and Organizational Behavior, 3, 377-406. https://doi.org/10. 1146/annurev-orgpsych-041015-062337 
Bolino, M. C., \& Turnley, W. H. (1999). Measuring impression management in organizations: A scale development based on the Jones and Pittman taxonomy. Organizational Research Methods, 2(2), 187-206. https://doi.org/10.1177/109442819 922005

Bolino, M. C., \& Turnley, W. H. (2003). More than one way to make an impression: Exploring profiles of impression management. Journal of Management, 29(2), 141160. https://doi.org/10.1016/S0149-2063(02)00212-X

Bolino, M. C., Varela, J. A., Bande, B., \& Turnley, W. H. (2006). The impact of impressionmanagement tactics on supervisor ratings of organizational citizenship behavior. Journal of Organizational Behavior, 27(3), 281-297. https://doi.org/10.1002/job.379

Bourdage, J. S., Wiltshire, J., \& Lee, K. (2015). Personality and workplace impression management: Correlates and implications. Journal of Applied Psychology, 100(2), 537-546. https://doi.org/10.1037/a0037942

Bozeman, D. P., \& Kacmar, K. M. (1997). A cybernetic model of impression management processes in organizations. Organizational Behavior and Human Decision Processes, 69(1), 9-30. https://doi.org/10.1006/obhd.1996.2669

Brockner, J. (1988). Self-esteem at work: Research, theory, and practice. Lexington, Mass: Lexington Books.

Browne, M. W., \& Cudeck, R. (1993). Alternative ways of assessing model fit. Sage Focus Editions, 154, 136-136. https://doi.org/10.1177/0049124192021002005

Byrne, D., Rasche, L., \& Kelley, K. (1974). When "I like you" indicates disagreement an experimental differentiation of information and affect. Journal of Research in Personality, 8(3), 207-217. https://doi.org/10.1016/0092-6566(74)90032-4

C

Caesens, G., Marique, G., \& Stinglhamber, F. (2014). The relationship between perceived organizational support and affective commitment. Journal of Personnel Psychology, 13(4), 167-173. https://doi.org/10.1027/1866-5888/a000112

Chaiken, S., \& Trope, Y. (Eds.). (1999). Dual-process theories in social psychology. New York, NY: Guilford Press.

Chandler, M., Kennedy, P., \& Sandhu, N. (2007). The association between threat appraisals and psychological adjustment in partners of people with spinal cord injuries. Rehabilitation Psychology, 52(4), 470-477. https://doi.org/10.1037/00905550.52.4.470

Chapman, D. S., \& Webster, J. (2003). The use of technologies in the recruiting, screening, and selection processes for job candidates. International Journal of Selection and Assessment, 11(2), 113-120. https://doi.org/10.1111/1468-2389.00234 
Chen, C. C., Wen-Fen Yang, I., \& Lin, W. C. (2010). Applicant impression management in job interview: The moderating role of interviewer affectivity. Journal of Occupational and Organizational Psychology, 83(3), 739-757. https://doi.org/10.1348/096317 909X473895

Chen, S., Westman, M., \& Eden, D. (2009). Impact of enhanced resources on anticipatory stress and adjustment to new information technology: A field-experimental test of conservation of resources theory. Journal of Occupational Health Psychology, 14(3), 219-230. https://doi.org/10.1037/a0015282

Cheng, G. H. L., \& Chan, D. K. S. (2008). Who suffers more from job insecurity? A metaanalytic review. Applied Psychology, 57(2), 272-303. https://doi.org/10.1111/ j.1464-0597.2007.00312.x

Cialdini, R. B., Borden, R. J., Thorne, A., Walker, M. R., Freeman, S., \& Sloan, L. R. (1976). Basking in reflected glory: 3 (football) field studies. Journal of Personality and Social Psychology, 34, 366-375. https://doi.org/10.1037/0022-3514.34.3.366

Cialdini, R. B., \& De Nicholas, M. E. (1989). Self-presentation by association. Journal of Personality and Social Psychology, 57(4), 626-631. https://doi.org/10.1037/00223514.57.4.626

Cooper, C. D. (2005). Just joking around? Employee humor expression as an ingratiatory behavior. Academy of Management Review, 30(4), 765-776. https://doi.org/ 10.5465/amr.2005.18378877

Crandall, R. (1973). The measurement of self-esteem and related constructs. In J. P. Robinson and P. R. Shaver (Eds.), Measures of Social Psychological Attitudes, (pp. 45-167). Ann Arbor, Michigan: University of Michigan Press.

D

Dawson, J. F., \& Richter, A. W. (2006). Probing three-way interactions in moderated multiple regression: Development and application of a slope difference test. Journal of Applied Psychology, 91(4), 917-926. https://doi.org/10.1037/0021-9010.91.4.917

De Cuyper, N., Bernhard-Oettel, C., Berntson, E., De Witte, H., \& Alarco, B. (2008). Employability and employees' well-being: Mediation by job insecurity. Applied Psychology, 57(3), 488-509. https://doi.org/10.1111/j.1464-0597.2008.00332.x

De Cuyper, N., Schreurs, B., Van der Elst, T., Baillien, E., \& De Witte, H. (2014). Exemplification and perceived job insecurity: Associations with self-rated performance and emotional exhaustion. Journal of Personnel Psychology, 14(1), 1-10. https://doi.org/10.1027/1866-5888/a000099

Demerouti, E., Bakker, A. B., Nachreiner, F., \& Schaufeli, W. B. (2001). The job demandsresources model of burnout. Journal of Applied psychology, 86(3), 499-512. https://doi.org/101037//0021-9010863499 
Douglas, K. M., \& Sutton, R. M. (2010). By their words ye shall know them: Language abstraction and the likeability of describers. European Journal of Social Psychology, 40(2), 366-374. https://doi.org/10.1002/ejsp.634

Drachman, D., \& Insko, C. A. (1978). The extra credit effect in interpersonal attraction. Journal of Experimental Social Psychology, 14(5), 458-465. https://doi.org/ 10.1016/0022-1031(78)90042-2

Druckman, J. N., \& Kam, C. D. (2011). Students as experimental participants. Cambridge Handbook of Experimental Political Science, 1, 41-57. https://doi.org/10.1017/ CBO9780511921452.004

Duffy, M. K., Shaw, J. D., \& Stark, E. M. (2000). Performance and satisfaction in conflicted interdependent groups: When and how does self-esteem make a difference? Academy of Management Journal, 43(4), 772-782. https://doi.org/10.5465/ 1556367

Dushane, M. (2015). Re: Five trends for talent acquisition in 2016. Retrieved from: https://www.recruiter.com/i/5-trends-for-talent-acquisition-in-2016/

Dutton, J. E., \& Ashford, S. J. (1993). Selling issues to top management. Academy of Management Review, 18(3), 397-428. https://doi.org/10.2307/258903

\section{E}

Edwards, M. R., \& Peccei, R. (2010). Perceived organizational support, organizational identification, and employee outcomes. Journal of Personnel Psychology, 9(1), 1726. https://doi.org/10.1027/1866-5888/a000007

Ellis, A. P. J., West, B. J., Ryan, A. M., \& DeShon, R. P. (2002). The use of impression management tactics in structured interviews: A function of question type? Journal of Applied Psychology, 87(6), 1200-1208. https://doi.org/10.1037/0021-9010.87. 6.1200

$\mathbf{F}$

Ferris, G. R., \& Hochwarter, W. A. (2011). Organizational politics. APA Handbook of Industrial and Organizational Psychology, 3, 435-459.

Ferris, G. R., Judge, T. A., Rowland, K. M., \& Fitzgibbons, D. E. (1994). Subordinate influence and the performance evaluation process: Test of a model. Organizational Behavior and Human Decision Processes, 58(1), 101-135. https://doi.org/10.1006/ obhd.1994.1030

Ferris, D. L., Lian, H., Brown, D. J., Pang, F. X., \& Keeping, L. M. (2010). Self-esteem and job performance: The moderating role of self-esteem contingencies. Personnel Psychology, 63(3), 561-593. https://doi.org/10.1111/j.1744-6570.2010.01181.x 
Fiedler, K. (2007). Construal level theory as an integrative framework for behavioral decision-making research and consumer psychology. Journal of Consumer Psychology, 17(2), 101-106. https://doi.org/10.1016/S1057-7408(07)70015-3

Fiske, S. T., \& Taylor, S. E. (1991). Social cognition (2nd ed.). New York, NY: McGraw-Hill.

Fletcher, R. (2013). Practical methods of optimization (2nd edition.). Chichester, UK: John Wiley \& Sons Ldt.

Foulk, T.A., \& Long, D. M. (2016). Impressed by impression management: Newcomer reactions to ingratiated supervisors. Journal of Applied Psychology, 101(10), 14871497. https://doi.org/10.1037/apl0000146

Fugate, M., Kinicki, A. J., \& Prussia, G. E. (2008). Employee coping with organizational change: An examination of alternative theoretical perspectives and models. Personnel Psychology, 61(1), 1-36. https://doi.org/10.1111/j.1744-6570.2008.00104.x

Fugate, M., Prussia, G. E., \& Kinicki, A. J. (2012). Managing employee withdrawal during organizational change: The role of threat appraisal. Journal of Management, 38(3), 890-914. https://doi.org/10.1177/0149206309352881

Fujita, K., Eyal, T., Chaiken, S., Trope, Y., \& Liberman, N. (2008). Influencing attitudes toward near and distant objects. Journal of Experimental Social Psychology, 44(3), 562-572. https://doi.org/10.1016/j.jesp.2007.10.005

Fujita, K., Henderson, M. D., Eng, J., Trope, Y., \& Liberman, N. (2006). Spatial distance and mental construal of social events. Psychological Science, 17(4), 278-282. https://doi.org/10.1111/j.1467-9280.2006.01698.x

G

Gardner, W. L., \& Martinko, M. J. (1988). Impression management in organizations. Journal of Management, 14(2), 321-338. https://doi.org/10.1177/014920638 801400210

Giacalone, R. A., \& Rosenfeld, P. (1986). Self-presentation and self-promotion in an organizational setting. The Journal of Social Psychology, 126(3), 321-326. https://doi.org/10.1080/00224545.1986.9713592

Giacalone, R. \& Rosenfeld, P. (1991). Applied impression management: How imagemaking affects managerial decisions. Newbury Park, CA: Sage Publications.

Gilmore, D. C., \& Ferris, G. R. (1989). The effects of applicant impression management tactics on interviewer judgments. Journal of Management, 15(4), 557-564. https://doi.org/10.1177/014920638901500405

Goffman, E. (1959). The presentation of self in everyday life. New York, NY: Doubleday Anchor Books. 
Goldberg, C. B. (2005). Relational demography and similarity-attraction in interview assessments and subsequent offer decisions: are we missing something? Group \& Organization Management, 30(6), 597-624. https://doi.org/10.1177/10596011 04267661

Gordon, R. A. (1996). Impact of ingratiation on judgments and evaluations: A metaanalytic investigation. Journal of Personality and Social Psychology, 71(1), 54-70. https://doi.org/10.1037/0022-3514.71.1.54

Gould, S., \& Penley, L. E. (1984). Career strategies and salary progression: A study of their relationships in a municipal bureaucracy. Organizational Behavior and Human Performance, 34(2), 244-265. https://doi.org/10.1016/0030-5073(84)90006-0

Graves, L. M., \& Powell, G. N. (1995). The effect of sex-similarity on recruiters' evaluations of actual applicants: a test of the similarity-attraction paradigm. Personnel Psychology, 48(1), 85-98. https://doi.org/10.1111/j.1744-6570.1995.tb01747.x

Greenberg, J. (1987). The college sophomore as guinea pig: Setting the record straight. Academy of Management Review, 12(1), 157-159. https://doi.org/10.2307/258001

Gilboa, S., Shirom, A., Fried, Y., \& Cooper, C. (2008). A meta-analysis of work demand stressors and job performance: Examining main and moderating effects. Personnel Psychology, 61(2), 227-271. https://doi.org/10.1111/j.1744-6570.2008.00113.x

Griffin, M. A., Neal, A., \& Parker, S. K. (2007). A new model of work role performance: Positive behavior in uncertain and interdependent contexts. Academy of Management Journal, 50(2), 327-347. https://doi.org/10.5465/amj.2007.24634438

H

Halbesleben, J. R., Neveu, J. P., Paustian-Underdahl, S. C., \& Westman, M. (2014). Getting to the "COR": Understanding the role of resources in conservation of resources theory. Journal of Management, 4O(5), 1334-1364. https://doi.org/10.1177/014920 6314527130

Hansen, J., \& Wänke, M. (2010). Truth from language and truth from fit: The impact of linguistic concreteness and level of construal on subjective truth. Personality and Social Psychology Bulletin, 36(11), 1576-1588. https://doi.org/10.1177/0146167 210386238

Harris, K. J., Kacmar, K. M., Zivnuska, S., \& Shaw, J. D. (2007). The impact of political skill on impression management effectiveness. Journal of Applied Psychology, 92(1), 278-285. https://doi.org/10.1037/0021-9010.92.1.278

Heaney, C. A., Israel, B. A., \& House, J. S. (1994). Chronic job insecurity among automobile workers: Effects on job satisfaction and health. Social Science \& Medicine, 38(10), 1431-1437. https://doi.org/10.1016/0277-9536(94)90281-X 
Hellgren, J., Sverke, M., \& Isaksson, K. (1999). A two-dimensional approach to job insecurity: Consequences for employee attitudes and well-being. European Journal of Work and Organizational Psychology, 8(2), 179-195. https://doi.org/10.1080/ 135943299398311

Henderson, M. D., Fujita, K., Trope, Y., \& Liberman, N. (2006). Transcending the 'here': The effect of spatial distance on social judgment. Journal of Personality and Social Psychology, 91(5), 845-856. https://doi.org/10.1037/0022-3514.91.5.845

Higgins, R. L., \& Berglas, S. (1990). The maintenance and treatment of selfhandicapping. In Self-Handicapping (pp. 187-238). New York, NY: Plenum.

Higgins, E. T., Idson, L. C., Freitas, A. L., Spiegel, S., \& Molden, D. C. (2003). Transfer of value from fit. Journal of Personality and Social Psychology, 84(6), 1140-1153. https://doi.org/10.1037/0022-3514.84.6.1140

Higgins, C. A., \& Judge, T. A. (2004). The effect of applicant influence tactics on recruiter perceptions of fit and hiring recommendations: A field study. Journal of Applied Psychology, 89(4), 622-632. https://doi.org/10.1037/0021-9010.89.4.622

Higgins, C. A., Judge, T. A., \& Ferris, G. R. (2003). Influence tactics and work outcomes: A meta-analysis. Journal of Organizational Behavior, 24(1), 89-106. https://doi.org/10.1002/job.181

Higgins, R. L., Snyder, C. R., \& Berglas, S. (2013). Self-handicapping: The paradox that isn't. New York, NY: Plenum.

Hobfoll, S. E. (1989). Conservation of resources: A new attempt at conceptualizing stress. American Psychologist, 44(3), 513-524. https://doi.org/10.1037/0003066X.44.3.513

Hobfoll, S. E. (2001). The influence of culture, community, and the nested-self in the stress process: advancing conservation of resources theory. Applied Psychology, 50(3), 337-421. https://doi.org/10.1111/1464-0597.00062

Hobfoll, S. E., Johnson, R. J., Ennis, N., \& Jackson, A. P. (2003). Resource loss, resource gain, and emotional outcomes among inner city women. Journal of personality and social psychology, 84(3), 632. https://doi.org/10.1037/0022-3514.84.3.632

Huang, C. (2013). Relation between self-esteem and socially desirable responding and the role of socially desirable responding in the relation between self-esteem and performance. European Journal of Psychology of Education, 28(3), 663-683. https://doi.org/10.1007/s10212-012-0134-5

Huang, G. H., Zhao, H. H., Niu, X. Y., Ashford, S. J., \& Lee, C. (2013). Reducing job insecurity and increasing performance ratings: Does impression management matter? Journal of Applied Psychology, 98(5), 348-363. https://doi.org/10.1037/a0033151

Hu, L. T., \& Bentler, P. M. (1999). Cutoff criteria for fit indexes in covariance structure analysis: Conventional criteria versus new alternatives. Structural Equation Modeling: A Multidisciplinary Journal, 6(1), 1-55. https://doi.org/10.1080/107055 19909540118 
Huffcutt, A. I., \& Arthur, W. (1994). Hunter and Hunter (1984) revisited: Interview validity for entry-level jobs. Journal of Applied Psychology, 79(2), 184-190. https://doi.org/10.1037/0021-9010.79.2.184

\section{I}

Inceoglu, I., \& Warr, P. (2011). Personality and job engagement. Journal of Personnel Psychology, 10(4), 177-181. https://doi.org/10.1027/1866-5888/a000045

Ito, J. K., \& Brotheridge, C. M. (2003). Resources, coping strategies, and emotional exhaustion: A conservation of resources perspective. Journal of Vocational Behavior, 63(3), 490-509. https://doi.org/10.1016/S0001-8791(02)00033-7

\section{J}

Jex, S. M., \& Elacqua, T. C. (1999). Self-esteem as a moderator: A comparison of global and organization-based measures. Journal of Occupational and Organizational Psychology, 72(1), 71-81. https://doi.org/10.1348/096317999166509

Jones, R. A., Jimmieson, N. L., \& Griffiths, A. (2005). The impact of organizational culture and reshaping capabilities on change implementation success: The mediating role of readiness for change. Journal of Management Studies, 42(2), 361-386. https://doi.org/10.1111/j.1467-6486.2005.00500.x

Jones, E. E., \& Pittman, T. S. (1982). Toward a general theory of strategic selfpresentation. In J. Suls (Eds.), Psychological perspectives on the self (pp. 231-262). Hillsdale, NJ: Erlbaum.

Judge, T. A., \& Bretz, R. D. (1994). Political influence behavior and career success. Journal of Management, 20(1), 43-65. https://doi.org/10.1177/014920639402000103

Judge, T. A., Cable, D. M., \& Higgins, C. A. (2001). The employment interview: A review of recent research and recommendations for future research. Human Resource Management Review, 10(4), 383-406. https://doi.org/10.1016/S1053-4822(00) 00033-4

K

Kacmar, K. M., \& Carlson, D. S. (1999). Effectiveness of impression management tactics across human resource situations. Journal of Applied Social Psychology, 29(6), 12931311. https://doi.org/10.1111/j.1559-1816.1999.tb02040.x 
Kacmar, K. M., Carlson, D. S., \& Bratton, V. K. (2004). Situational and dispositional factors as antecedents of ingratiatory behaviors in organizational settings. Journal of Vocational Behavior, 65(2), 309-331. https://doi.org/10.1016/j.jvb.2003.09.002

Kacmar, K. M., Delery, J. E., \& Ferris, G. R. (1992). Differential effectiveness of applicant impression management tactics on employment interview decisions. Journal of Applied Social Psychology, 22(16), 1250-1272. https://doi.org/10.1111/j.15591816.1992.tb00949.x

Kang, D. S., Gold, J., \& Kim, D. (2012). Responses to job insecurity: The impact on discretionary extra-role and impression management behaviors and the moderating role of employability. Career Development International, 17(4), 314-332. https://doi.org/10.1108/13620431211255815

Kees, J. (2011). Advertising framing effects and consideration of future consequences. Journal of Consumer Affairs, 45(1), 7-32. https://doi.org/10.1111/j.17456606.2010.01190.x

Kiesinger, C. E. (1998). From interview to story: Writing Abbie's life. Qualitative Inquiry, 4(1), 71-95. https://doi.org/10.1177/107780049800400105

Kim, H., Rao, A. R., \& Lee, A. Y. (2009). It's time to vote: The effect of matching message orientation and temporal frame on political persuasion. Journal of Consumer Research, 35(6), 877-889. https://doi.org/10.1086/593700

Kipnis, D., Schmidt, S. M., \& Wilkinson, I. (1997). Intraorganizational influence tactics: Explorations in getting one's way. In R. P. Vecchio (Eds.), Leadership: Understanding the dynamics of power and influence in organizations (pp. $124-143$ ). Notre Dame, IN: University of Notre Dame Press.

König, C. J., Klehe, U. C., Berchtold, M., \& Kleinmann, M. (2010). Reasons for being selective when choosing personnel selection procedures. International Journal of Selection and Assessment, 18(1), 17-27. https://doi.org/10.1111/j.14682389.2010.00485.x

Kreitner, R., \& Kinicki, A., (2004) Organisational behaviour 6th Ed. New York, NY: McGraw-Hill.

Kristof-Brown, A., Barrick, M. R., \& Franke, M. (2002). Applicant impression management: Dispositional influences and consequences for recruiter perceptions of fit and similarity. Journal of Management, 28(1), 27-46. https://doi.org/10.1177\% 2F014920630202800103

Kühnel, J., Sonnentag, S., \& Bledow, R. (2012). Resources and time pressure as day-level antecedents of work engagement. Journal of Occupational and Organizational Psychology, 85(1), 181-198. https://doi.org/10.1111/j.2044-8325.2011.02022.x 
Langfred, C. W. (2004). Too much of a good thing? Negative effects of high trust and individual autonomy in self-managing teams. Academy of Management Journal, 47(3), 385-399. https://doi.org/10.5465/20159588

Lazarus, R. S., \& Folkman, S. (1984). Coping and adaptation. The Handbook of Behavioral Medicine, 282-325.

Leary, M. R. (1999). Making sense of self-esteem. Current Directions in Psychological Science, 8(1), 32-35. https://doi.org/10.1111\%2F1467-8721.00008

Leary, M. R., \& Baumeister, R. F. (2000). The nature and function of self-esteem: Sociometer theory. Advances in Experimental Social Psychology, 32, 1-62. https://doi.org/10.1016/S0065-2601(00)80003-9

Leary, M. R., \& Kowalski, R. M. (1990). Impression management: A literature review and two-component model. Psychological Bulletin, 107(1), 34-47. https://doi.org/10.1037/0033-2909.107.1.34

Leary, M. R., \& Miller, R. S. (2012). Social psychology and dysfunctional behavior: Origins, diagnosis, and treatment. Springer Science \& Business Media.

Leary, M. R., Tambor, E. S., Terdal, S. K., \& Downs, D. L. (1995). Self-esteem as an interpersonal monitor: The sociometer hypothesis. Journal of Personality and Social Psychology, 68(3), 518-530. https://doi.org/ 10.1037/0022-3514.68.3.518

Lee, A. Y., Keller, P. A., \& Sternthal, B. (2010). Value from regulatory construal fit: The persuasive impact of fit between consumer goals and message concreteness. Journal of Consumer Research, 36(5), 735-747. https://doi.org/10.1086/605591

Levy, P. E., \& Williams, J. R. (2004). The social context of performance appraisal: A review and framework for the future. Journal of Management, 30(6), 881-905. https://doi.org/10.1016/j.jm.2004.06.005

Li, Y., Fan, J., \& Zhao, S. (2015). Organizational identification as a double-edged sword. Journal of Personnel Psychology, 14(4), 182-191. https://doi.org/10.1027/1866$5888 / \mathrm{a} 000133$

Liberman, N., \& Trope, Y. (1998). The role of feasibility and desirability considerations in near and distant future decisions: A test of temporal construal theory. Journal of Personality and Social Psychology, 75(1), 5-18. https://doi.org/10.1037/00223514.75.1.5

Liden, R. C., \& Mitchell, T. R. (1988). Ingratiatory behaviors in organizational settings. Academy of Management Review, 13(4), 572-587. https://doi.org/10.5465/amr. 1988.4307430

Liviatan, I., Trope, Y., \& Liberman, N. (2008). Interpersonal similarity as a social distance dimension: Implications for perception of others' actions. Journal of Experimental Social Psychology, 44(5), 1256-1269. https://doi.org/10.1016/j.jesp.2008.04.007 
McAleer, M. (1995). The significance of testing empirical non-nested models. Journal of Econometrics, 67(1), 149-171. https://doi.org/10.1016/0304-4076(94)01631-9

McCormack, C. (2000). From interview transcript to interpretive story: Part 1 - Viewing the transcript through multiple lenses. Field Methods, 12(4), 282-297. https://doi.org/10.1177\%2F1525822X0001200402

McFarland, L. A., Ryan, A. M., \& Kriska, S. D. (2003). Impression management use and effectiveness across assessment methods. Journal of Management, 29(5), 641-661. https://doi.org/10.1016\%2FS0149-2063_03_00030-8

Miles, J., \& Shevlin, M. (2001). Applying regression and correlation: A guide for students and researchers. London, UK: Sage.

Morrison, E. W., \& Bies, R. J. (1991). Impression management in the feedback-seeking process: A literature-review and research agenda. Academy of Management Review, 16, 522-541. https://doi.org/10.2307/258916

Moust, J. H., Berkel, H. V., \& Schmidt, H. G. (2005). Signs of erosion: Reflections on three decades of problem-based learning at Maastricht University. Higher education, 50(4), 665-683.

$\mathrm{N}$

Nussbaum, S., Trope, Y., \& Liberman, N. (2003). Creeping dispositionism: the temporal dynamics of behavior prediction. Journal of Personality and Social Psychology, 84(3), 485-497. https://doi.org/10.1037/0022-3514.84.3.485

$\mathbf{P}$

Paolacci, G., \& Chandler, J. (2014). Inside the turk: Understanding mechanical turk as a participant pool. Current Directions in Psychological Science, 23(3), 184-188. https://doi.org/10.1177/0963721414531598

Park, H. I., Jacob, A. C., Wagner, S. H., \& Baiden, M. (2014). Job control and burnout: A meta-analytic test of the conservation of resources model. Applied Psychology, 63(4), 607-642. https://doi.org/10.1111/apps.12008

Parker, S. (2000). From passive to proactive motivation: The importance of flexible role orientations and role breadth self-efficacy. Applied Psychology, 49(3), 447-469. https://doi.org/10.1111/1464-0597.00025

Parker, S. K., Williams, H. M., \& Turner, N. (2006). Modeling the antecedents of proactive behavior at work. Journal of Applied Psychology, 91(3), 636-652. https:// doi.org/10.1037/0021-9010.91.3.636 
Peeters, H., \& Lievens, F. (2006). Verbal and nonverbal impression management tactics in behavior description and situational interviews. International Journal of Selection and Assessment, 14(3), 206-222. https://doi.org/10.1111/j.1468-2389.2006. 00348. $\mathrm{x}$

Pierce, J. L., Gardner, D. G., Dunham, R. B., \& Cummings, L. L. (1993). Moderation by organization-based self-esteem of role condition-employee response relationships. Academy of Management Journal, 36(2), 271-288. https://doi.org/10.5465/256523

Podsakoff, P. M., Mackenzie, S. B., \& Podsakoff, N. P. (2012). Sources of method bias in social science research and recommendations on how to control it. Annual Review of Psychology, 63, 539-569. https://doi.org/10.1146/annurev-psych-120710100452

Posthuma, R. A., Morgeson, F. P., \& Campion, M. A. (2002). Beyond employment interview validity: A comprehensive narrative review of recent research and trends over time. Personnel Psychology, 55(1), 1-81.

Probst, T. M., Stewart, S. M., Gruys, M. L., \& Tierney, B. W. (2007). Productivity, counterproductivity and creativity: The ups and downs of job insecurity. Journal of Occupational and Organizational Psychology, 80(3), 479-497. https://doi.org/10.1348/ $096317906 \times 159103$

Proost, K., Germeys, F., \& Schreurs, B. (2012). When does self-promotion work? The influence of temporal distance on interviewer evaluations. Journal of Personnel Psychology, 11(3), 109-117. https://doi.org/10.1027/1866-5888/a000062

Proost, K., Schreurs, B., De Witte, K., \& Derous, E. (2010). Ingratiation and selfpromotion in the selection interview: The effects of using single tactics or a combination of tactics on interviewer judgments. Journal of Applied Social Psychology, 40(9), 2155-2169. https://doi.org/10.1111/j.1559-1816.2010.00654.x

Purkiss, S. L., Perrewé, P. L., Gillespie, T. L., Mayes, B. T., \& Ferris, G. R. (2006). Implicit sources of bias in employment interview judgments and decisions. Organizational Behavior and Human Decision Processes, 101(2), 152-167. https://doi.org/10.1016/ j.obhdp.2006.06.005

\section{R}

Rand, T. M., \& Wexley, K. N. (1975). Demonstration of the effect," similar to me," in simulated employment interviews. Psychological Reports, 36(2), 535-544. https://doi.org/10.2466\%2Fpr0.1975.36.2.535

Rao, A., Schmidt, S. M., \& Murray, L. H. (1995). Upward impression management: Goals, influence strategies, and consequences. Human Relations, 48(2), 147-167. https://doi.org/10.1177/001872679504800203 
Roe, R. A. (2008). Time in applied psychology: The study of" what happens" rather than" what is.". European Psychologist, 13(1), 37-52. https://doi.org/10.1027/10169040.13.1.37

Rosenberg, M. (1979). Conceiving the Self. New York, NY: Basic Books.

Rosenfeld, P., Giacalone, R. A., \& Riordan, C. A. (1995). Impression management in organizations: Theory, measurement, and practice. New York, NY: Routledge.

Roulin, N., Bangerter, A., \& Levashina, J. (2015). Honest and deceptive impression management in the employment interview: Can it be detected and how does it impact evaluations? Personnel Psychology, 68(2), 395-444. https://doi.org/10.1111/ peps.12079

Rudman, L. A. (1998). Self-promotion as a risk factor for women: The costs and benefits of counterstereotypical impression management. Journal of Personality and Social Psychology, 74(3), 629-645. https://doi.org/10.1037/0022-3514.74.3.629

\section{S}

Saks, A. M., \& Ashforth, B. E. (2000). The role of dispositions, entry stressors, and behavioral plasticity theory in predicting newcomers' adjustment to work. Journal of Organizational Behavior, 21(1), 43-62. https://doi.org/10.1002/(SICl)10991379(200002)21:1\%3C43::AID-JOB985\%3E3.0.CO;2-W

Scheck, C. L., \& Kinicki, A. J. (2000). Identifying the antecedents of coping with an organizational acquisition: A structural assessment. Journal of Organizational Behavior, 21(6), 627-648. https://doi.org/10.1002/1099-1379(200009)21:6<627::AID-JOB43> 3.0.CO;2-D

Scheier, M. F., Carver, C. S., \& Bridges, M. W. (1994). Distinguishing optimism from neuroticism (and trait anxiety, self-mastery, and self-esteem): A reevaluation of the life orientation test. Journal of Personality and Social Psychology, 67(6), 1063-1078. https://doi.org/10.1037/0022-3514.67.6.1063

Schlenker, B.R. (1980). Impression management: The self-concept, social identity, and interpersonal relations. Monterey, CA: Brooks/Cole.

Schlenker, B. R., \& Pontari, B. A. (2000). The strategic control of information: Impression management and self-presentation in daily life. In A. Tesser, R. B. Felson, \& J. M. Suls (Eds.), Psychological perspectives on self and identity (pp. 199-232). Washington, DC, US: American Psychological Association.

Schlenker, B. R., \& Weigold, M. F. (1992). Interpersonal processes involving impression regulation and management. Annual Review of Psychology, 43(1), 133-168. https://doi.org/10.1146/annurev.ps.43.020192.001025

Schmidt, K. H., \& Diestel, S. (2012). The relation of self-control demands to job strain: The moderating role of organisational commitment. Applied Psychology, 61(3), 479497. https://doi.org/10.1111/j.1464-0597.2011.00479.x 
Schreurs, B., Van Emmerik, H., Notelaers, G., \& De Witte, H. (2010). Job insecurity and employee health: The buffering potential of job control and job self-efficacy. Work \& Stress, 24(1), 56-72. https://doi.org/10.1080/02678371003718733

Seibert, S. E., Kraimer, M. L., \& Crant, J. M. (2001). What do proactive people do? A longitudinal model linking proactive personality and career success. Personnel Psychology, 54(4), 845-874. https://doi.org/10.1111/j.1744-6570.2001.tb00234.x

Sekaquaptewa, D., \& Espinoza, P. (2004). Biased processing of stereotype-incongruency is greater for low than high status groups. Journal of Experimental Social Psychology, 40(1), 128-135. https://doi.org/10.1016/S0022-1031(03)00093-3

Sherman, J. W., Stroessner, S. J., Conrey, F. R., \& Azam, O. A. (2005). Prejudice and stereotype maintenance processes: Attention, attribution, and individuation. Journal of Personality and Social Psychology, 89(4), 607. https://doi.org/10.1037/00223514.89.4.607

Shoss, M. K. (2017). Job insecurity: An integrative review and agenda for future research. Journal of Management, 43(6), 1911-1939. https://doi.org/10.1177\%2F 0149206317691574

Shoss, M. K., \& Probst, T. M. (2012). Multilevel outcomes of economic stress: An agenda for future research. In P. Perrewe, C. Rosen, \& J. Halbesleben (Eds.) Research in occupational stress and well-being: The role of economic context on occupational stress and well-being (pp. 43-86). Bingley, UK: Emerald Group Publishing Limited.

Sibunruang, H., Garcia, P. R. J. M., \& Tolentino, L. R. (2016). Ingratiation as an adapting strategy: Its relationship with career adaptability, career sponsorship, and promotability. Journal of Vocational Behavior, 92, 135-144. https://doi.org/10.1016/j.jvb. 2015.11.011

Singh, V., Kumra, S., \& Vinnicombe, S. (2002). Gender and impression management: Playing the promotion game. Journal of Business Ethics, 37(1), 77-89. https://doi.org/10.1023/A:1014782118902

Staufenbiel, T., König, C. J. (2010). A model for the effects of job insecurity on performance, turnover intention, and absenteeism, Journal of Occupational and Organizational Psychology, 83(1), 101-117. https://doi.org/10.1348/096317908X401912

Stern, I., \& Westphal, J. D. (2010). Stealthy footsteps to the boardroom: Executives' backgrounds, sophisticated interpersonal influence behavior, and board appointments. Administrative Science Quarterly, 55(2), 278-319. https://doi.org/10.2189\%2 Fasqu.2010.55.2.278

Stevens, C. K., \& Kristof, A. L. (1995). Making the right impression: A field study of applicant impression management during job interviews. Journal of Applied Psychology, 80(5), 587-606. https://doi.org/10.1037/0021-9010.80.5.587

Sturman, M. C. (2003). Searching for the inverted U-shaped relation- ship between time and performance: Meta-analyses of the experience/ performance, tenure/performance, and age/performance relationships. Journal of Management, 29, 609-640. https://doi.org/10.1016\%2FS0149-2063_03_00028-X 
Sverke, M., Gallagher, D. G., \& Hellgren, J. (2000). Alternative work arrangements: Job stress, well-being and work attitudes among employees with different contracts. Health Effects of The New Labour Market, New York, NY: Kluwer.

Sverke, M., \& Hellgren, J. (2001). Exit, voice and loyalty reactions to job insecurity in Sweden: Do unionized and non-unionized employees differ? British Journal of Industrial Relations, 39(2), 167-182. https://doi.org/10.1111/1467-8543.00195

Sverke, M., Hellgren, J., \& Näswall, K. (2002). No security: a meta-analysis and review of job insecurity and its consequences. Journal of Occupational Health Psychology, 7(3), 242-264.

Swencionis, J. K., \& Fiske, S. T. (2016). Promote up, ingratiate down: Status comparisons drive warmth-competence tradeoffs in impression management. Journal of Experimental Social Psychology, 64, 27-34. https://doi.org/10.1016/j.jesp.2016.01.004

Swider, B. W., Barrick, M. R., Harris, T. B., \& Stoverink, A. C. (2011). Managing and creating an image in the interview: The role of interviewee initial impressions. Journal of Applied Psychology, 96(6), 1275-1288. https://doi.org/10.1037/a0024005

\section{T}

Tedeschi, J. T., \& Melburg, V. (1984). Impression management and influence in the organization. Research in the Sociology of Organizations, 3, 31-58.

Tedeschi, J. T., \& Norman, N. (1985). Social power, self-presentation, and the self. In B. Schlenker (Eds.), The self and social life (pp. 293-322). New York, NY: McGraw-Hill.

Thacker, R. A., \& Wayne, S. J. (1995). An examination of the relationship between upward influence tactics and assessments of promotability. Journal of Management, 21(4), 739-756. https://doi.org/10.1177/014920639502100408

Trope, Y., \& Liberman, N. (2003). Temporal construal. Psychological Review, 110(3), 403-421. https://doi.org/10.1037/0033-295X.110.3.403

Trope, Y., \& Liberman, N. (2010). Construal-level theory of psychological distance. Psychological Review, 117(2), 440-463. https://doi.org/10.1037/a0020319

Trope, Y., Liberman, N., \& Wakslak, C. (2007). Construal levels and psychological distance: Effects on representation, prediction, evaluation, and behavior. Journal of Consumer Psychology: The Official Journal of The Society for Consumer Psychology, 17(2), 83-95. https://doi.org/10.1016/S1057-7408(07)70013-X

Tsai, W. C., Chen, C. C., \& Chiu, S. F. (2005). Exploring boundaries of the effects of applicant impression management tactics in job interviews. Journal of Management, 31(1), 108-125. https://doi.org/10.1177/0149206304271384

Tsai, W. C., Huang, T. C., Wu, C. Y., \& Lo, I. H. (2010). Disentangling the effects of applicant defensive impression management tactics in job interviews. International Journal of Selection and Assessment, 18(2), 131-140. https://doi.org/10.1111/ j.1468-2389.2010.00495.x 
Tsai, C. I., \& McGill, A. L. (2011). No pain, no gain? How fluency and construal level affect consumer confidence. Journal of Consumer Research, 37(5), 807-821. https://doi.org/10.1086/655855

Turnley, W. H., \& Bolino, M. C. (2001). Achieving desired images while avoiding undesired images: exploring the role of self-monitoring in impression management. Journal of Applied Psychology, 86(2), 351-360. https://doi.org/10.1037//00219010.86 .2 .351

\section{V}

Van Iddekinge, C. H., McFarland, L. A., \& Raymark, P. H. (2007). Antecedents of impression management use and effectiveness in a structured interview. Journal of Management, 33(5), 752-773. https://doi.org/10.1177/0149206307305563

Van Hercke, D., De Cuyper, N., Peeters, E., \& De Witte, H. (2014). Defining perceived employability: a psychological approach. Personnel Review, 43(4), 592-605. https://doi.org/10.1108/PR-07-2012-0110

Vinokur, A. D., \& Schul, Y. (2002). The web of coping resources and pathways to reemployment following a job loss. Journal of Occupational Health Psychology, 7(1), 68-83. https://doi.org/10.1037//1076-8998.7.1.68

Vohs, K. D., Baumeister, R. F., \& Ciarocco, N. J. (2005). Self-regulation and selfpresentation: Regulatory resource depletion impairs impression management and effortful self-presentation depletes regulatory resources. Journal of Personality and Social Psychology, 88(4), 632-657. https://doi.org/10.1037/0022-3514.88.4.632

\section{W}

Wayne, S. J., \& Ferris, G. R. (1990). Influence tactics, affect, and exchange quality in supervisor-subordinate interactions: A laboratory experiment and field study. Journal of Applied Psychology, 75(5), 487-499. https://doi.org/10.1037/00219010.75.5.487

Wayne, S. J., \& Kacmar, K. M. (1991). The effects of impression management on the performance appraisal process. Organizational Behavior and Human Decision Processes, 48(1), 70-88. https://doi.org/10.1016/0749-5978(91)90006-F

Wayne, S. J., Kacmar, K. M., \& Ferris, G. R. (1995). Coworker responses to others' ingratiation attempts. Journal of Managerial Issues, 7(3), 277-289.

Wayne, S. J., \& Liden, R. C. (1995). Effects of impression management on performance ratings: A longitudinal study. Academy of Management Journal, 38(1), 232-260. https://doi.org/10.5465/256734 
Wayne, S. J., Liden, R. C., Graf, I. K., \& Ferris, G. R. (1997). The role of upward influence tactics in human resource decisions. Personnel Psychology, 50(4), 979-1006. https://doi.org/10.1111/j.1744-6570.1997.tb01491.x

Webster, J. R., Beehr, T. A., \& Love, K. (2011). Extending the challenge-hindrance model of occupational stress: The role of appraisal. Journal of Vocational Behavior, 79(2), 505-516. https://doi.org/10.1016/j.jvb.2011.02.001

Weick, K. E., \& Quinn, R. E. (1999). Organizational change and development. Annual Review of Psychology, 50(1), 361-386. https://doi.org/10.1146/annurev. psych.50.1.361

Weiss, B., \& Feldman, R. S. (2006). Looking good and lying to do it: Deception as an impression management strategy in job interviews. Journal of Applied Social Psychology, 36(4), 1070-1086. https://doi.org/10.1111/j.0021-9029.2006.00055.x

Weng, L. C., \& Chang, W. C. (2015). Does impression management really help? A multilevel testing of the mediation role of impression management between personality traits and leader-member exchange. Asia Pacific Management Review, 20(1), 2-10. https://doi.org/10.1016/j.apmrv.2013.03.001

Westman, M., Etzion, D., \& Danon, E. (2001). Job insecurity and crossover of burnout in married couples. Journal of Organizational Behavior, 22(5), 467-481. https://doi.org/10.1002/job.91

Westman, M., Hobfoll, S. E., Chen, S., Davidson, O. B., \& Laski, S. (2004). Organizational stress through the lens of conservation of resources (COR) theory. In Exploring interpersonal dynamics (pp. 167-220). Emerald Group Publishing Limited.

White, K., MacDonnell, R., \& Dahl, D. W. (2011). It's the mind-set that matters: The role of construal level and message framing in influencing consumer efficacy and conservation behaviors. Journal of Marketing Research, 48(3), 472-485. https://doi.org/10.1509/jmkr.48.3.472

Wille, L., Van Hoye, G., Weijters, B., Rangarajan, D., \& Carpentier, M. (2018). To be yourself or to be your ideal self? Journal of Personnel Psychology, 17(3), 107-119. https://doi.org/10.1027/1866-5888/a000213

Wu, L. Z., Kwan, H. K., Wei, L. Q., and Liu, J. (2013). Ingratiation in the workplace: The role of subordinate and supervisor political skill. Journal of Management Studies, 50, 991-1017. https://doi.org/10.1111/joms.12033

\section{$\mathrm{X}$}

Xanthopoulou, D., Bakker, A. B., Demerouti, E., \& Schaufeli, W. B. (2009). Reciprocal relationships between job resources, personal resources, and work engagement. Journal of Vocational behavior, 74(3), 235-244. https://doi.org/10.1016/j.jvb. 2008.11.003 


\section{Y}

Yang, X., Ringberg, T., Mao, H., \& Peracchio, L. A. (2011). The construal (in) compatibility effect: The moderating role of a creative mind-set. Journal of Consumer Research, 38(4), 681-696. https://doi.org/10.1086/660118

Yukl, G., \& Falbe, C. M. (1990). Influence tactics and objectives in upward, downward, and lateral influence attempts. Journal of Applied Psychology, 75(2), 132-140. https://doi.org/10.1037/0021-9010.75.2.132

\section{Z}

Zapf, D., Dormann, C., \& Frese, M. (1996). Longitudinal studies in organizational stress research: A review of the literature with reference to methodological issues. Journal of Occupational Health Psychology, 1(2), 145-169. https://doi.org/10.1037/10768998.1.2.145 



\section{About the author}

Katharina Schmitte (née Schmitz) was born September 20th, 1987 in Cologne, Germany. She obtained her Bachelor degree in International Business from Maastricht University in 2011. During her studies, Katharina spent a semester abroad in Grenoble, France, where she continued to study in the French language. In between her Bachelors and Masters, Katharina worked as an intern in a company in Cologne working in the sector of selection, training, and development. Katharina continued with her Masters in Maastricht in the field of Organizational Behavior and graduated Cum Laude in 2012. As from 2012, she was employed as a PhD candidate at the School of Business and Economics (SBE) in Maastricht. After pursuing another Master in Research, Katharina mainly worked on her dissertation as of 2013 onwards. Next to doing research, Katharina also worked as a tutor for courses including topics such as organizational change and consultancy, organizational learning and development, management of organizations, and crisis management. Katharina presented her doctoral research at different internal seminars at SBE and international conferences in the US; among others the Academy of Management (AOM) in Philadelphia, the Southern Management Association (SMA) in St. Pete Beach, and the Society for Industrial and Organizational Psychology (SIOP) in Anaheim. 

«In real life you don't react to what someone did; you only react what you think someone did. The gap between action and perception is bridged by the art of impression management.»

\author{
Jonathan Haidt
}

